Portland State University

PDXScholar

$1-1-1984$

\title{
Determination of toluene's degradation products under simulated atmospheric conditions
}

Bruce E. Dumdei

Portland State University

Follow this and additional works at: https://pdxscholar.library.pdx.edu/open_access_etds Let us know how access to this document benefits you.

\section{Recommended Citation}

Dumdei, Bruce E., "Determination of toluene's degradation products under simulated atmospheric conditions" (1984). Dissertations and Theses. Paper 818.

https://doi.org/10.15760/etd.818

This Dissertation is brought to you for free and open access. It has been accepted for inclusion in Dissertations and Theses by an authorized administrator of PDXScholar. Please contact us if we can make this document more accessible: pdxscholar@pdx.edu. 
DETERMINATION OF TOLUENE'S

DEGRADATION PRODUCTS UNDER

SIMUIATED ATMOSPHERIC CONDITIONS

by

BRUCE E. DUMDEI

A dissertation submitted in partial fulfillment of the requirements for the degree of

\section{DOCTOR OF PHILOSOPHY}

in

ENVIRONMENTAL SCIENCES AND RESOURCES/CHEMISTRY

Portland State University

1984 
TO THE OFFICE OF GRADUATE STUDIES AND RESEARCH:

The members of the committee approve the dissertation of Bruce E. Dumdei presented May 18, 1984.
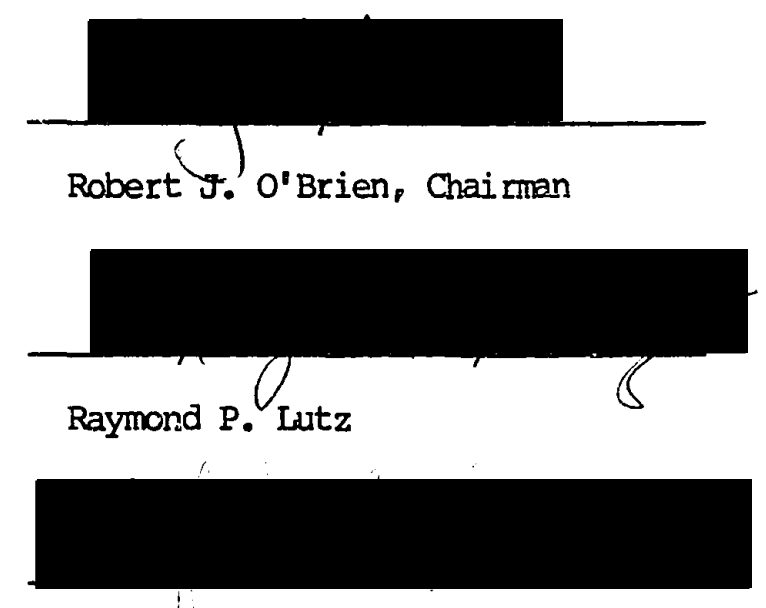

Alfred S. Levinson
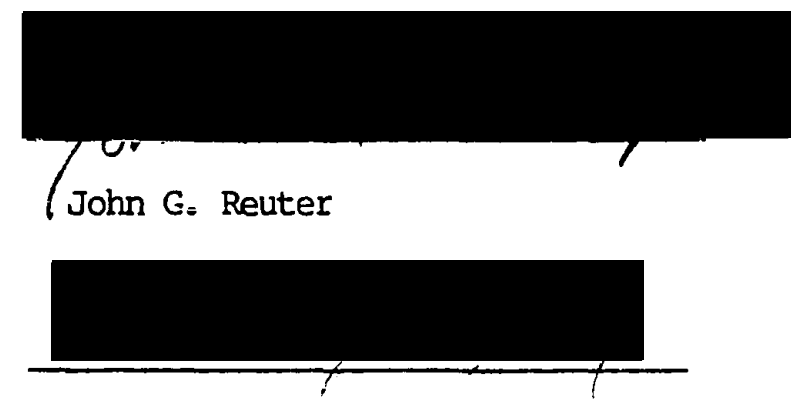

Pavel K. Smejtek

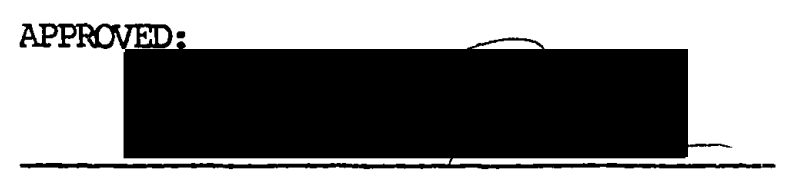

Robert 0. Tinnin, Director, Envirormental Sciences and Resources

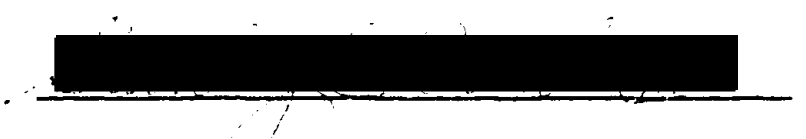

Stanley E. Rauch, Dean, Graduate Studies and Research 
AN ABSIRACT OF THE DISSERTATION OF Bruce Eugene Dumdei for the Doctor of Philosophy in Environmental Sciences and Resources/ Chemistry presented May 18, 1984.

Title: Determination of the Reaction Products of Toluene Under Simulated Atmospheric Conditions.

APPROVED BY MEMBERS OF THE DISSERTATION COMMITTEE:

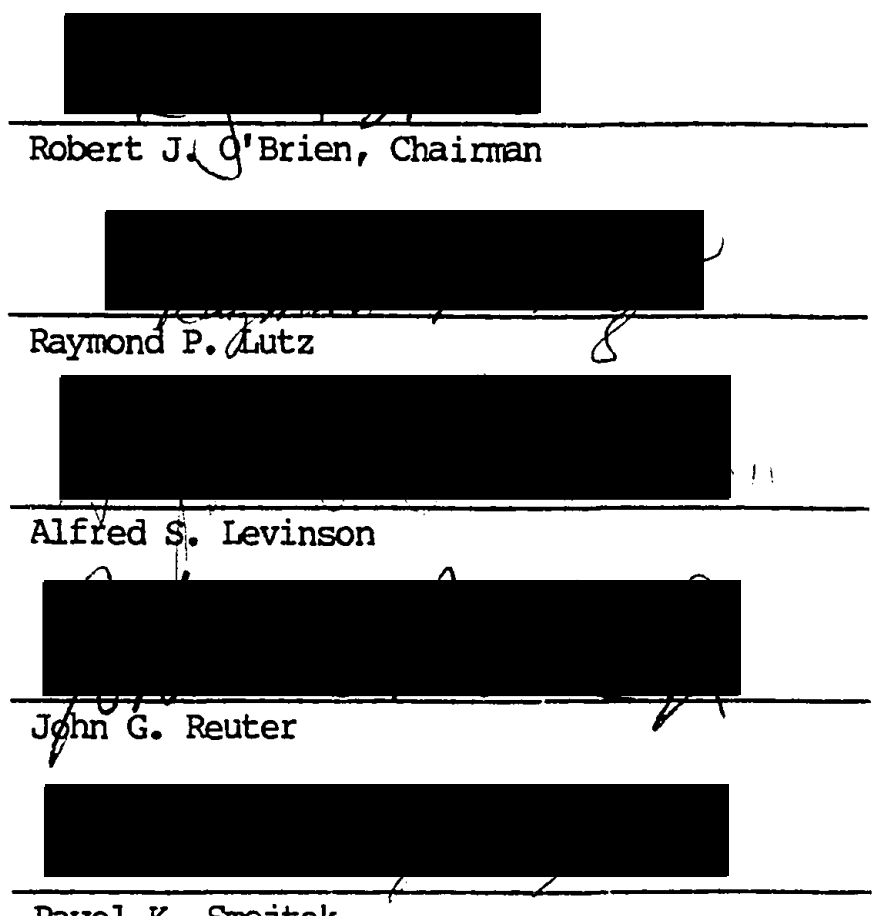

Pavel K. Smejtek

The reactions of aromatic hydrocarbons represent a major area of uncertainty in urban atmospheric photochemistry. Much effort has been spent studying the simulated atmospheric oxidation chemistry of model aromatics, such as toluene, in order to delineate their reaction mechanisms. These studies are motivated both by interest in fundamental processes and a desire to discover an aromatic's contribution to the formation of ozone in polluted 
ambient atmospheres.

Previous work on toluene includes both product studies and proposed mechanisms. In all previous studies, the combined product yields are half or less of the initially reacted toluene. A major reason for the poor carbon balances found in these studies is the precipitation of intermediate reaction products from the gas phase to the reaction walls.

We have studied the oxidation process by blacklight irradiation of 1-10 ppm each of toluene and oxides of nitrogen in 22-liter pyrex flasks, in zero-air at 508 relative humidity. The flasks were pre-cleaned by baking at $350 \mathrm{C}$ and the products were recovered from the walls by extraction with methanol or dichloromethane. Some gas-phase products were recovered in the solvent as well. The extracts were analyzed on a Finnigan MAT triple stage quadrupole mass spectrometer/ data system by direct probe injection. Methane chemical ionization converted the products to $\mathrm{M}+1$ parent ions. The molecular weights of the products were determined from the CI mass spectrum, and also by the general survey methods of neutral loss and parent ion spectra. Once their molecular weights were determined, the products were fragmented by collision-induced-dissociation (CID) in the middle quadrupole to produce characteristic daughter ions. To assist in the spectral interpretation, toluene in three isomeric forms was subjected to simulated atmospheric reaction. In addition to normal (H8) toluene, methyl-deuterated (D3) and per-deuterated (D8) toluene were used. 
This study confinmed the existence of a number of products identified in past studies, confirmed the formation of some products which have been hypothesized in several proposed mechanisss for toluene oxidation, identified a number of previously unidentified and unproposed products. In some cases the fragmentation patterns dian't allow choice among several methylor hydroxyl-positional iscmers, and undoubtedly more than one isomer was often present, as would be expected.

Detailed mechanistic steps have been olitined for all reaction products' formation and destruction. Other analytical technigues including GC, GC/MS, and HPLC, have supplemented the MS/MS analysis.

These results and the further study of the types of compounds identified should make a significant contribution to the understanding of atmospheric aromatic systems. 


\section{ACKNOWLEDGEMENIS}

The author wishes to acknowledge the great assistance of many individuals in the completion of this research: Sue Hummel and Richard Yost at the University of Florida; William Davidson at Sciex, Inc.; and Mary Stevens at the Oregon Graduate Center.

The author would also like to thank the past and present members of Lab 463 SBII, including: Ebrahim Moshiri, Pat Green, Cornelius Chan, Rich Doty, Lien Nguyen, Thuy-Thang Dang, Tom Hard, and Sam Bilden, for their help and encourgement.

Special thanks are due to Karen "Smiley" D'Arcy for her many helpful discussions and moral support. Dr. Robert $0^{\prime} B r i e n$ has been an extraordinary research advisor. I cannct thank him enough for his interest and effort in making this work both challenging and exciting. 
TABLE OF CONTENIS

PAGE

ACKNOWLEDGEMENTS

iii

LIST OF TABLES

vi

LIST OF FIGURES

vii

CHAPTER.

I INIRODUCIION

II CARBON BALANCE MEASUREMENTS

Introduction 7

$\begin{array}{ll}\text { Experimental } & 8\end{array}$

$\begin{array}{lll}\text { Results } & 11\end{array}$

$\begin{array}{ll}\text { Discussion } & 14\end{array}$

III MS/MS DETERMINATTON OF TOLUENE'S 20 REACTION PRODUCIS

Experimental 21

Reagents $\quad 21$

Instrumentation 21

Proceedure $\quad 22$

Results and Discussion $\quad 27$

Compound class survey by nuetral loss and 29

parent scans

Identification of photooxidation products 38

CI/CID spectra and fragmentation schemes 44

Direct air vs extraction $\quad 62$

Conclusions $\quad 66$

IV ANALYSIS BY GC, GC/MS, AND HPLC 70 
Capillary Gas Chromatography Gas Chromatography/Mass Spectromentry 78 Quantification from GC analysis 94

High Performance Liquid Chromatography

95

V MECHANISM FOR TOLUENE'S ATMOSPHERIC DEGRADATION

Toluene Reactions

Effect of Reaction Conditions on Product Yields 109

VI CONCLUSTONS

112

REFERENCES

115

APPENDIX A - MS/MS DAUGETER ION SPECTRA

120

APPENDIX B - TOLUENE REACTION MECHANISM 


\section{LIST OF TABLES}

$\begin{array}{lll}\text { TABLE } & \text { PAGE }\end{array}$

I Hydrocarbon concentrations in ground level samples 2 collected at Janesville, Michigan down wind of a GM painting plant.

II Products of toluene degradation determined by MS/MS. $\quad 39$

III Relative response factors for MS/MS. 43

IV Masses of $(M+1)$ ions of toluene and several reaction 47 products based on toluene's isotopic form.

V GC/FID response factors for toluene products. $\quad 80$

VI Toluene products identified by GC/MS analysis. 83 
1. Total gas-phase carbon measurement for butane reaction. 12

2. Total gas-phase carbon measurement for toluene reaction. 13

3. Dimensionless plot of carbon monoxide data for toluene 16 reaction in four reaction vessels.

4. Time profile for $\mathrm{m} / \mathrm{z}=99$ ions during solid probe warming. 23

5. Toluene prođuts mass spectrum. 28

6. D3-Toluene and D8-toluene products mass spectra. 30

7. Neutral loss of 18 experiment. 31

8. Neutral loss of 32 experiment. 34

9. Neutral loss of 17 experiment. 36

10. Parents of $\mathrm{m} / \mathrm{z}=43$ experiment. 37

11. Neutral loss of 44 experiment. 42

12. Daughter spectra for methyl glyoxal. 51

13. Daughter spectra for 6-oxo-2,4-heptadienal. 52

14. Daughter spectra for 4,5-dioxo-2-hexenal. 54

15. Daughter spectra for 4-oxo-2-pentenal. 56

16. Daughter spectra for 5-oxo-1,3-hexadiene. 57

17. Daughter spectra for butendial. 60

18. Daughter spectra for hydroxylbutenal. 61

19. Daughter spectra for hydroxy-4-oxo-2-pentenal. 63

20. Daughter spectra for hydroxy-5-oxo-1,3-hexadiene. 64 
21. APCI/Daughter spectra of $\mathrm{m} / \mathrm{z}=99$ and $\mathrm{m} / \mathrm{z}=97$.

22. Typical capillary gas chromatogram of toluene's extrated products.

23. Capillary gas chromatogram of gas-phase injection of toluene reaction mixture.

24. Capillary gas chromatogram of toluene's extracted products with prior gas-phase purging.

25. Capillary gas chromatogram of normal and deuterated toluene's extracted products mixture.

26. Typical toluene product standard's capillary gas chromatogram.

27. Example of data output for HP5880A showing aromatic products identified in the extration mixture.

28. Total ion chromatogram from GC/MS analysis.

29. Sample and library spectra for GC/MS peak \#6. 85

30. Sample and library spectxa for GC/MS a) peak\#7, b) peak \#8.

31. Sample and library spectra for GC/MS peak \#9.

32. Sample and library spectra for GC/MS peak \#10. 89

33. Sample spectra for GC/MS a) peak $\# 18$, b) $\# 20$, c) $\# 11$. 90

34. Sample and library spectra for GC/MS peak \#13. 91

35. Sample and library spectra for GC/MS peak \#14. 93

36. Typical high performace liquid chromatography 96 chromatogram for toluene's extracted products.

37. Aromatic products of toluene formation mechanism. 100

38. Ring fragmentation products formation which convert 102 
two $\mathrm{NO}$ to $\mathrm{NO2}$.

39. Ring fragmentation products formation which convert 103 six NO to $\mathrm{NO2}$.

40. Reaction of 6-oxo-2,4-heptadiene to produce methyl 104 glyoxal and glyoxal.

41. Criegee intermediate formation and rearrangement to 106 produce organic acids.

42. Summary of ring fragmentation mechanism. 107

43. Aiternate reactions to produce toluene products with 110

a) terminal methylene group, b) hydroxy group. 
CHAPTER I

INIRODUCTION

The reactions of aromatic hydrocarbons represent a major area of uncertainty in urban atmospheric photochemistry. Alkylaromatic hydrocarbons currently comprise about 358 of gasoline in the United States and they are widely used as solvents. Toluene, the most commonly used member of the family, is perhaps the most abundant constituent of gasoline and is a major industrial solvent (1). The ambient concentrations and reactivities of aromatic hydrocarbons are comparable to those for alkanes and alkenes (2). In some areas, toluene's ambient concentration can become quite high. Table I shows ambient concentrations measured at Janesville, Michigan, downwind of an automotive painting plant (3). Toluene is the most abundant aromatic prosent in the study, and its concentration is comparable to the sum of all other major species. In most airsheds the aromatic hydrocarbons' concentrations are less than the alkanes'. Alkanes are much less reactive than the aromatics however (4). 
TABIE I

\section{HYDROCARBON CONCENIIRATIONS IN GROUND LEVEL SAMPLES AT JANESVILLE MICHIGAN, DOWN WIND OF A \\ GM PAINITING PLANT}

Compound
2-methylpentane
3-methlypentane
n-hexane
methylcylopentane
2,4-dimethylpentane
2,3-dimethylpentane
3-methylhexane
n-heptane
methylcyclohexane
toluene
2,3-dimethylhexane
2-methylheptane
3-methylheptane
n-octane
ethylbenzene
m- and p-xylene
o-xylene
n-propylbenzene
p-ethyltoluene
m-ethyltoluene
o-ethyltoluene
l,3,5-trimethylbenzene
l,2,4-trimethylbenzene

$u g /$ cubic mater
1.5
1.5
2.5
1.5
1.0
1.5
1.0
1.0
1.0
75.5
4.5
6.5
5.5
5.0
11.5
22.0
7.0
1.0
2.5
1.5
2.0
1.5
3.5


Alkenes are more reactive than the aromatics, but alkene concentrations are usually far lower. Since both concentration and reactivity are important in determining a hydrocarbon's participation in polluted air photochemistry, aromatics have a major influence.

Simulated atmospheric studies of toluene and other aromatics date back to experiments of the 1960's (5-8). These experiments were concerned largely with the ozone-forming potential of these compounds. Recent studies have used more sophisticated reaction vessels and more powerful analytical techniques in the attempt to identify and quantify the reaction products (9-34). These studies have been motivated both by a fundamental interest in the reaction mechanism and a desire to discover an aromatic's contribution to the formation of ozone in polluted atmospheres. Further interest is warranted, due to the presence of toluene's oxidation products as possibly significant constituents of polluted air.

Chemical processes occurring in sunlit, polluted atmospheres are usually simulated in so-called smog chambers. Hydrocarbons and oxides of nitrogen in the parts per billion (ppb) to parts per million (ppm) range in air are exposed to real or simulated sunlight and the products of the reaction are determined by a variety of analyticai techniques, usually gas chromatography (GC) for the hydrocarbons and their oxidation products. This procedure has been successfully applied to the alkenes and alkanes (e.g. 35). For the aromatic hydrocarbons, toluene has received the most study but very few products have been found by $\subseteq C$ analysis. 
Several studies have been published in which a partial characterization of toluene's oxidation products has been carried out (7-19). These studies have normally useù gas phase sampling, with concentration of the sample using a cold trap or adsorptive cartridge such as Tenax. In one case (12) suspended aerosols were collected by filtration and extracted from the filter with solvents. Separation and identification of the products have been carried out using GC or GC combined with mass spectrometry (GC/MS). 'Tine chief gas phase products identified were peroxyacetylnitrate (PAN), benzaldehyde, cresol and nitrotoluene isomers, $\infty$, and $\mathrm{CO} 2$, but their combined yields are half or less of the reacted toluene.

Many of the prior studies $(11,13-15,19,21)$ have employed high concentrations of reactants (toluene and oxides of nitrogen) in order to increase the amount of products formed. This is somewhat counterproductive since high concentration of nitrogen oxides favors radical termination processes to produce various nitro-aromatics and aryl-nitrates. These products are relatively easy to characterize by gas chromatography but their yield at ambient levels of nitrogen oxides is minimal. The products of major interest are the ring-fragmentation species, produced by attack of atmospheric hydroxyl radical on toluene, followed by addition of atmospheric oxygen, and subsequent extensive rearrangement and fragmentation. The identification of ring fragmentation products is especially interesting because the aromatic products also must react and fragment, ultimately leading 
to the final products carbon monoxide and carbon dioxide. (Carbon monoxide is also slowly converted to carbon dioxide.) Currently, quantitative gas-phase product data are available for PAN, $\infty$, benzaldehyde, cresols, some nitroaromatics, and for photooxidation of NO to NO2 with accompanying 03 formation (9). In addition, several ring-fragmentation products have been identified in various studies but never quantified (I1). This information, along with several hypothesized products, has been used to develop explicit mechanisms $(9,26,34)$ for the atmospheric oxidation of toluene as carried out in smog chambers.

Mechanistc efforts are hampered by the poor carbon balances in the product studies. By necessity, a large portion of the proposed mechanistic pathways for toluene must be considered tentative because of the limited data on the identities and reactivities of the intermediate reaction products. Thus, the mechanisms are based largely upon upon fitting the experimentally observed time profiles for nitric oxide photooxidation and ozone formation, a necessary but by no means sufficient condition for validity. A thorough understanding of the intermediate products is required if accurate models of the system are to be constructed.

The intent of the work described in this thesis has been to more fully characterize the products of toluene's atmospheric degradation. The work has centered on discovering the "missing" ring-fragmentation products, which were previously poorly understood. Total gas-phase carbon measurements were made to determine if the reaction products were in the gas-phase or in the 
aerosol-phase. The relatively new technique of mass spectrometry/mass spectromectry (MS/MS) has been the most useful technique in characterizing the products found in the study. The techniques of gas chromatography (GC), gas chromatography/mass spectrometry (GC/MS), and high performance liquid chromatography (HPLC), have been used to supplement the MS/MS studies. In the final pages of this thesis, a mechanism for toluene's atmospheric degradation is outlined. This mechanism puts the identified products into their proper reacton system framework. It is hoped that the results presented here will be a substantial aid in the understanding of atmospheric aromatic systems. This information in turn, will increase the accuracy of comprehensive tropospheric chemicai models used by air pollution control authorities, and ultimately lead to more effective control strategies. 
CHAPTER II

\section{CARBON BALANCE MESUREMENTS}

\section{INIRODUCTION}

Considerable mention has been made of the carbon balance in smog chamber experiments. The goal of course, is to account for all the reacted hydrocarbon in terms of intermediate product molecules, with the ultimate gas phase products being carbon monoxide and carbon dioxide $\left(C O\right.$ is slowly oxidized to $0_{0} 2$ as well). In the past, this carbon balance could only be attempted by adding up the sum of all the concentrations of the detected proulucts. Carbon balances of this type for the lower molecular weight alkanes and alkenes are fairly good, with the identified products accounting for most of the reacted hydrocarbon over the course of the reaction. The case of carbon balances for the higher molecular weight alkanes and alkenes has been studied to a very limited extent. Carbon balances for the aromatic hydrocarbons, although the subject of considerable study, have always been 
extremely poor (36). Lack of adequate product data in a sense makes the job of chemical mechanicians easier, since it reduces the constraints put upon their mechanisms. However, the reliability of these models must remain in doubt until better product data is obtained.

The experience in our laboratory in studying the products of the reactions of arcmatic hydrocarbons under simulated atmospheric conditions (10) has convinced us of the importance of determining carbon balances before undertaking explicit model development. Consequently, our laboratory has carried out a direct study of the yield of gas phase hydrocarbon products formed under simulated atmospheric conditions. This type of study has never previously been attempted-in part because it is difficult or even impossible in many smog chambers, due to high background levels of organic compounds, and/or carbon dioxide. Results indicate that ignoring heterogeneous processes in reactions of all aromatic hydrocarbons, at least in smog chambers, may be a serious error. For instance, recent, detailed mechanisms for the reactions of toluene in a smog chamber make no mention of wall loss of reaction products (9). However, these studies reguired invoking a "wall" source for free radicals, thus indicating the likelihood of condensed products.

\section{EXPERIMENTAL.}

The reactions were carried out in evacuable glass vessels of 22 and 239 liter volumes. The flasks were spherical and were fitted with Teflon-plug glass stopoocks. The smaller vessels could 
be cleaned by heating to $723 \mathrm{~K}$ in an annealing oven. The large vessel was cleaned by radio frequency glow discharge at a pressure of about one torr of oxygen, a technique similar to that used in the semiconductor industry for cleaning substrates (37). Both these processes served to remove condensed hydrocarbon products of previous experiments from the walls. The cleanliness of the vessels was monitored by irradiating air-zero gas $(50 \%$ relative humidity) with about a part-per-million (ppm) of nitrogen dioxide. Oxides of nitrogen were measured by a chemiluminescent $\mathrm{NOx}$ analyzer. During this pre-irradiation, which lasted several days or weeks if necessary, $\infty, \mathrm{CO2}$, and total gas-phase carbon (TGC) were measured (TGC in the 239 liter flask only). When the background rate had been characterized sufficiently, the hydrocarbon was added to initiate the reaction. Background TGC were generally less than 2ppmc, 002 generally less than lppm, and co less than 0.05ppm.

The flasks were irradiated with fluorescent lights to simulate the ultraviolet portion of the solar spectrum. The large flask had an equal combination of fluorescent black lights and fluorescent $\sin$ lamps. The overall light intensity gave an ND2 photolysis rate (k1) of about $0.2 \mathrm{~min}$ (38). The absolute spectral intensity distrj.bution was not measured but was probably deficient at the short wavelength end compared to actual sunlight. The 22 liter flasks were irradiated with blacklights only.

We obtained the gas phase carbon measurements by passing the air sample for analysis over an oxidative catalyst heated to $923 \mathrm{~K}$ 
(39). This oxidized all nydrocarbons, and carbon monoxide, to $\infty^{2} 2$, which was then measured quantitatively by gas chronatography. We call this measured quantity total gas-phase carbon. Since no filtering of the air sample was used, TGC includes suspended aerosol when present. The total carbon analysis was calibrated quantitatively by pressure/volume expansion into the large reaction vessel. Known amounts of various hyärocarbons, and carbon monoxide, were compared in their GC response to carbon dioxide to verify their quantitative conversion to $\mathrm{c02}$. Then, in each experiment, the hydrocarbon added initially was calibrated as 002 after combusion in the flow system. The sample lines leading from the flask to the combustion chamber were heated to $325 \mathrm{~K}$. In addition to TGC, $\infty, \infty 22$, and hydrocarbon were measured by gas chromatography as a function of time. Carbon monoxide has often been measured as a reaction product, but measurement of carbon dioxide is not frequently carried out by other reseachers.

Hydrocarbons were measured with a Perkin-Elmer PE 990 gas chromatograph with a flame ionization detector (FID), and equipped with a laboratory built automatic sampler. A one meter glass column packed with Porpack QS (Supelco) was used for the butane reaction. Toluene was separated on a one meter glass column packed with 208 SP-2100/0.18 Carbowax 1500 on 100/120 Supelooport (Supelco). Temperatures for the separations were $110^{\circ} \mathrm{C}$ for butane and $90^{\circ} \mathrm{C}$ for toluene. $\infty$ and $C 22$ chromatography was performed on a modified Perkin-Elmer PE 3920 using a FID. CO separation was on a one meter glass column packed with Carbosieve S, 002 separation 
was on a two meter glass column packed with Porpack QS. Both these separations were conducted at room temperature $\left(23^{\circ} \mathrm{C}\right)$.

\section{RESULTS}

Gas phase carbon balances were measured for several hydrocarbons in addition to the aromatics. Hydrocarbons such as cyclohexene, which are known to be prolific aerosol formers, were not studied. In the case of the low molecular weight hydrocarbons, current mechanisms predict very good gas phase carbon balances. This was observed to be the case for propene, acrolein, formaldehyde, acetaldehyde, butane, and hexane, which all gave essentially 100\% TGC yields. Figure 1 shows an example of the butane results. The TGC measurement remains constant at the initial value, indicating the gas phase carbon balance remains constant, even though the butane decreases from reaction with hydroxyl-radical.

Experiments were carried out with two aromatic hydrocarbons, toluene and o-xylene, and with two known toluene reaction products, benzaldehyde and o-cresol. All these compounds gave large TGC deficits. The aromatics did this without formation of any condensation nuclei while both benzaldehyde and o-cresol generated large amounts of condensation nuclei at the time the lights were turned on. Tolvene was studied in considerable detail. Eigure 2 shows typical carbon data which indicate that during the first 30 hours of continuous irradiation, toluene reaction gave a gas phase carbon (TCC) yield of only 37\%. Other reactions of 


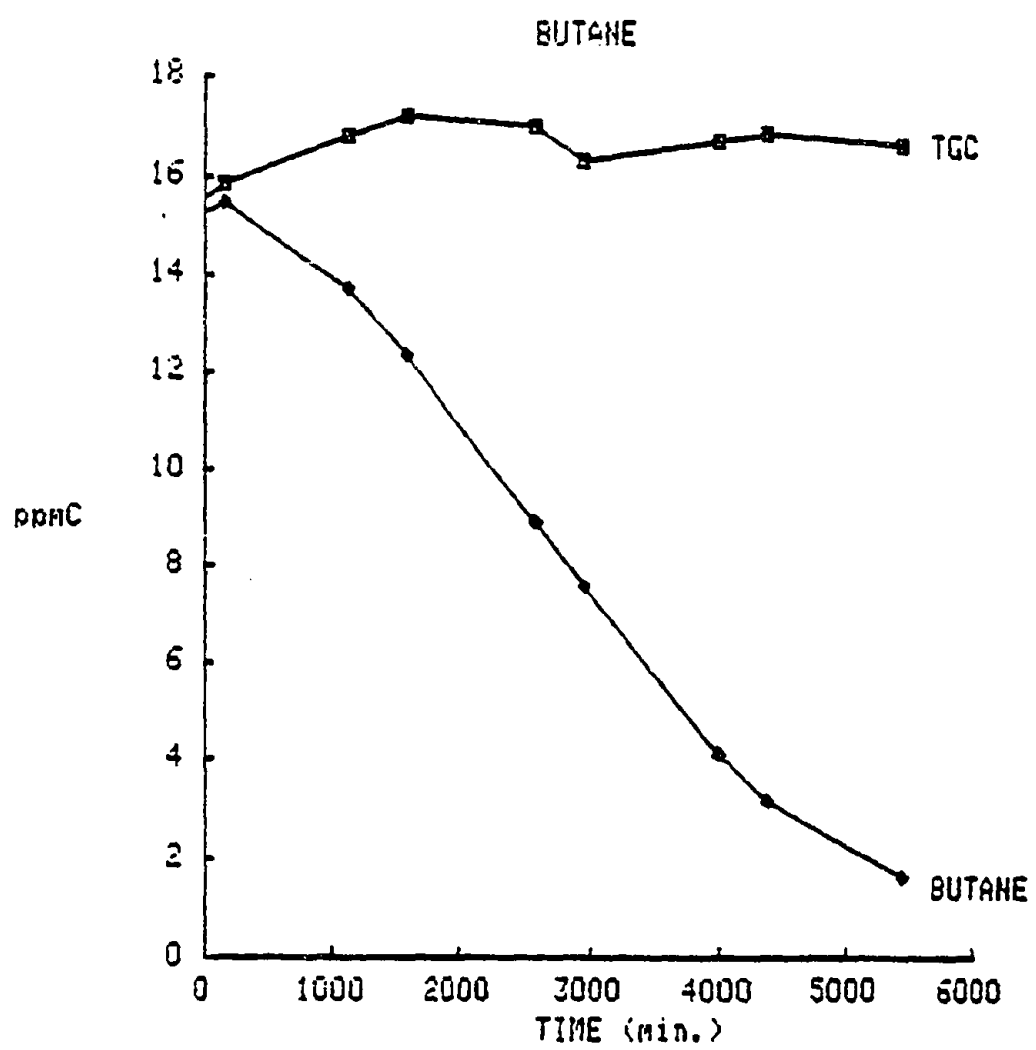

Figure 1. Total gas-phase carbon measurement for butane reaction. 


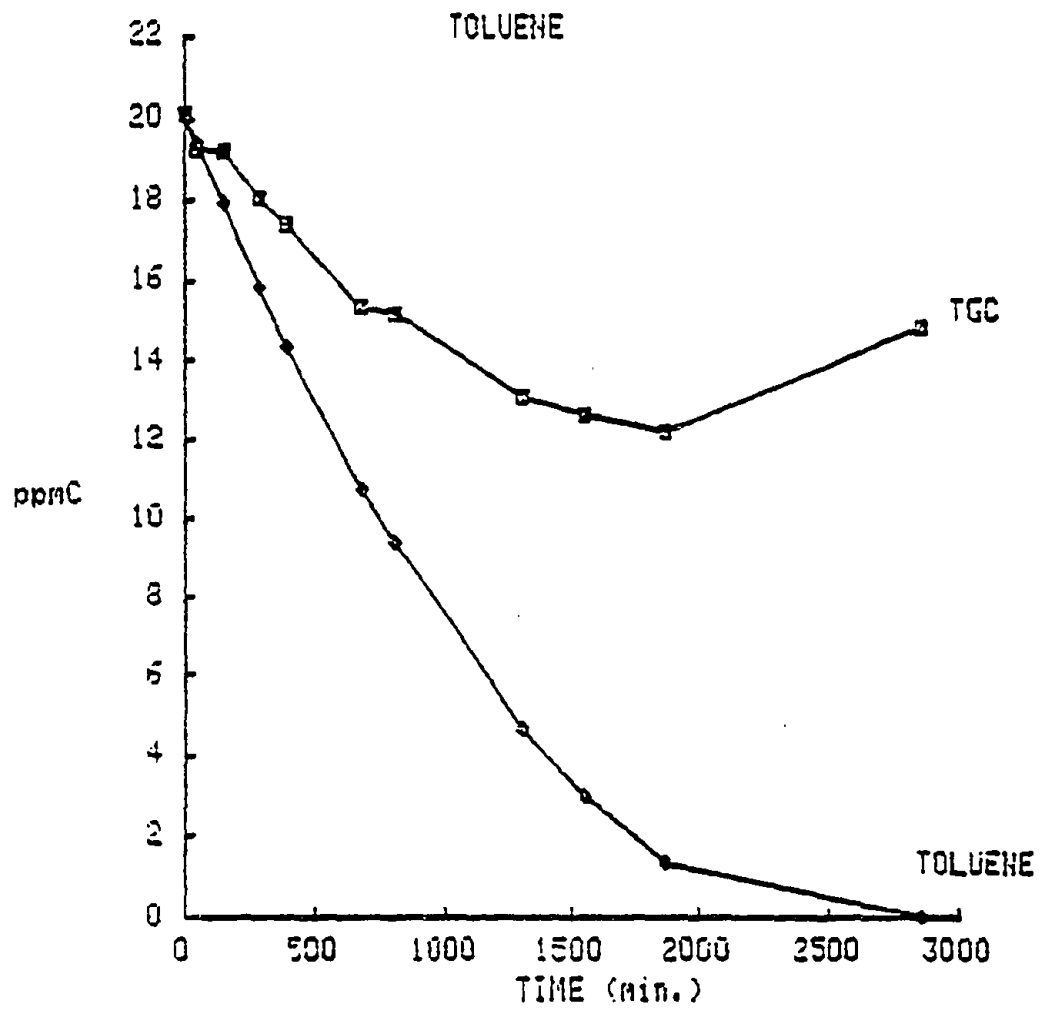

Figure 2. Total gas-phase carbon measurement for toluene 
toluene in the 239 liter reaction vessel gave similar results. The initial concentrations ranged from 0.2 to 4.3 ppm and the TGC yields were not significantly higher at lower concentrations. In the case of o-xylene, the TGC yield was 53\%. The TGC yield from o-cresol was 50\%, and benzaldehye was also 50\%. All these yields are uncorrected for the background $\infty$ and $\infty 2$ generation rate, and for the suspended aerosol formed from the oxygenated aromatics. Thus they represent upper limits. At longer reaction times, the TGC deficit decreased as the material on the walls and/or its gas phase vapor component continued to react and form $\infty$ and $\mathrm{CO}_{2}$. Figure 2 indicates this at times after $1800 \mathrm{~min}$. Several reactions were carried out in the 22 liter flasks for extended periods, up to a maximum of 40 days pre-irradiation and 40 days after toluene was added. In this case a complete recovery of the added toluene as $\mathrm{CO} 2$ and $\mathrm{co}$ was obtained. However, in these experiments it was not possible to measure TGC.

\section{DISCUSSION}

Since experiments of this type have apparently not been carried out previously, it is not possible to compare the TCC results to data from other reaction vessels. It is possible to compare the carbon monoxide data from both the large and small reaction vessels with the extensive data available from the large, evacuable smog chamber at the Statewide Air Pollution Research Center at the University of California, Riverside, and with data from the outdoor Teflon chamber at the University of North 
Carolina. These data are shown in Fig. 3. Dr. Robert O'Brien has derived a time independant method for the comparison of product data from different experimental chambers. This is described briefly below.

The data presented in Figure 3 can be simulated with a simple kinetic scheme representing $\infty$ in terms of prampt and delayed yields as follows (40):

TOLUENE + HO $\stackrel{\mathrm{kI}}{\longrightarrow}$ al $\mathrm{CO}+$ other products

TOLUENE + HO $\stackrel{k l}{\longrightarrow}$ a2 INIERMEDIATE

INIERMEDIATE $+\mathrm{HO} \stackrel{\mathrm{k} 2}{\longrightarrow} \mathrm{b} \infty$

Here, $\mathrm{kl}$ and $\mathrm{k} 2$ are rate constants for the overall reaction with HO; reaction $I$ gives a direct $\infty$ yield and reaction 2 produces an intermediate which ultimately produces some $\infty$ as well; al, a2, and $b$ are the fractional yields for the various steps. For simplicity, photolysis of the intermediate and overall dilution have been ignored here. The effect of dilution was minimal since the chemical lifetime of toluene was much shorter than the dilution lifetime (about 500 and 5000 minutes, respectively) in our large reaction vessel. Photolysis of the intermediate can be incorporated into an effective value of $k 2$. Analytical solution of these kinetic differential equations on a time-independent basis yields the following equation for the reaction product, carbon monoxide, expressed as a function of the concentration of its 

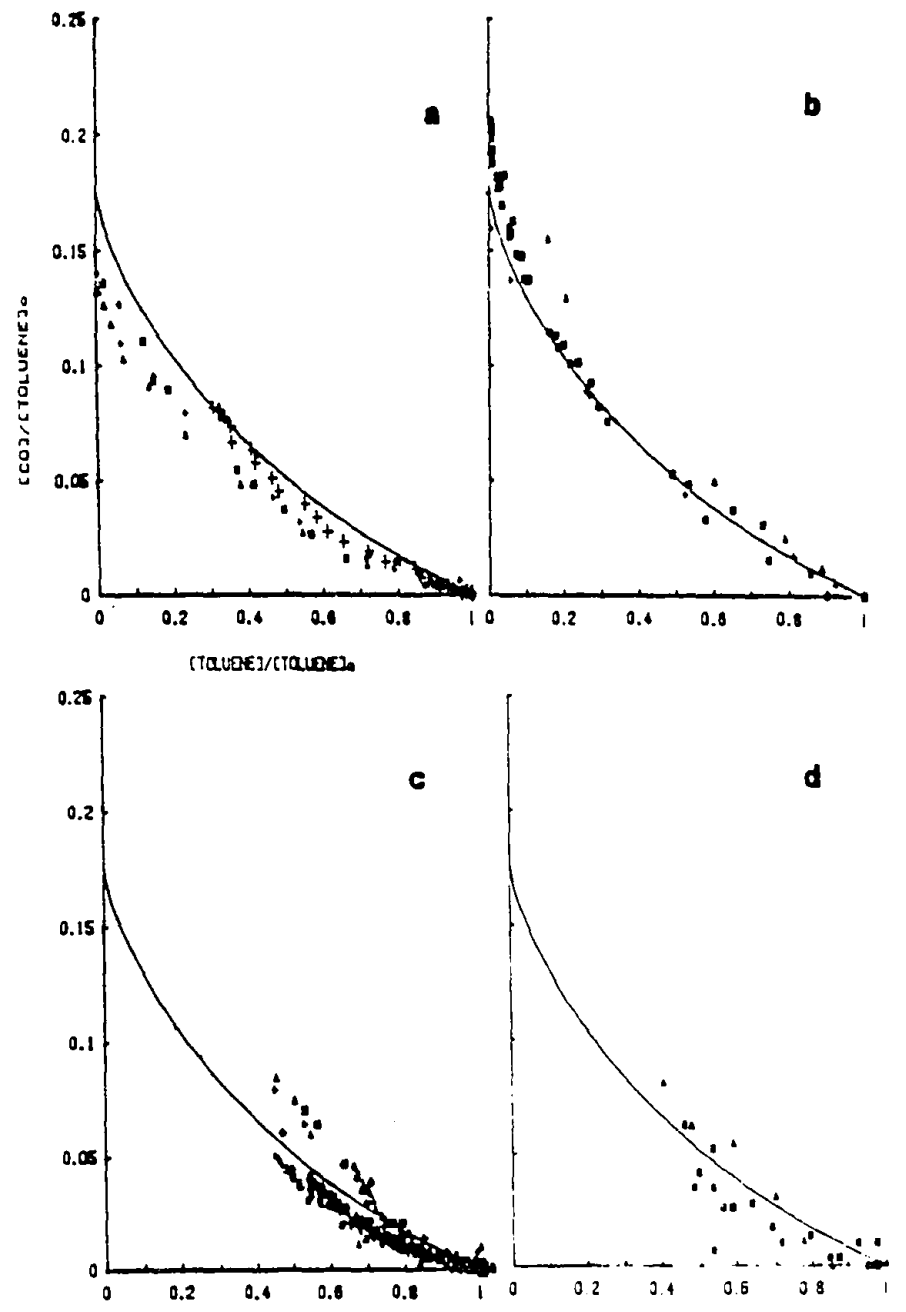

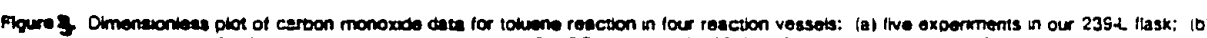

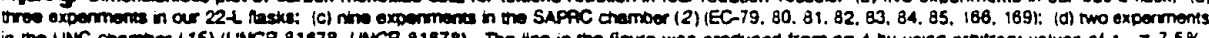
in the UNC chamber (15) (UNCB 81678, UNCB 81878). The the in the figure was prooucod trom eq 4 by using arbitrary values of $A_{1}=75 \%$.

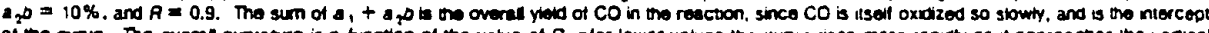

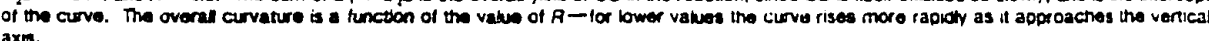


parent hydrocarbon, toluene.

$[\infty]=-a l \Delta[T]-\frac{a 2 b r}{R-1}\left|\Delta[T]+\frac{[T o]}{R}\left(1-\frac{[T]}{[T 0}\right)^{R}\right|(4)$

Here, [T] is the toluene concentration; the subscript, 0 , indicates initial concentration-all other concentrations are at time, t. $R$ is the rate constant ratio, $k 2 / k l$. The first term is the direct $\infty$ yield in reaction 1 . The second term is the indirect $\infty$ yield from the intermediate. The actual mechanism is undoubtedly more complex than reactions $1-3$, with several intermediates being important, and probably multistep $\infty$ formation as well. Nevertheless, this simple model is seen in Fig. 3 to be adequate for comparison of data from different reaction vessels. Note that the equation is independent of the hydroxyl radical concentration as well as time, and that it can be made dimensionless by dividing by the initial toluene concentration. This dimensionless data analysis procedure shows promise in normalizing results fram any type of smog chamber reaction carried out at any light intensity and at any initial concentration, provided only that ozone reactions are of minimal importance. If dilution or product photolysis are important, more complete equations are available (40). Figure $3 a$ presents data from the 239 liter flask, and Figure $3 \mathrm{~b}$ is from the small 22 liter flasks. A line is shown with arbitrary values of 7.5 percent of the carbon appearing as $\infty$ shortly after hydroxyl attack on toluene, and 10 percent appearing sonewhat later from the reaction of intermediate 
compounds. There is an apparent difference in the overall yields of carbon monoxide in these two reaction vessels with about $20 z$ overall yield in the small reaction vessel and about 148 overall yield in the larger reaction vessel. Data from the SAPRC chamber, Fig. 3c, is virtually identical to data from the 239 liter vessel, although the reactions did not run long enough to unambiguously obtain the overall yield. Data from the UNC chamber, Fig. $3 d$, is similar as well. More discussion of the significnce of the $\infty 2$ and $\infty$ yields will be given in Chapter VI.

The nominal surface-to-volume ratio is most favorable in the UNC chamber, and is worst in the 22 liter flasks. However, the UNC Teflon walls and the Teflon coating on the SAPRC chamber probably have a high surface roughness factor (porosity), so it is difficult to compare these directly. When the 239 liter flask is first filled with air-zero, the TGC reading is quite low, but then it rises in several hours to 1 to 2 ppmc, apparently due to desorption. Thus the commonly observed chamber "wall effects" may in fact be due to photolysis of gas phase material which is desorbed from the walls. Geonetrical considrrations indicate that in all but the UNC reaction vessel, leiss than a monolayer can be formed by deposition of reaction products from a single reaction at normal concentrations of reactant hydrocarbon. Thus the overall wall deposition process is probably controlled by adsorption and/or absorption rather than by condensation to the bulk phase. This is confirmed by the insensitivity of the TCC yields to the starting toluene concentration. The similarities between the $\infty$ 
data from the other chambers and the 239 liter flask are so great that we believe the overall chemistry of the toluene intermediates which yield $C O$ cannot be greatly different in the two reaction vessels. Comparison of $\mathrm{CO} 2$ data would be even more informative but unfortunately no $\mathbf{\infty 2}$ data is available from the other chambers. It is also significant that a recent toluene mechanism (9), based upon totally gas phase processes, apparently overpredicts the $\infty$ yields by a factor of three. It is probable that the low $\infty$ yields observed experimentally are due to wall deposition of most of the intermediates, rather than to extensive fragmentation as proposed. The overall goal of the study of pollution chemistry is to develop a greater understanding of both the homogeneous and heterogeneous processes occurring in real atmospheres, and not in smog chambers. The bearing of the results presented here on the situation in real atmospheres is not entirely clear. Certainly, the atmospheric surface to volume ratio is not greatly different from that in large smog chambers, due to the presence of suspended aerosols. On the other hand, smog chamber experiments carried out even in large reaction vessels do not show aromatic hydrocarbons to give suspended aerosol yields as large as the TCC deficits reported here. Thus the actual atmospheric case remains sonewhat enigmatic. 
CHAPTER III

MS/MS DETERMINATION OF TOLUENE'S REACTION PRODUCTS

Chapter II described discovering that the intermediate reaction products of toluene adsorb on the flask walls during the reaction. The next step is the analysis of this adsorbed-phase. This chapter describes the major method used for the characterization of the reaction products.

Mass spectrometry/mass spectrometry (MS/MS) was selected as the method of choice for the determination of toulene's reaction products. The method was reported to be sensitive, selective or general (as desired), and able to give structural information about each species in a complex mixture $(41,42)$. These expectations were found to be true. The experimental methods and instrumental techniques described below proved to be very effective.

The general field of tandem mass spectrometry has been reviewed $(41,42)$. This chapter describes a methodology for the identification of enviromental degradation products using MS/MS 
in conjunction with isotopic labeling. Although analysis of unknowns in complex mixtures is considered to be a major capability of MS/MS, a limited number of applications have been published to date. The samples analyzed here constitute complex mixtures of unknowns, although considerable information about compound classes and some specific compounds was available.

\section{EXPERIMENIAL}

\section{Reagents}

All chemicals were reagent grade. Methanol and dichloromethane solvents were further purified by fractional distillation. Methyl-deuterated (D3) toluene $(99.58$ D) was obtained frcm Stohlet Isotope Chemicals, Rutherford, N.J. Perdeuterated (D8) toluene $(99.58$ D) was obtained from KOR Isotopes, Cambridge, MA. Nitric oxide (998) was from Matheson. Zero-air ( $<0.1$ ppmc, Airco), and zero-nitrogen ( $<0.2$ ppmc, Airco and Matheson) were used in the experiments.

\section{Instrumentation}

Two instruments were used in this study. The majority of the analyses were performed on a Finnigan MAT triple stage quadrupole mass spectromeier/data system (43). The mass spect rometer was operated in the positive chemical ionization (CI) mode using 99.98 pure methane (Matheson) at a pressure of 0.23 torr as reagent gas. Samples were placed in glass sample vials and inserted into the ion source region with the direct probe. The probe was cooled to 
$-20^{\circ} \mathrm{C}$ by Freon expansion before insertion and was warmed by the ion source over a period of one minute to $120^{\circ} \mathrm{C}$. All compounds evaporated from the probe at relatively low temperature, however. A typical example is illustrated in Fig. 4 which gives the temporal evolution of the daughter-ion spectrum for $\mathrm{m} / \mathrm{z}=99$ showing compound evaporation between 9 and 28 seconds after probe insertion $\left(T<50^{\circ} \mathrm{C}\right)$. Zero- nitrogen (Matheson) was used as the collision gas at a pressure of 1.8 mTlor in the center quadrupole. The ion energy was $18 \mathrm{ev}$. Susan Humel of the University of Florida operated the instrument.

A preliminary analysis was performed using a SCIEX TAGA 6000 atmospheric pressure chemical ionization (APCI) triple quadrupole mass spectrometer (44). Sample (air) flow rate was approximately 5 liters/min. Water present in the sample at about 508 relative humidity acted as the CI reagent. Collision gas (argon) at a pressure of 0.45 mTor $r$ was used in the center quadrupole.

\section{Procedure}

The toluene oxidation products were generated by irradiating toluene and nitrogen oxides with zero-air in a 22-liter Pyrex vessels. The radiation was provided by fluorescent black-lights which adequately simulate the ultra violet portion of the solar spectrum, although they are deficient at the short-wavelength end. Toluene and nitrogen oxides were initially present at concentrations of $1-10 \mathrm{ppmV}$ and the relative humidity was about 508. Reactions were carried out for 24-30 hours and resulted in 


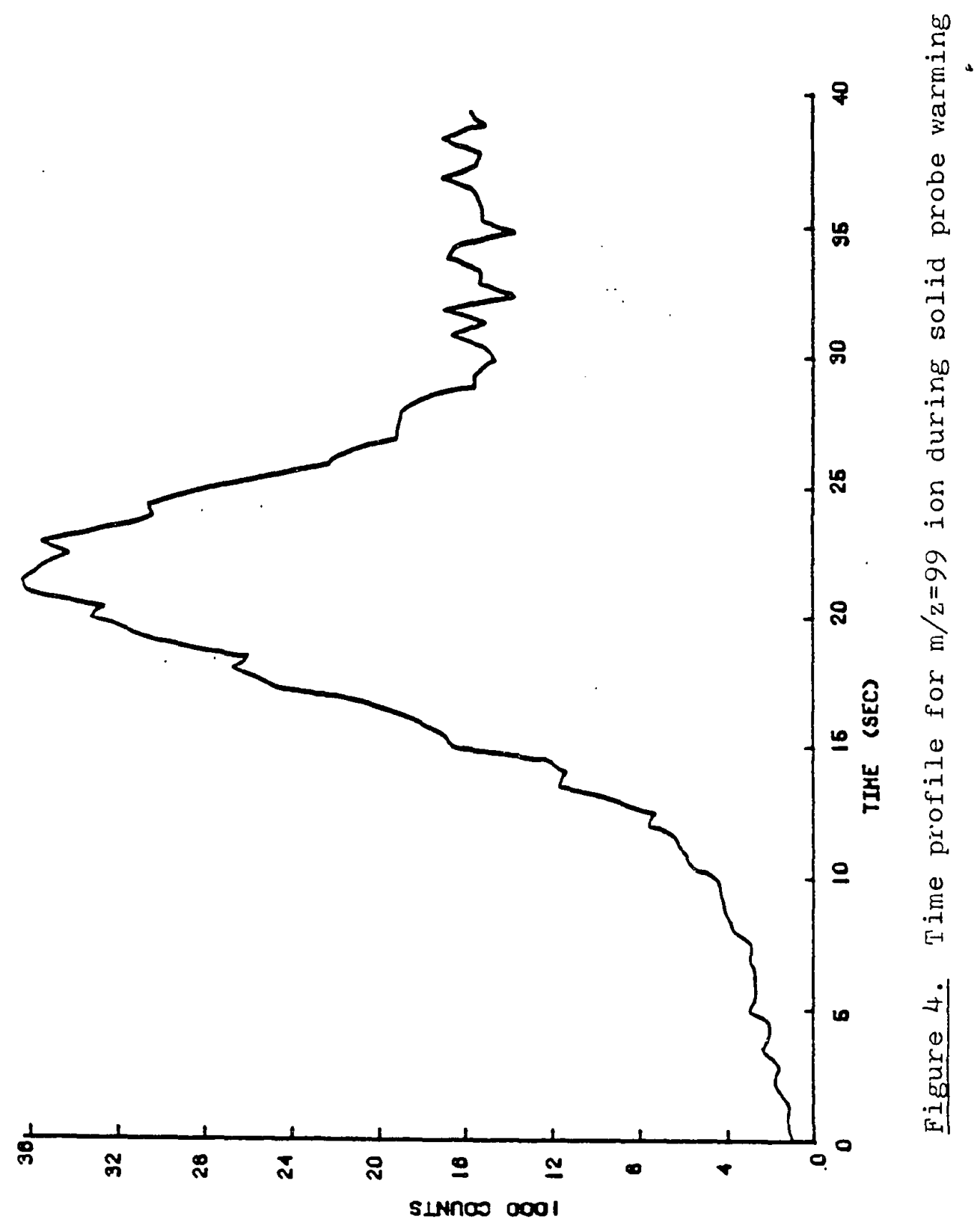


reaction of $60-80 \%$ of the added toluene. The glass vessels were pre-cleaned of organic contaminants by baking for several hours in an annealing oven at $550^{\circ} \mathrm{C}$. The products were recovered from the reaction vessel walls by washing with either methanol or dichloromethane. Typically, 40-50 ml solvent was used, of which about $20 \mathrm{ml}$ remained in the gas phase in the reaction vessel. Some products present in the gas phase may also have partitioned into the solvent while the walls were being washed. The recovered solvent was evaporated under zero-nitrogen to about $20 \mu l$.

A major difficulty of this study is that the molecular weights of the toluene ring-fragmentation products are under 150, where background from the direct probe inlet and vacuum system may interfere with their detection at trace levels. This background problem required us to concentrate our samples sufficiently : 0 that a single reaction in a 22 liter flask (resulting in about 50 $\mu g$ of products) was dissolved in the $20 \mu \mathrm{l}$ of solvent. Each direct probe sample consisted of about $2 \mu l$, or $10 z$ of the sample from a single reaction. The total quantity of products on the probe was thus about $5 \mu \mathrm{g}$. Following each probe insertion, approximately ten different masses were monitored in the various MS/MS operating modes. Ultimate sensitivity was limited by chemical noise in the mass spectrometer. This noise problen was mitigated by isotopic substitution in the reactant, toluene, thereby shifting most of the $(M+1)$ product ions of the methyl-deuterated toluene to even masses where the background was lower. As an added precaution all spectra taken in this study were compared with data from a blank 
run.

Isotopic substitution in the reactant (metringl-de:uterated toluene (D3)), assisted in confinming our simulated atmospheric reaction as the source of the compounds detected, and corroborating and clarifying the collision-induced tragmentation patterns. Reactions with completely deuterated (D8) toluene were also carried out to further clarify the product analysis. A potential difficulty with deuterium labeling of the reactant toluene molecule is isotopic exchange with hydrogen during the course of the simulated atmospheric reaction or at some stage of the analysis, particularly in the ion source region of the mass spectrometer. However, Hunt and Sethi (45) have studied and discussed isotopic exchange in the chemical ionization process, and it may be concluded that exchange is unlikely with methane as the reagent because methane is not basic enough to accept a deuterium ion from the protonated, deuterated sample molecule. In the simplest sense, these exchange processes will not affect the identification of deuterated molecules unless they lower the concentration of the non-exchanged molecules below the detection limit, or unless they shift other compounds to the same molecular weight as the non-exchanged molecules. We found no evidence for isotopic exchange at any stage of this study.

The reader is referred to several excellent summaries of the basic instrumental techniques possible with MS/MS $(41,42)$. The following is a brief description to help define terminology to be used throughout this chapter. 
The triple quadrupole mass spectrometers used in this study consist of three qudrupole rods alined in series. The quadrupole rods can be thought of as "mass filters" through which ions, generated in the source region, must pass. The "mass filters" can be operated to transmit all ions ( $R F$ only mode) or operated to pass a single mass to charge ratio at unit mass resolution. Additionally the rods can be set at a single mass to charge ratio on a continuous basis, or scanned through a range of mass to charge ratios over time. Four types of experiments result from different combinations of these modes. (Each of the experimental types will be shown in the results section).

Total mass spectrum experiment. In this experiment the first and second quadrupoles transmit all ions; the third quadrupole scans through the complete mass to charge ratio range. This produces a mass spectrum of all ions formed in the ion source; in this case the methane CI spectrum.

Daughter ion experiment. This is the normal MS/MS experiment. The first quadrupole selects a single mass to charge ratio to transmit to the second quadrupole. In the second quadrupole's RF only containing field the selected ions (parent ions) are fragmented in a collision induced disociation (CID) process. This CID process is a collision or near collision with a target gas such as nitrogen, fed in at a right angle to the ions' path through the second quadrupole. The fragmented ions (daughter ions) are then scanned by the third quadrupole, producing a CID daughter spectrum of the selected parent ions. 
Parent ion experiment. In this experiment the first quadrupole is scanned through possible parent ions, and the third quadrupole is fixed at a given daughter ion mass to charge ratio. This produces a spectrum of all parent ions which fragment to produce the selected daughter ion.

Neutral loss experiment. In this experiment the first and third quadrupoles are scanned together at a given mass to charge ratio difference. This produces a spectrum which gives all daughter ions which resulted from the selected neutral loss from their parent ions. In all the fragmentation experiments the intensities of the resulting ions detected are a function of both the intensity of the parent ion produced by the ion source and the relative amount of fragmentation producing those daughter ions.

RESULIS AND DISCUSSION

Figure 5 shows typical methane/CI mass spectra for (a) the toluene degradation products, and (b) a blank run; each was extracted and introduced in dichloromethane on the direct probe. Blanks were obtained by irradiating the flasks with nitrogen oxides, water vapor, and zero-air, but with no toluene. These runs produced no discernible products, and the slight level of contamination was due to impurities in the extracting solvent. The mass spectrum of a reaction blank was only slightly different from the mass spectrum produced by insertion of an empty probe, indicating that most interference peaks were not from our sample work-up. The background mass spectrum in Fig. $5 b$ is noticeably 
TOLUENE PRODUCT MASS SPECTRA

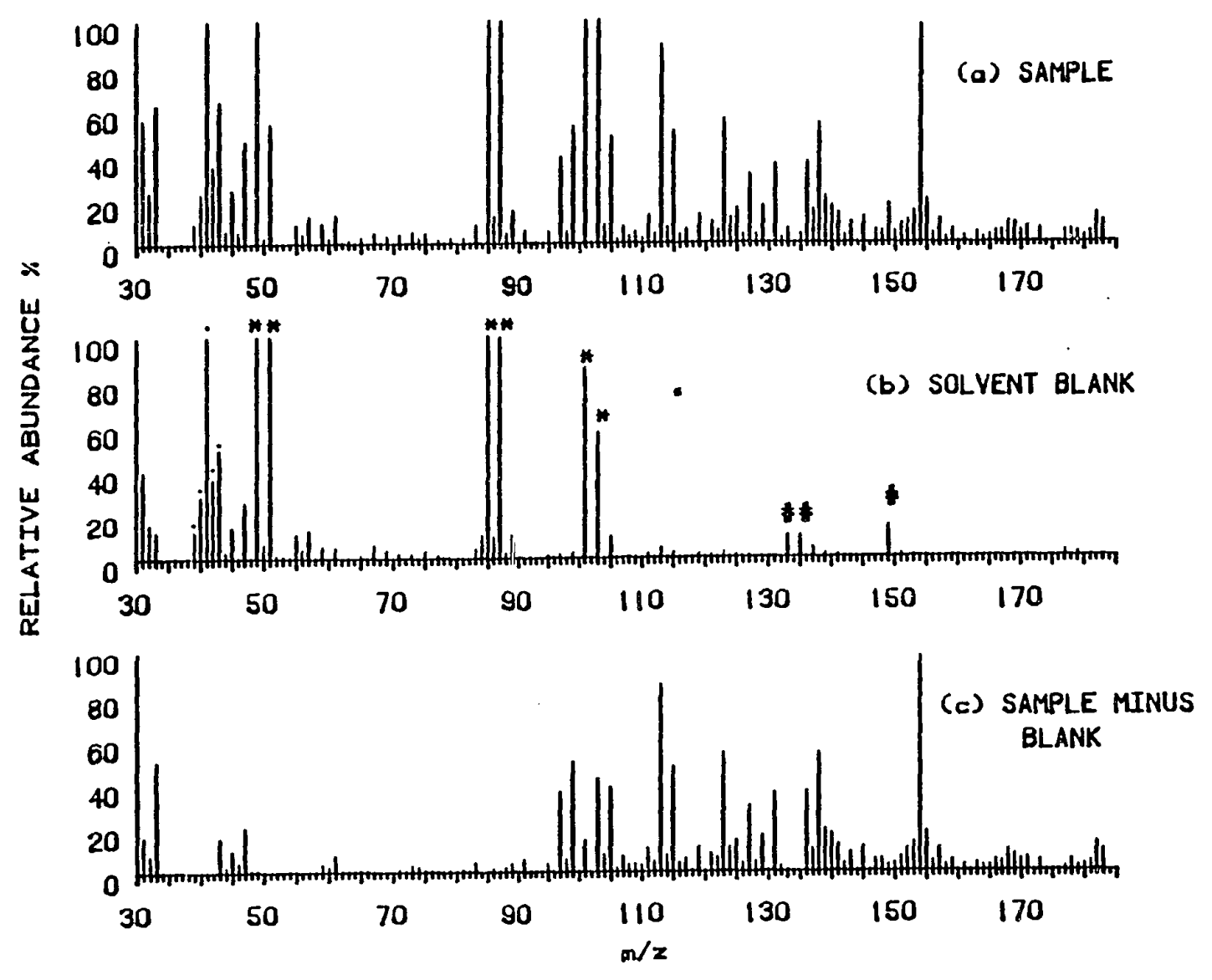

Figure 5. 'ioluene product mass spectrum. 
cleaner at even masses as described above. In Fig. 5 the solvent peaks are indicated by an $n * n$, the major contamination peaks by a "\#", and the CI cluster ions by a ".". Figure 5c shows the sample with the blank spectrum subtracted. Figure 6a shows the methane/CI mass spectrum for a D3 toluene sample, and Figure $6 \mathrm{~b}$ shows the D8 toluene sample. Discussion of how the products of the reaction are shifted in the deuterium labeled toluene reactions is described in the CI/CID section below.

Compound class survey by neutral loss and parent scans

Atmospheric reaction of other classes of hydrocarbons gives predominantly aldehydes and ketones as products, with less frequent production of acids, alcohols, peroxides, etc. Since we were interested in searching for members of each class of compound, we initially employed the two survey methods of neutral loss and parent ion scans.

The major neutral loss scans which were found useful were loss of $17(\mathrm{OH}), 18(\mathrm{H} 2 \mathrm{O}), 28(\mathrm{CO}, \mathrm{C} 2 \mathrm{H} 4), 30(\mathrm{NO}, \mathrm{C} 2 \mathrm{H} 6, \mathrm{CH} 2 \mathrm{O}), 42$ (ketene), 44 (CO2, acetaldehyde) and 46 ( $\mathrm{NO} 2$, HOOOH). The most useful parent scans were for parents producing daughter ions with $\mathrm{m} / \mathrm{z}$ of 43 ( $\mathrm{C} 3 \mathrm{H} 7, \mathrm{C} 2 \mathrm{H} 3 \mathrm{O}), 45(\mathrm{C} 2 \mathrm{H} 5 \mathrm{O})$ and 55 (C4H7, С3H3O). These masses are for the normal toluene as starting materiai; the nominal mass coincidences were eliminated by the use of deuterated toluene.

Figure 7 gives the spectra for the neutral loss of water from (M+1) parents in (a) H8, (b) D3, and (c) D8 samples. Loss of 


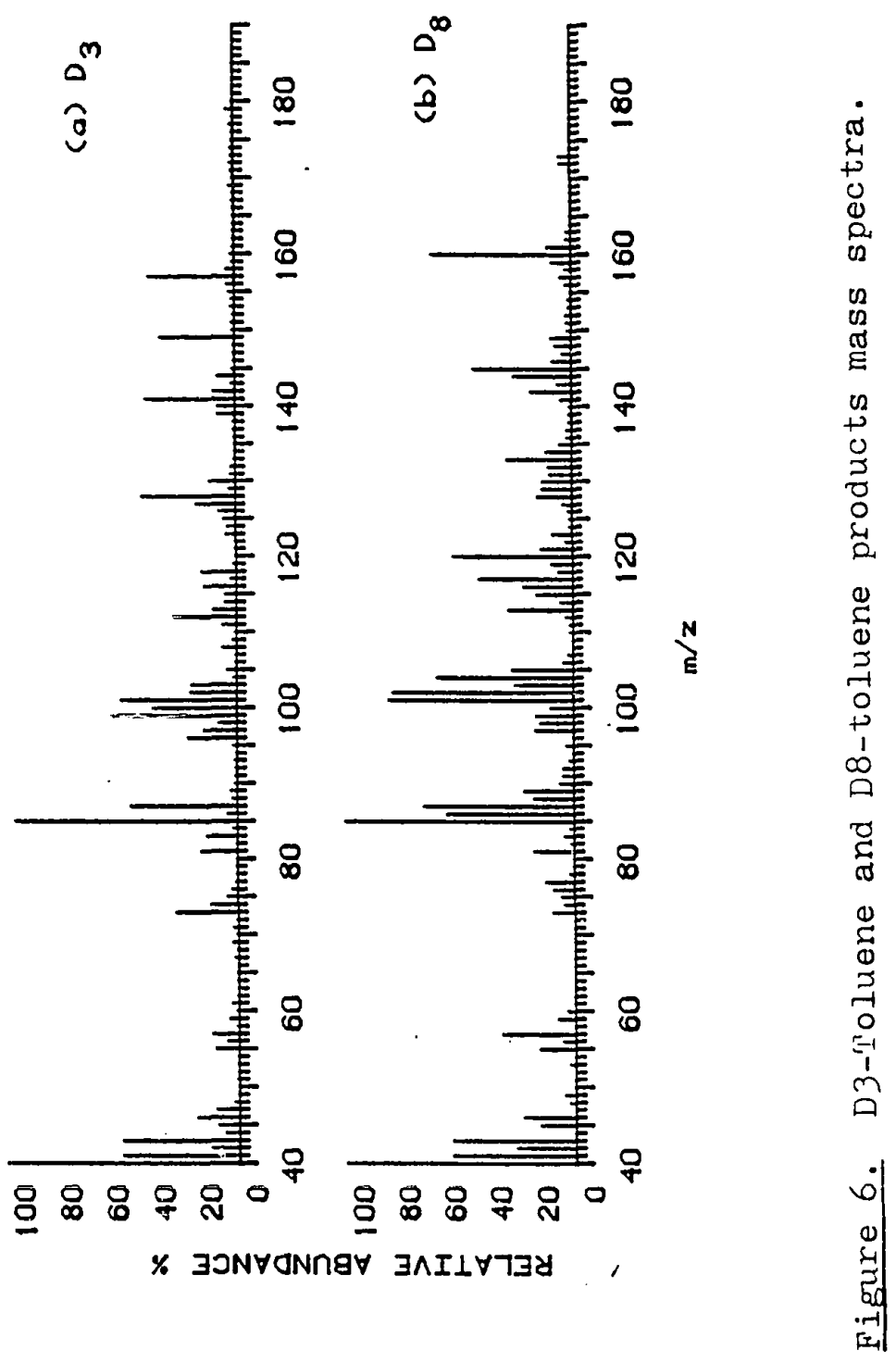


NEUTRAL LOSS OF 18

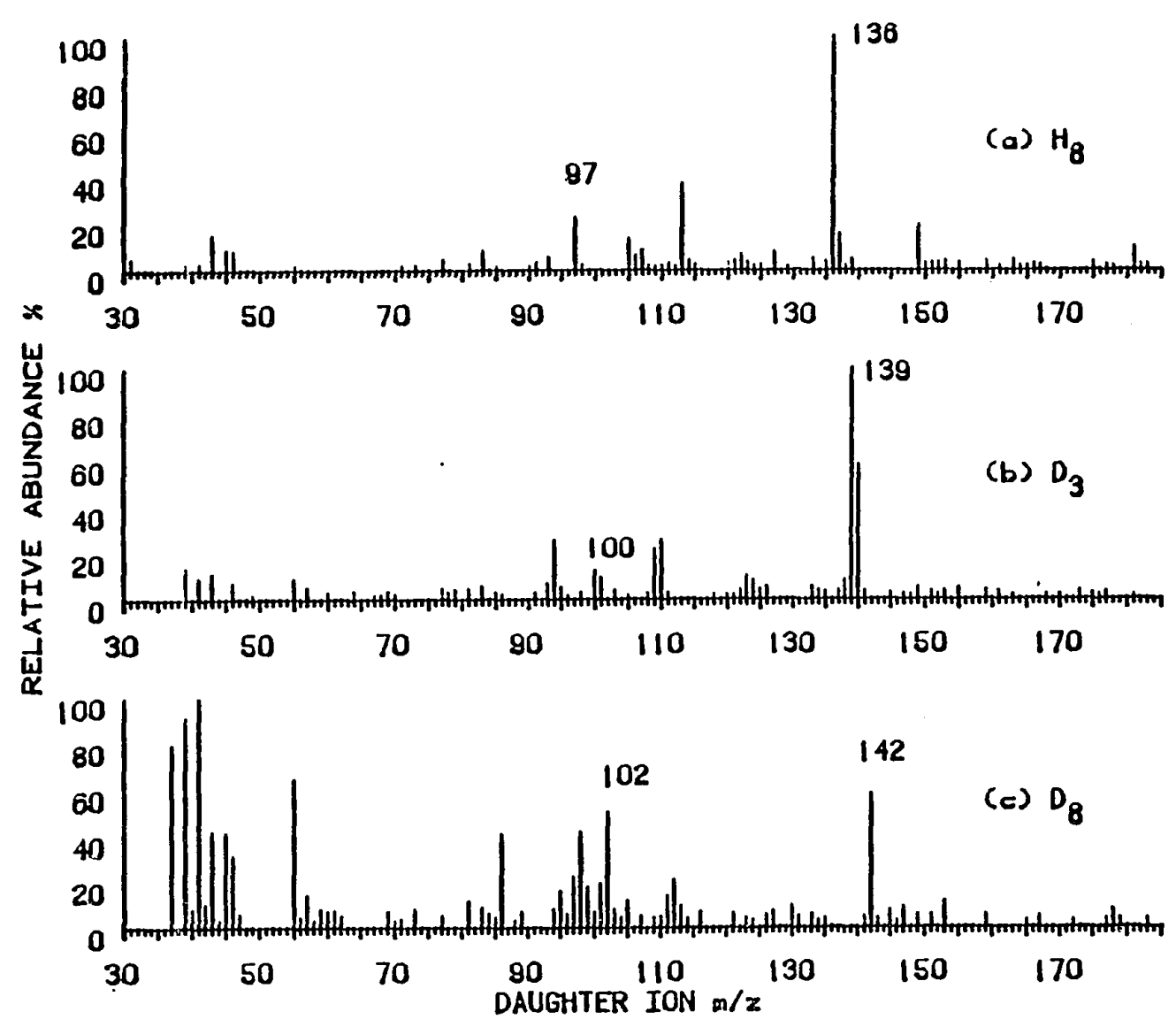

Figure 7. Neutral loss of 18 experiment. 
18 (water) is possible even in the D8 experiment because a hydroxyl group can originate from $\alpha H$ radical addition to the $D 8$ toluene. This OH-containing species then can be protonated in the ion source. Several mass shifts are apparent in the spectra. A prominent example is $\mathrm{m} / \mathrm{z}=97$ (parent ion $\mathrm{m} / \mathrm{z}=115$, $M+1$ of hydroxy-4-oxopentenal in the $\mathrm{H} 8, \mathrm{~m} / \mathrm{z}=100$ in the $\mathrm{D} 3$, and $\mathrm{m} / \mathrm{z}=102$ in the D8). Compound identification is described below. Another example is $\mathrm{m} / \mathrm{z}=136$ in the $H 8$ (parent ion $M+I$ of nitrocresol, $\mathrm{m} / \mathrm{z}=139$ in $\mathrm{D} 3$, and $\mathrm{m} / \mathrm{z}=142$ in $\mathrm{D} 8$ ). The nitrocresol isomers, previously identified as toluene products $(9,13-15)$, have the same molecular weight as benzylnitrate, (another oxidation product (10)) in $\mathrm{H8}$, but not in D3 or D8. 
Notice the aforementioned shift of products to even masses in the D3 experiment, where the intensities in the background are guite low. These spectra illustrate the substantial improvement in sensitivity obtained by deuterium labeling. Since the oxidation products were expected to be highly oxidized and quite polar, methanol seemed a preferable solvent to dichloromethane. However, we observed derivatization of some reaction products (addition of methanol) when samples in methanol were introduced via the direct probe. The chemical ionization process was also significatly perturbed by large amounts of methanol in the source region. This is due to the relatively large proton affinity of methanol compared to the methane CI reagent (46). Reproducibility was difficult since slight variations in the methanol concentration (due to methanol quickly evaporating off the probe), caused varying amounts of CI reagent scavenging. Dichloromethane's proton affinity is much lower than that of methanol (46), and is lower than most expected products. Using dichloromethane did not cause the same difficulties as the methanol. Later gas chromatography and high performance liquid chromatography analysis of the reaction products sample (to be described in Chapter IV) showed no differences in methanol vs dichloromethane vessel wall extractions. When a methanol extract was evaporated to dryness and redissolved in dichloromethane, the derivitization products were still observed. These peaks were not present in the spectrum of the dichloromethane extract. When the two extracts were analyzed for neutral loss of 32 (Figure 8) significant losses were observed 


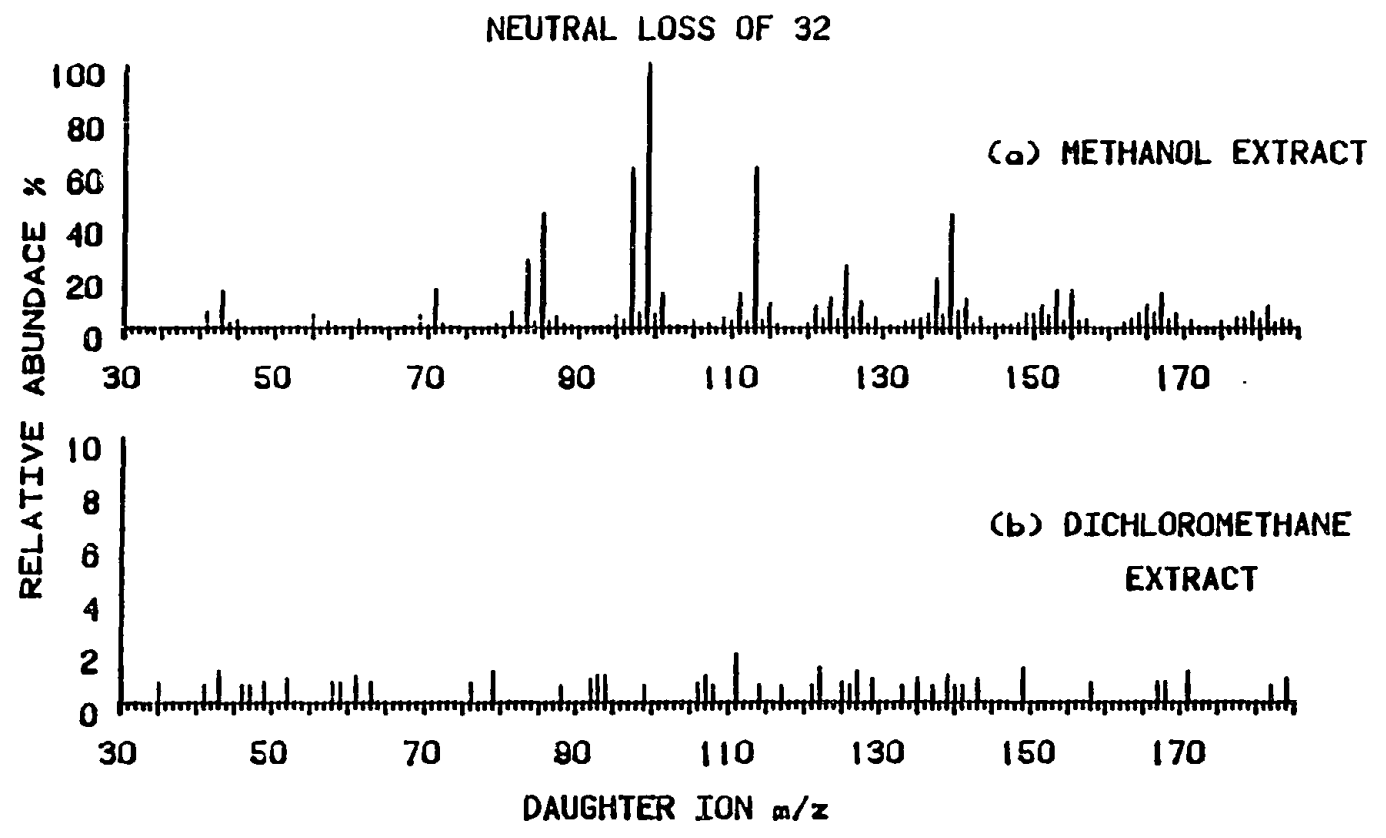

Figure 8. Neutral loss of 32 experiment. 
only in the sample extracted initially in methanol. This derivitization involves the formation of hemiacetals and hemiketals from aldehydes and ketones. As confimation, a small amount of heptaldehyde was dissolved in methanol and inserted on the direct probe. The mass spectrum showed a protonated molecular ion at $\mathrm{m} / \mathrm{z}=147(\mathrm{M}+\mathrm{CH} 3 \mathrm{OH}+\mathrm{H})$ rather than $\mathrm{m} / \mathrm{z}=115$ (M+H). This derivitization process is an interesting feature of the extraction procedure and indicates the potential which ms/ms possesses for the selective analysis of derivitized compounds in general, by neutral loss of a labile derivitizing agent. Conversely, ms/ms allowed the straightforward discovery of a chemical transformation process incurred during extraction with a solvent (methanol) commonly employed with air samples; a transformation process which could lead to severe complications if not recognized or anticipated.

A further neutral loss spectrum example is given in Figure 9. This is neutral loss of 17 mass units. It is characteristic of nitro compounds, (in this case nitroaromatics and nitrates) (47). Figure 9a, b, c, gives the neutral loss of 17 spectra for H8, D3, and D8 toluene respectively.

Parent scans are alternatives to neutral loss scans in surveying for chemical classes which fragment to produce a characteristic daughter ion. Figure 10 gives the parent spectrum of (a) $\mathrm{m} / \mathrm{z}=43$ ( $\mathrm{CH} 30$ ) from toluene $\mathrm{H8}$; and $\mathrm{m} / \mathrm{z}=46(\mathrm{CD} 30$ ) from (b) toluene D3 and (c) toluene D8. The loss of the acetyl fragment is characteristic of methylketones. Here again, several mass shifted 


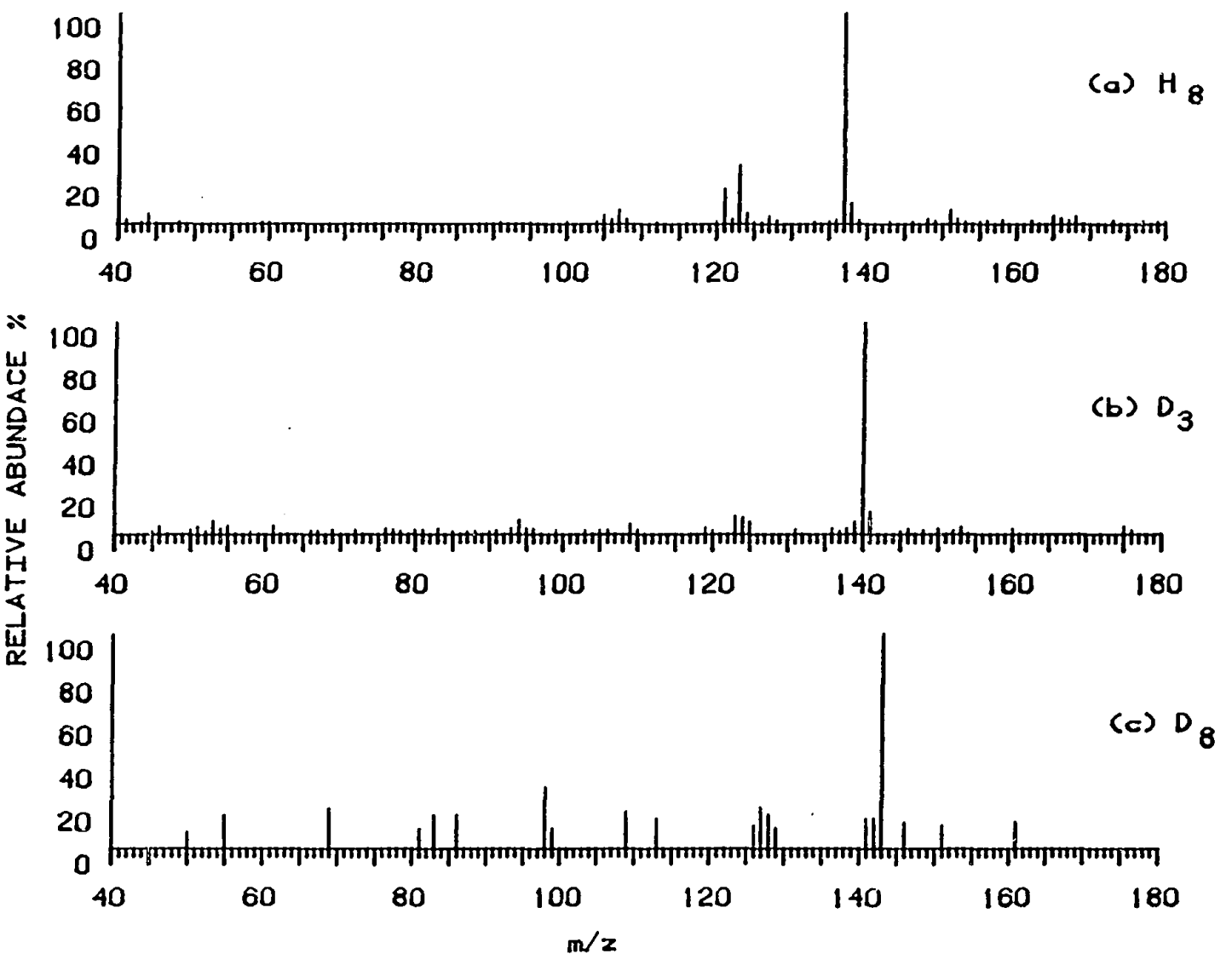

Figure 9. Neutral loss of 1.7 experiment. 


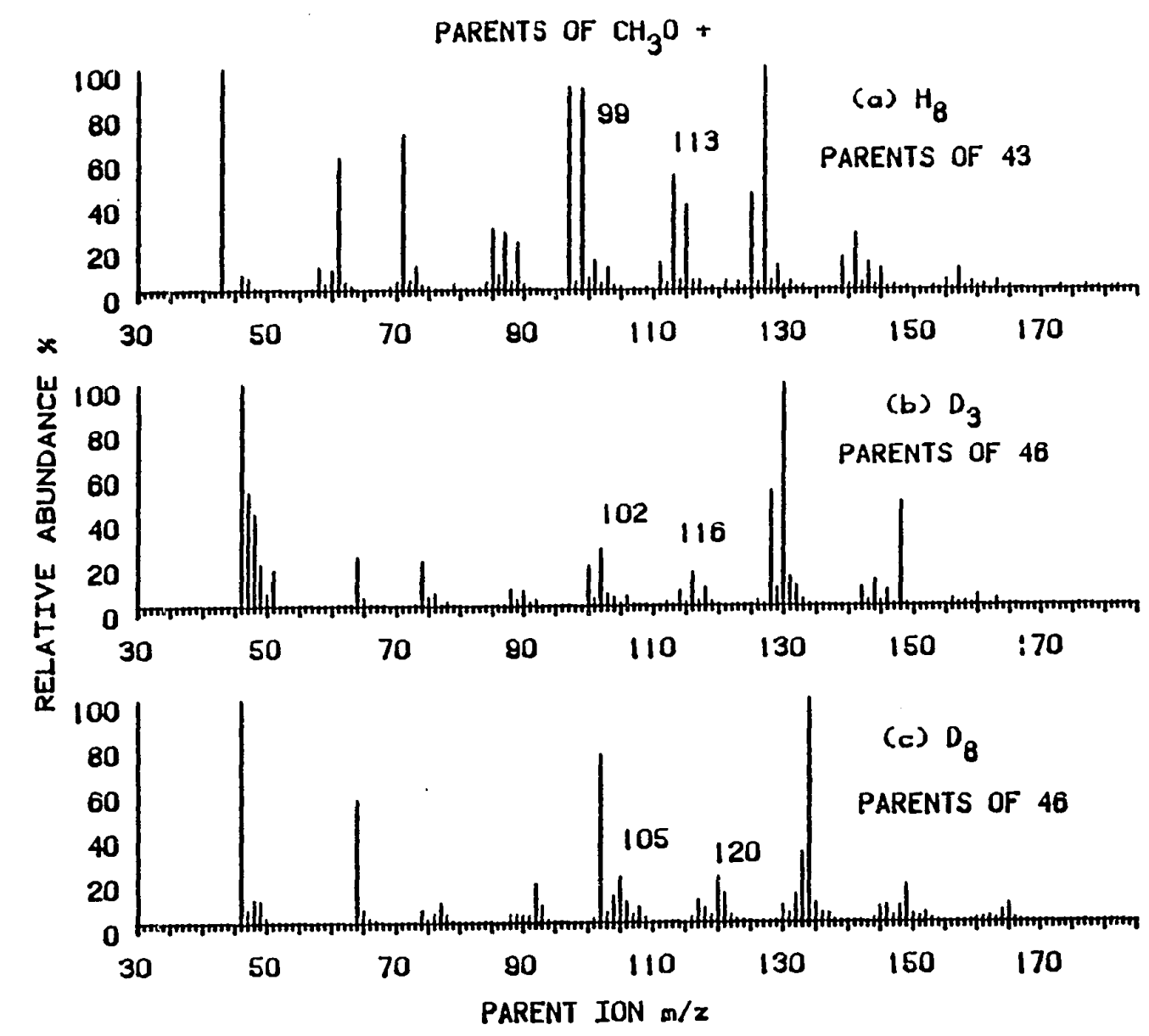

Figure 10. varents of $\mathrm{m} / \mathrm{z}=43$ experiment. 
peaks are apparent in these three experiments. Examples include: $\mathrm{m} / \mathrm{z}=99$ (parent ion $\mathrm{M}+\mathrm{l}$ of $4-\mathrm{oxo}-2$-pentenal) in $\mathrm{H8}, \mathrm{m} / \mathrm{z}=102$ in $\mathrm{D} 3$, and $\mathrm{m} / \mathrm{z}=105$ in $\mathrm{D} 8 ; \mathrm{m} / \mathrm{z}=113$ (parent ion $\mathrm{M}+1$ of hydroxy-4-oxo-1,3-hexadiene) in $18, \mathrm{~m} / \mathrm{z}=116$ in $\mathrm{D} 3$, and $\mathrm{m} / \mathrm{z}=120$ in D8. The actual identification of these compounds is described in the next section.

The efficiency of the survey methods for finding the molecular weight of each member of various classes of compounds is apparent. These surveys, coupled with the original mass spectrum of the reaction products, indicate the choice of the molecular ions to be identified by daughter ion scans. Identification of Photooxidation Products

Table II presents a listing of all compounds identified in this study. The table gives compound name, structure, molecular weight, and a listing of previous studies which either experimentally identified the product or proposed its formation. of the 27 compounds listed only ten have been previously identified. Four others have been proposed in mechanisms but not identified. The previously identified products are those amenable to gas phase sampling and anaiysis by packed columin gas chromatography (GC) or gas chromatography mass spectrometry (GC/MS). The use of $G C$ or GC/MS is applicable and even preferred for most gas phase products such as benzaldehyde and the cresols. Thermally labile compounds or those of high polarity, such as acids, do not generally chromatograph well, especially when using packed columns. Strictly gas phase sampling also limited previous 
PRODUCTS OF TOIUENE DEGRADATION DETERMINED BY MS/MS

\begin{tabular}{|c|c|c|}
\hline Compound 0 & $(M+1)$ & $\underline{E E}$ \\
\hline GLYOXAL $H-\mathscr{C H}^{\breve{H}}-\mathrm{H}_{0}$ & 57 & $11 *$ \\
\hline ACETIC ACID $\mathrm{CH}_{3}-\mathrm{C}-\mathrm{OH}$ & 61 & \\
\hline $\begin{array}{c}\text { 3-OXO-BUTENE: } \quad \mathrm{CH}_{3}-\mathrm{C}-\mathrm{CH}=\mathrm{CH}_{2} \\
0\end{array}$ & 71 & \\
\hline METHYLGLYOXAL $\mathrm{CH}_{3}-\mathrm{C}^{4}-\mathrm{c}-\mathrm{C}-\mathrm{H}$ & 73 & $11 *$ \\
\hline BUTENEDIAL $\quad H " C^{\prime \prime}-\mathrm{CH}=\mathrm{CH}=\mathrm{CH}$ & 85 & $c^{*}, 26^{*}, j 4^{*}$ \\
\hline HYDROXY-3-OXOBUTENE: $\mathrm{CH}_{3}-\mathrm{C}-\mathrm{C}=\mathrm{CH}_{2}$ & 87 & \\
\hline Phenol & 95 & \\
\hline 5-OXO-1,3-HEXADIENE: $\mathrm{CH}_{3}-\mathrm{C}-\mathrm{C}-\mathrm{CH}=\mathrm{CH}-\mathrm{CH}=\mathrm{CH}_{2}$ & 97 & \\
\hline 4-OXO-2-PENTENAL: $\mathrm{CH}_{3} \mathrm{C}-\mathrm{CH}=\mathrm{CH}-\mathrm{CH}$ & 99 & $g^{\frac{1}{\pi}}, 26^{\frac{1}{*}}, 34^{\frac{\pi}{m}}$ \\
\hline HYDROXYBUTENEDIAL HC-C=CH-CH & 101 & $s^{\frac{1}{7}}$ \\
\hline HYDROXY-3-OXOBUTANAL: $\mathrm{CH}_{3}-\mathrm{C}^{-\prime}-\mathrm{CH}^{-} \mathrm{CH}-\mathrm{CH}$ & 103 & \\
\hline BENZALDEHYDE & 107 & $(5-10,13-15)$ \\
\hline CRESOL & 109 & $(9-10.13-16)$ \\
\hline HYDROXY-5-OXO-1,3-HEXADIENE: $\mathrm{CH}_{3}-\mathrm{C}-\mathrm{C}=\mathrm{CH}-\mathrm{CH}=\mathrm{CH}$ ? & 113 & \\
\hline HYDROXY-4-OXO-2-PENTENAL: $\mathrm{CH}_{3}-\mathrm{C}-\mathrm{C}=\mathrm{C}=\mathrm{CH}-\mathrm{CH}$ & 115 & $q$ \\
\hline BENZOIC ACID & 123 & \\
\hline HYDROXYBENZALDEHYDE & 123 & \\
\hline $\begin{array}{l}\text { DIHYDROXYTOLUENE } \\
\text { 6-OXO-2,4-HEPTADIENAL : } \mathrm{CH}_{3}-\mathrm{C}-\mathrm{CH}=\mathrm{CH}-\mathrm{CH}=\mathrm{CH}-\mathrm{CH} \\
00\end{array}$ & $\begin{array}{l}125 \\
125\end{array}$ & $g^{\vec{t}}$ \\
\hline 4,5-D 10XO-2-HEXENAL: $\mathrm{CH}_{3}-\stackrel{c}{\mathrm{C}}-\mathrm{C}-\mathrm{C}-\mathrm{CH}=\mathrm{CH}-\mathrm{CH}$ & 127 & \\
\hline NITROTOLUENE & 138 & $(9-10,13-15)$ \\
\hline NITROPHENOL & $0 \quad 140$ & $10^{*}$ \\
\hline HYDROXY-6-OXO-2,4-HEPTADIENAL: $\mathrm{CH}_{3}-\mathrm{C}-\mathrm{C}=\mathrm{CH}-\mathrm{CH}=\mathrm{CH}$ & $1-\mathrm{CH} 141$ & \\
\hline NITROCRESOL & 154 & $(9-10,12-15)^{*}$ \\
\hline BENZYLNITRATE & 154 & $(10,14-15)^{*}$ \\
\hline DINITROTOLUENE & 183 & \\
\hline
\end{tabular}

* identified; \#proposed only; : several isomers possible 
attempts since only 408 of the reacted carbon remains in the gas phase in our reation vessels (see Chapter II). The identification procedure for the new products will be discussed in detail below.

Missing from Table II are low molecular weight gaseous compounds such as carbon dioxide, carbon monoxide, acetylene, methylnitrate, peroxyacetylnitrate, and formaldehyde which have been previously identified as toluene products (9-10). These compounds are either unlikely to partition into the solvent, or are expected to be easily lost during the concentration of the solvent. Six tenatively identified ring fragmentation products found by Swartz (12) were not found in this study. Swartz analyzed less than six percent of the collected suspended toluene aerosol. His procedure also included extensive work-up and fractionation, during which modification of the sample was possible. With the exception of the well-known product benzylnitrate, no nitrate products hypothesized by Atkinson et.al. (9) were found by this analysis to date. These compounds should have been detected if they were formed in yields as proposed (approximately 25\%). Daughter spectra were taken at $\mathrm{m} / \mathrm{z}$ that corresponded to the major predicted nitrates. Neutral loss spectra were taken at the expected major fragmentations of neutral loss of 17 (OH), 30(ND), $46(\mathrm{ND} 2)$, and $62(\mathrm{NO} 3)$. For example, Figure 9 shows the neutral loss of 17 spectrum for toluene products. The only products found in these experiments were nitrocresol, benzyl nitrate, nitrophenol, and nitrotoluene.

The neutral loss of 44 spectrum corresponding to loss of 002 
from acids is shown in Figure 11. We were particularly interested in the acids because of their low vapor pressures and potential for adsorption on the reaction vessel walls. Benzoic acid and acetic acid were the only acids identified by MS/MS. Several other acids have been proposed in toluene mechanisms $(9,26,34)$ but in much lower yields than the nitrates. Acids as a group should be easily detected by MS/MS using the acids' predominate fragmentation of loss of 44 mass units (CO2) (48). It is unlikely therefore that any acids other than those identified were present in significant amounts in the samples analyzed. Examination of the deuterated samples indicated that the benzoic acid was mainly a contaminant, rather than an oxidation product of toluene. Thus MS/MG, when coupled with isotopic labelling, can efficiently eliminate artifacts.

Although the present work is basically a qualitative study, the relative product yields can be approximated by examination of Figure $5 \mathrm{c}$, the mass spectrum of the toluene oxidation products. The relative ion abundances will depend on not only the amount of each compound present but also on ionization efficiency. Table III lists aromatic and diketone model compounds with their experimentally determined relative molar response factors for CI/MS analysis. The standards mixture was run under the same conditions as the toluene aerosol, using dichloromethane as the solvent. Although response factors vary over a factor of twenty, most are within a factor of two. The relative ordering of these response factors is in accord with proton affinities and effects 


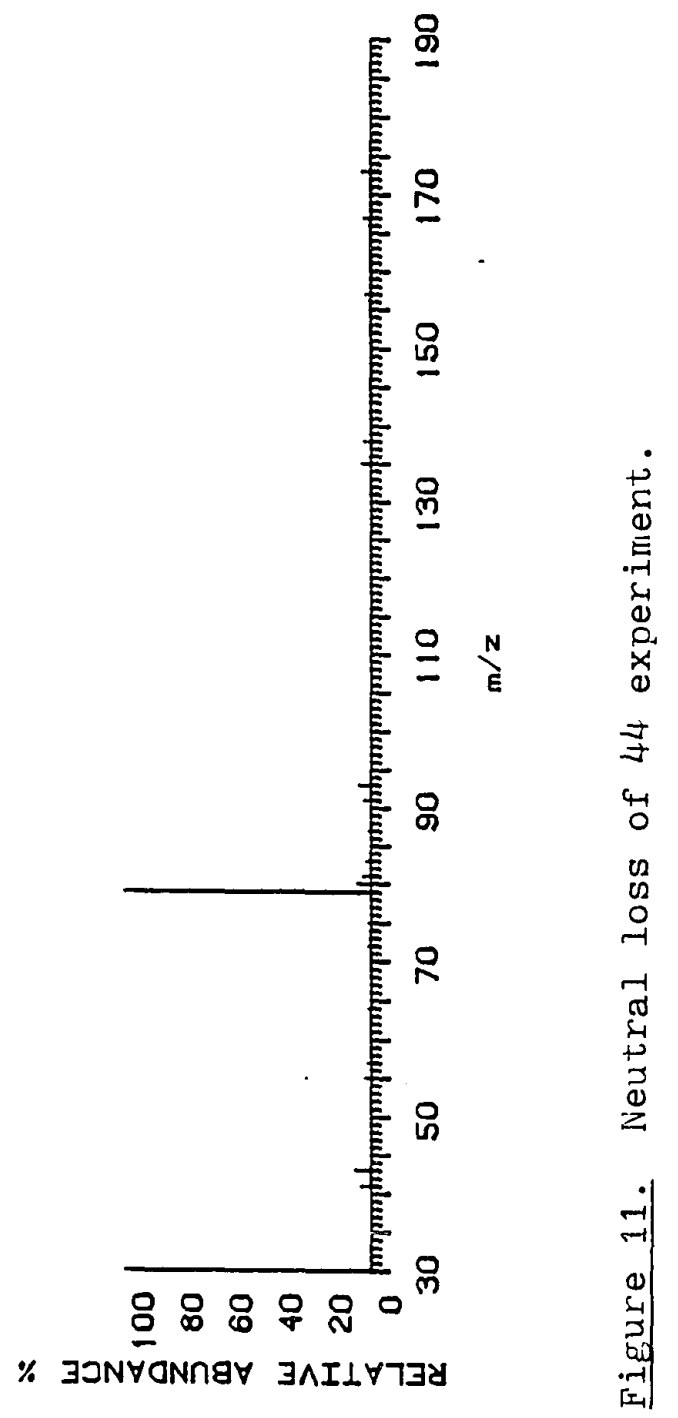




\section{TABLE III}

RELATIVE RESPONSE FACTORS FOR MS/MS

Compound

2-nitrobenzaldehyde

benzaldehyde

3-nitro-4-hydroxytoluene

2,3-dihydroxytoluene

2,5-hexadione

2-hydroxytoluene

3,5-heptadione

4-nitrobenzaldehyde

2-hydroxy-4-nitrotoluene

4-nitrotoluene

3,4-dinitrotoluene
Relative Response

0.2

0.4

1.0

1.1

1.2

1.2

1.4

1.8

1.9

2.3

4.1 
of intramulecular hydrogen bonding on protonation (46). The toluene reaction systen is a dynamic one in which the products are destroyed as well as formed. Therefore relative yields at single points in time do not give an accurate picture of the branching ratios between various pathways. Products which thenselves react quickly (eg. aldehydes) never build up to a high concentration while slowly reacting products (eg. nitrotoluenes) steadily build up even if they are formed in low yields. If concentration/time data are available the true product yields may be determined. Losses due to evaporation during concentration are also unknown at this time. These losses are expected to be low except for the low molecular weight compounds already discussed above. In light of these considerations, major products found in this study are: 6-oxo-2,4-heptadienal, 4-oxo-2-pentenal, bütenedial, 4,5-dioxo2-hexenal, 3-hydroxy-4-oxo-2-pentenal, 5-oxo-1,3-hexadiene, 4-hydroxy- 5-oxo-1,3-hexadiene, and hydroxybutenedial. These compounds' molecular protonated $(M+1)$ ion intensity vary by less than an order of magnitude. This implies that none of the identified products dominates toluene's atmospheric degradation. This result contrasts with some of the current mechanisms in which only two of these new products have been included $(9,26,34)$.

\section{CI/CID spectra and fragmentation schemes}

Identifications listed in Table II are based mainly on the chemical-ionization/collision-induced-dissociation

(CI/CID) spectra. These spectra provide both molecular weight and 
structural information. Each compound is found as a toluene reaction product and as a reaction product in each of the two deuterated toluene experiments. A compound's molecular weight and therefore its $M+1$ ion is shifted in the perdeuterated toluene experiment to a higher mass depending on the number of hydrogens in its structure. Products derived from methyldeuterated toluene may or may not have their $M+1$ ion shifted depending on whether they have one or more of their hydrogens derived from the methyl group of toluene. Each identified compound's CI/CID daughter spectrum will be presented for each of the three experiments: normal (H8) toluene, methyldeuterated (D3) toluene, and perdeuterated (D8) toluene. These three spectra when interpretated together give strong evidence for the compound's identification. The spectra of the major (as defined above) products which have not been previously identified are presented below with discussion of the fragmentation scheme for each. The remaining product's daughter ion spectra are presented in Appendix A.

It is possible that other compounds with the same nominal $\mathrm{m} / \mathrm{z}$ as the compound assigned are present in the spectra since the first quadrupole has only unit mass resolution. However, onlÿ compounds with the same molecular formula as the assigned compound will appear in all three spectra. Contributions from other reaction products are checked at the appropriate $\mathrm{m} / \mathrm{z}$ in the deuterated experiments. Contributions from the solvent and solvent artifacts can likewise be cross-checked since they do not shift in the deuterated experiments. This approach is illustrated and 
systematized by the information in Table IV, in which the various isotopic forms of several hypothesized products are listed. Same of these compounds were suspected based upon previous studies, while others were discovered either in the mass spectra or in the various MS/MS survey spectra. It was usually possible to propose an empirical formula and likely structure for a particular ion on the basis of its molecular weight, the reactant (toluene) and probable reaction mechanisms. Once probable structures were proposed, confimation was attempted using the MS/MS spectra from the various labeled compounds. The products can $\propto c c u r$ as various methyl-positional isomers whose structure depends upon the initial position of $O H$ radical addition to toluene, as well as the mechanism of internal addition and rearrangement. This is also true of the cis and trans iscmers possible for the compounds with a carbon-carbon double bond. Differentiation of the various isomers is possible when a unique daughter ion is produced. For instance, the acetyl fragment ion is indicative of methyl ketones, but not the isomeric aldehydes. Identification and quantition of all isomers by MS/MS, however, may in many cases be difficult or impossible.

Table IV illustrates the ability to cross-check spectra from different experiments to confirm that parent ions are in fact from the proposed reaction product and not from another compound or background contamination. These cross checks are in addition to comparison of each spectrum to the corresponding blank spectrum. For example (referring to Table IV) the daughter spectrum of 


\section{TABLE IV}

\section{MASSES OF $(M+1)$ IONS OF TOLUENE AND SEVERAL REACTION PRODUCTS BASED ON TOLUENE'S ISOTOPIC FORM}

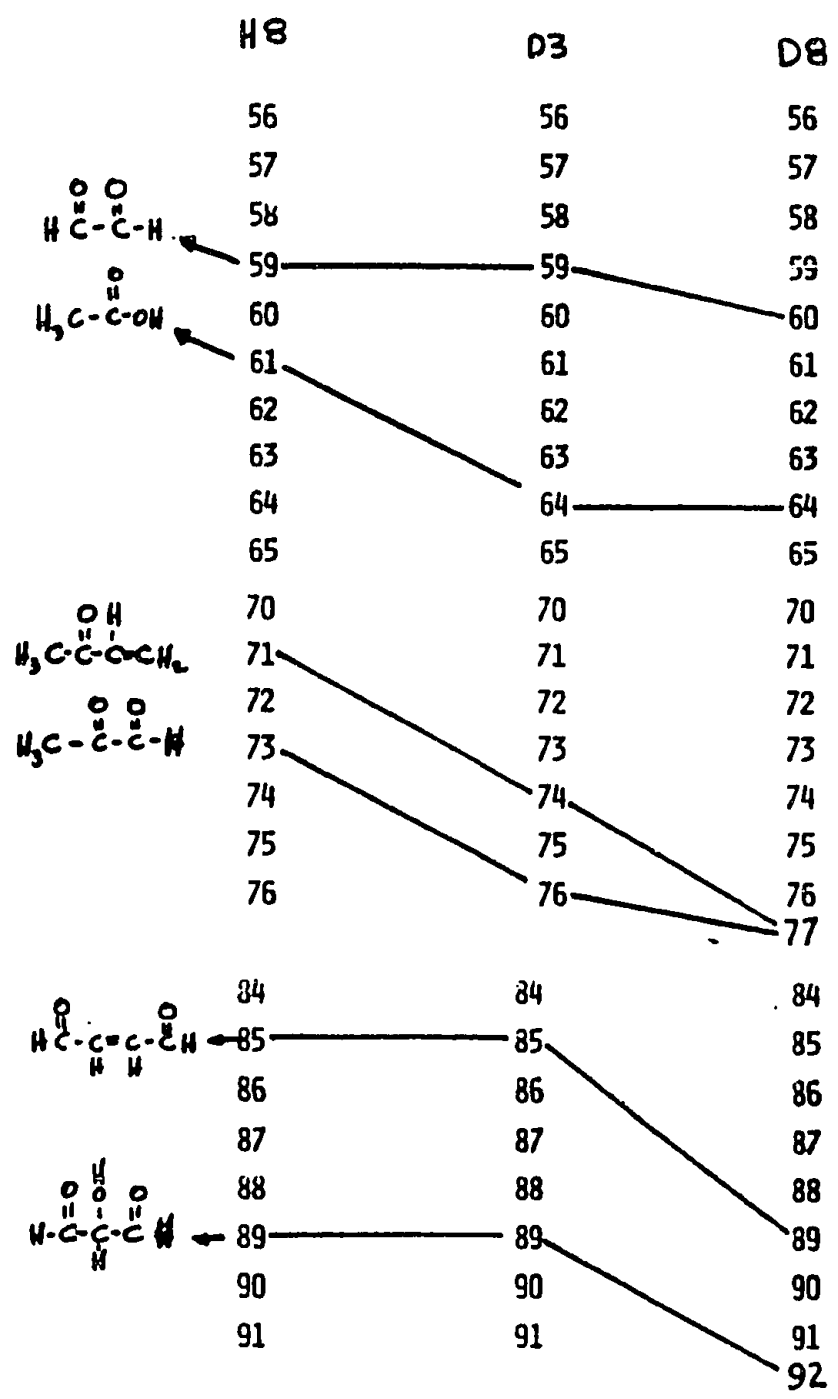




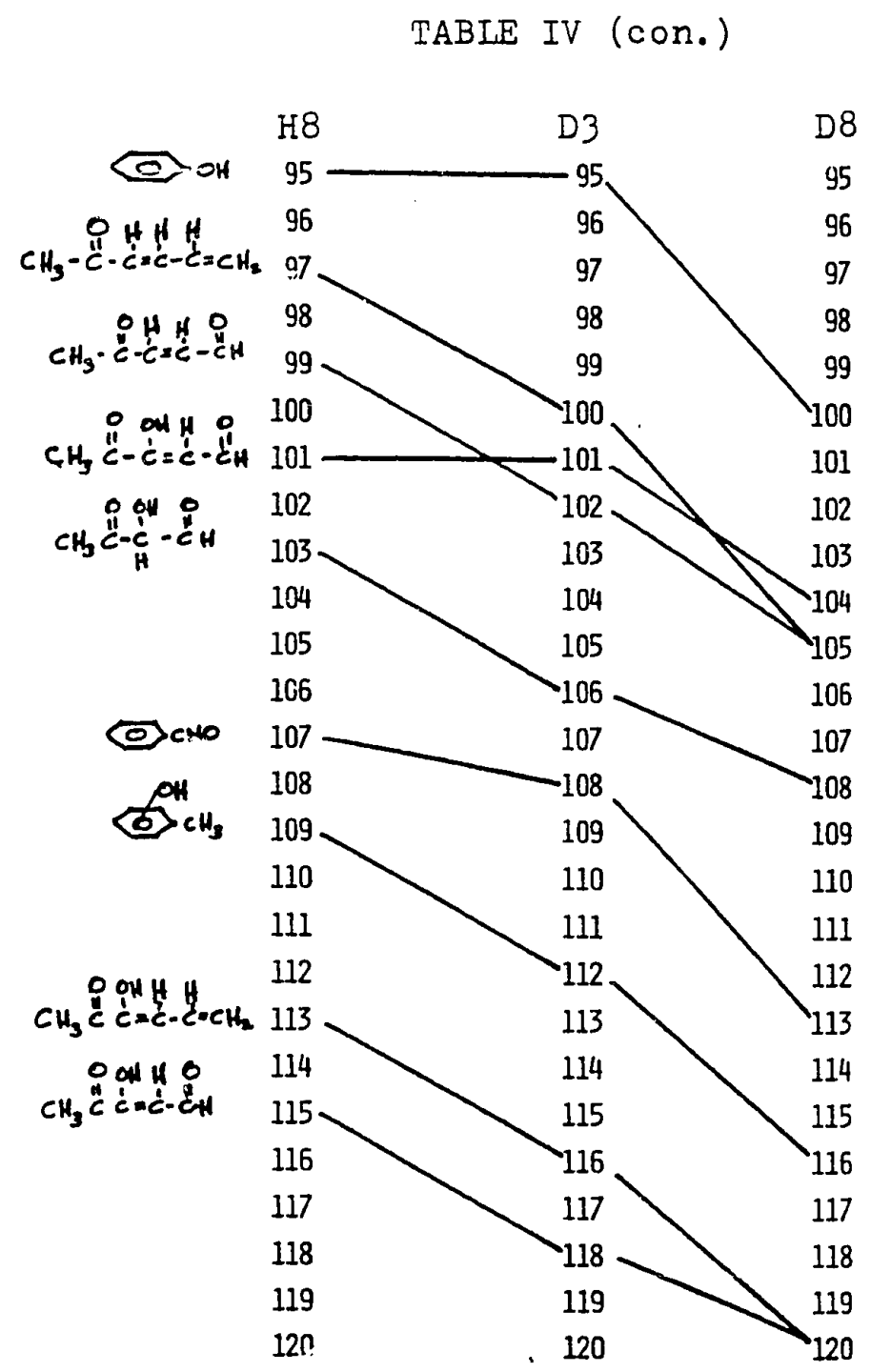




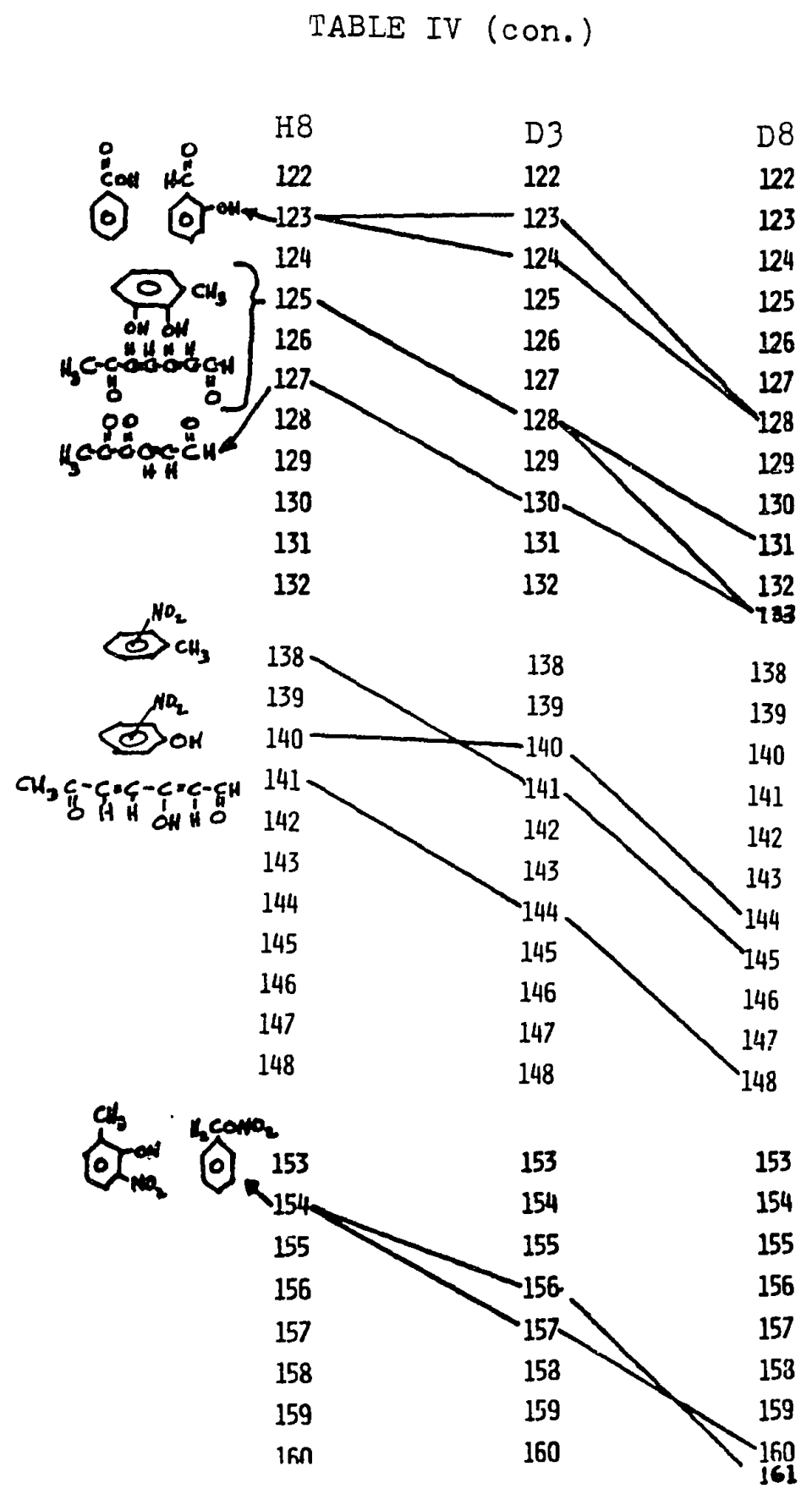


$\mathrm{m} / \mathrm{z}=101$ in the $\mathrm{HB}$ mixture should agree with that from the D3 mixture but not with that from the DB mixture. These cross checks are very important when the parent mass lies on a prominent background mass, such as the series $\mathrm{m} / \mathrm{z}=71,85,99,113$, etc. for alkanes and ketones. Cross checks as described above were performed on all compounds whose identities are proposed.

Methylglyoxal. A compound of prime interest, based upon previous identifications (II) and proposed toluene-oxidation mechanisms $(9,26,34)$, is methylglyoxal. Figure $12 a-c$ gives the daughter spectra of the io:s in the mass spectra of the toluene products which correspond to $(M+1)$ of methyl glyoxal formed from the various isotopic forms of toluene. The spectra show loss of carbon monoxide, formaldehyde, and ketene, as summarized in Figure $12 \mathrm{a}$.

6-0xo-2,4-heptadienal. Figure $13 a-c$ shows the CI/CID daughter spectra for the compound identified as 6-oxo-2,4-heptadienal. The $M+1$ ions are at $\mathrm{m} / \mathrm{z}=125$ (13a), 128 (13b), and 133 (13c) for the $\mathrm{HB}, \mathrm{D} 3$, and $\mathrm{D} 8$ tolvene experiments respectively. Figure 13d summarizes the major fragmentation pathways. Figure 13d, and the following fragmentation schemes, show the mass loss and $\mathrm{m} / \mathrm{z}$ of each ion for each of the three spectra. The base peak in each of the spectra in Figure 13a-c is the expected alpha cleavage at the carbonyl to produce the acetyl ion (48), $m / z=43$ (H8), and $m / z=46$ (D3 and D8). The large peak due to loss of 28 mass units $(-\infty)$ at $m / z=97,100,105$ in $13 a, 13 b$, and 13c respectively is characteristic of $\alpha, \beta$-unsaturated aldehydes 

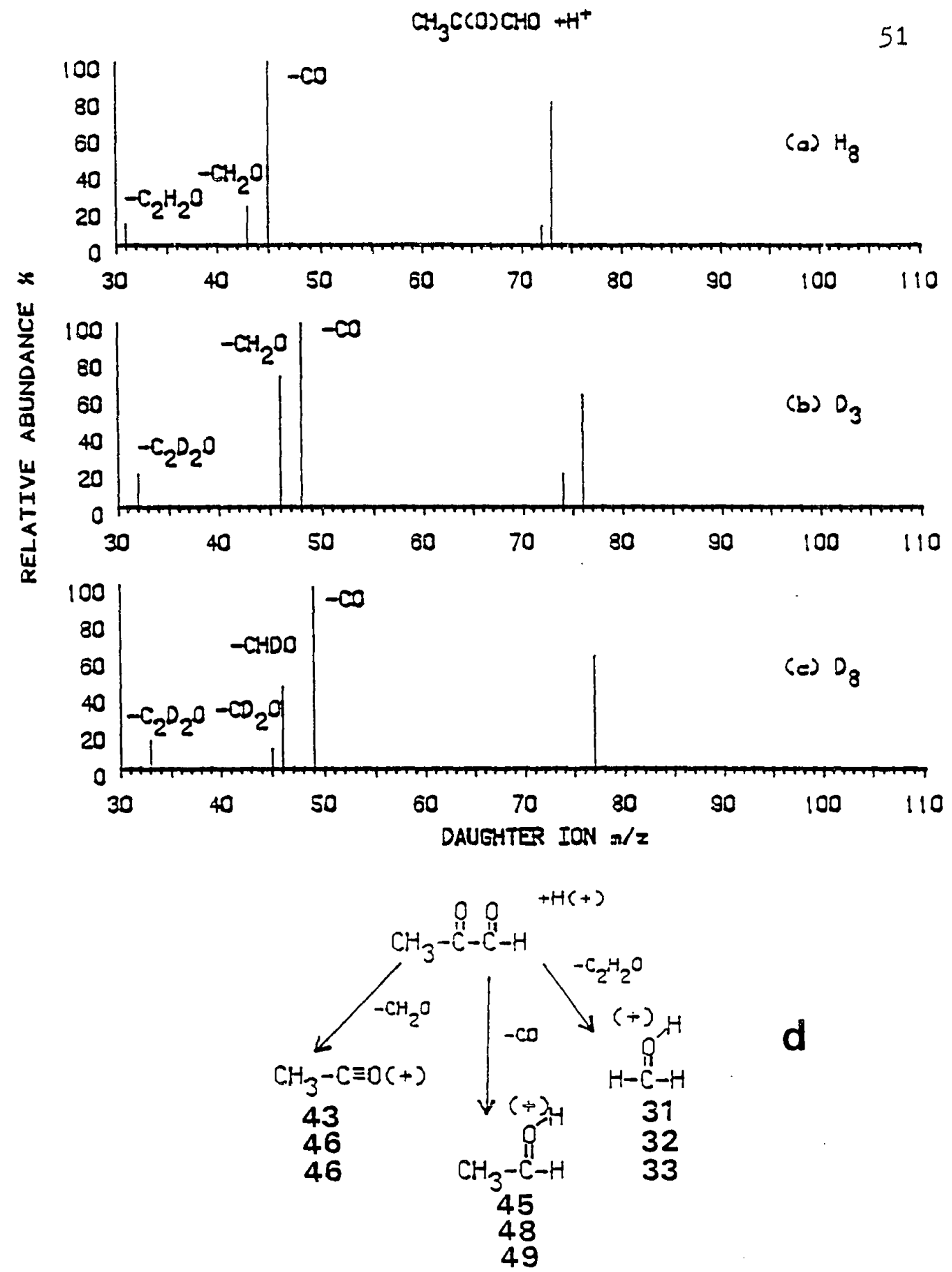

Figure 12. Daughter spectra for methyl glyoxal. 

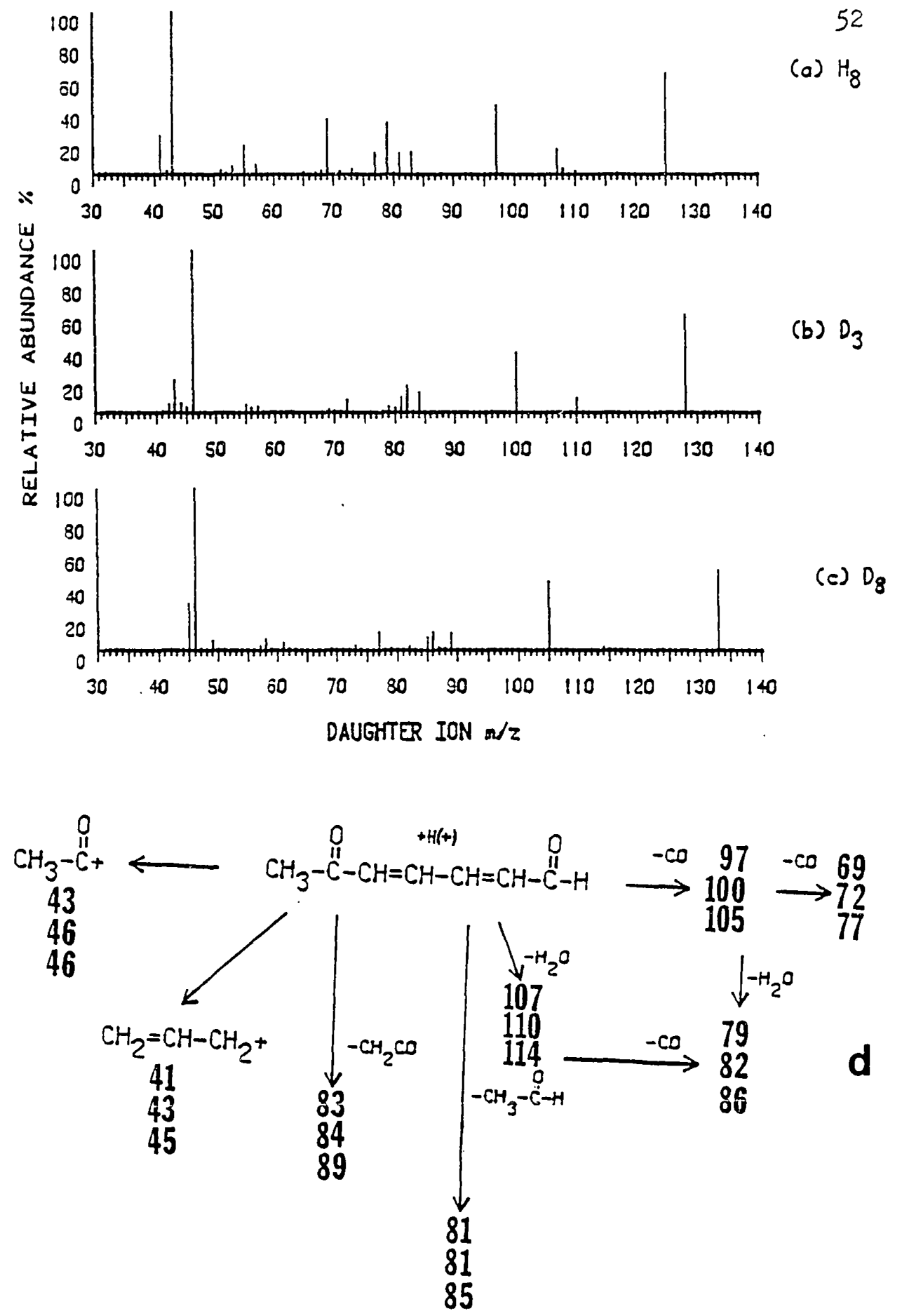

Figure 13. Daughter spectra for 6-oxo-2,4-heptadiene. 
$(49,50)$. From consideration of toluene's probable reaction mechanism (see dicussion Chapter VI), the only likely isomers for 6-oxo-2,4-heptadienal are the dialdehyde isaners. The dominance of the acetyl ion in the spectra suggests that the most prominant isomer is the methylketone as assigned. However, the ions at $\mathrm{m} / \mathrm{z}=69$ (HB), 72 (D3), 77 (D8) from successive loss of two $\infty$ would be the expected fragmentation of the dialdehyde isomers, as would be the ions at $\mathrm{N} / \mathrm{z}=41$ (H8), 43 (D3), 45 (D8); see Figure 13d. Therefore a small contribution from the dialdehyde isomers cannot be ruled out at this time. Authentic spectra of each of the isomers should be compared with the sample to determine the exact contributions. This would require synthesis of many of the compounds identified because they are not readily availible. The dialdehye 2-methyl-2,4-hexadienedial was tentatively identified by Hoshino et.al. (14) using $\mathrm{gc} / \mathrm{ms}$, but their spectrum is also consistent with the methylketone iscmer. They did not run an authenic sample for comparison.

st5-Diexo-2-hexenal. The spectral interpretation of 6-oxo-2,4-heptadienal and 4,5-dioxo-2-hexenal must be done together since the M+1 ion of both compounds in the L8 experiment have the same nominal mass $(m / z=133)$. Figure $14 \mathrm{a}$ and $14 \mathrm{~b}$ shows the spectra for 4,5-dioxo-2-hexenal in the $\mathrm{H} 8$ and the D3 toluene experiments respectively. Figure $14 \mathrm{c}$ presents the fragmentation pathways of this compound. The acetyl ion again dominates. Loss of $\infty$ is also large as would be expected from the $\alpha, \beta$-unsaturated aldehyde. Several methy1-positional isomers are also consistent 

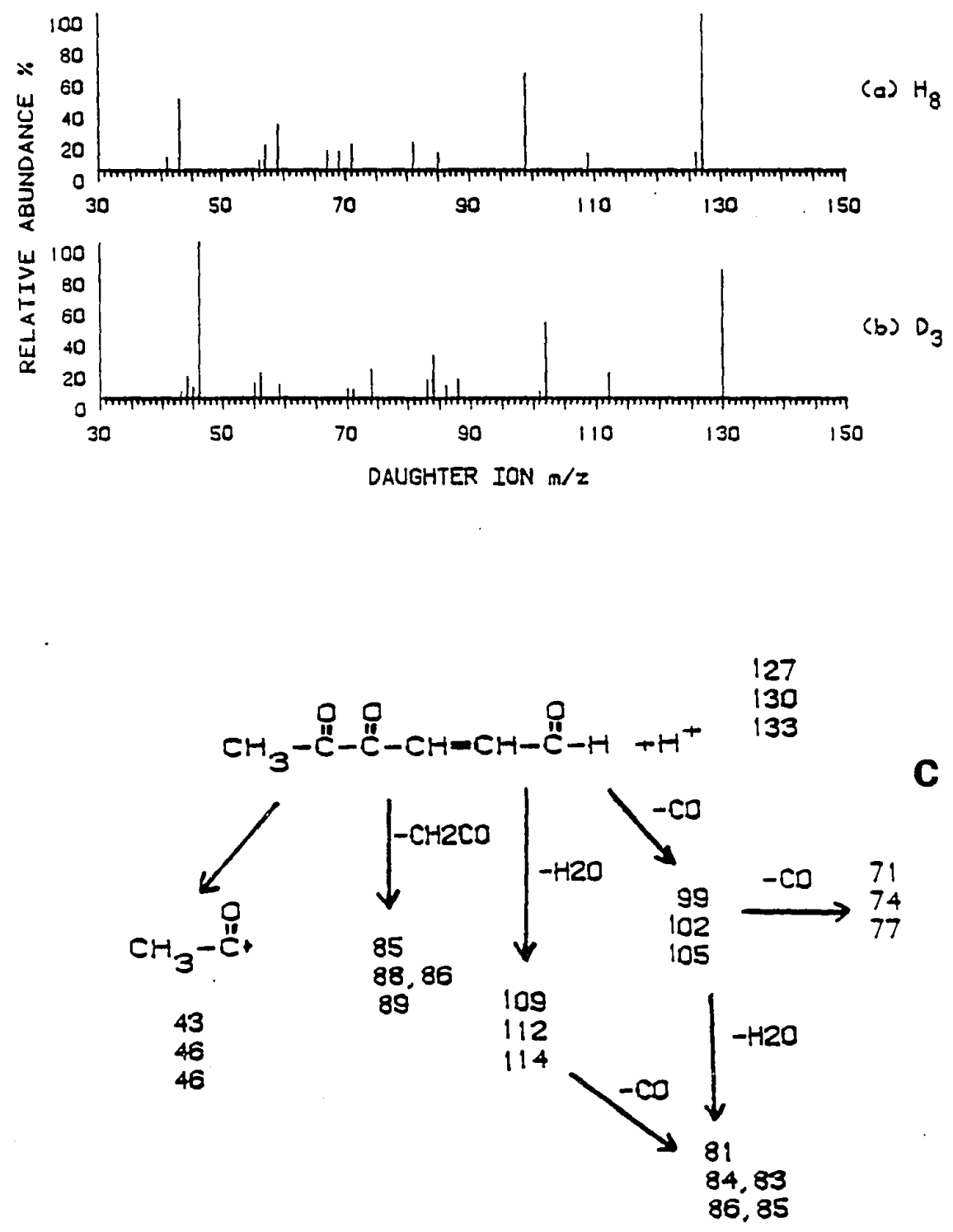

Figure 14. Daughter spectra for 4,5-dioxo-2-hexenal. 
with many of the fragment ions but the dominance of the acetyl ion suggests that the methylketone isomer is most abundant in the sample. The similar fragmentation of this compound to that of 6-oxo-2,4-heptadienal explains the coincidence of many of the peaks in the D8 spectra. Each compound is independently confirmed by the $\mathrm{H} 8$ and $\mathrm{D} 3$ spectra.

4-0xo-2-pentenal. Figure $15 a-c$ shows the spectra for the proposed product 4-oxo-2-pentenal in the three isotopic experiments. This compound has been included as an important intermediate in one of the proposed toluene photooxidation schemes (9), but has not been previously detected as a product. The corresponding product of p-xylene photooxidation (2,4-dioxo-3-hexene) has been detected by Tenax-adsorption and $\mathrm{gc} / \mathrm{ms}$ (21). The CID fragmentation shows loss of $\infty$, ketene, and acrolein (Figure 15d). The D8 parent ion of this compound occurs at the same nominal mass as the compound to be discussed next (see Table IV), resulting in additional peaks in the D8 spectrum. However, the $\mathrm{HB}$ and D3 experiments, in conjunction with the cross checking method mentioned above, provide considerable structural information.

5-0xo-1,3-hexadiene. Figure $16 a-b$ gives the daughter ion spectra of 5-oxo-1,3- hexadiene, a compound which has not previously been identified or hypothesized as a toluene oxidation product. Figure 16 gives the spectra of the (a) H8 and (b) D3 products. The D8 ion is at the same nominal mass (105) as the D8 product 4-oxo-2-pentenal discussed above (Figure 15c). The 

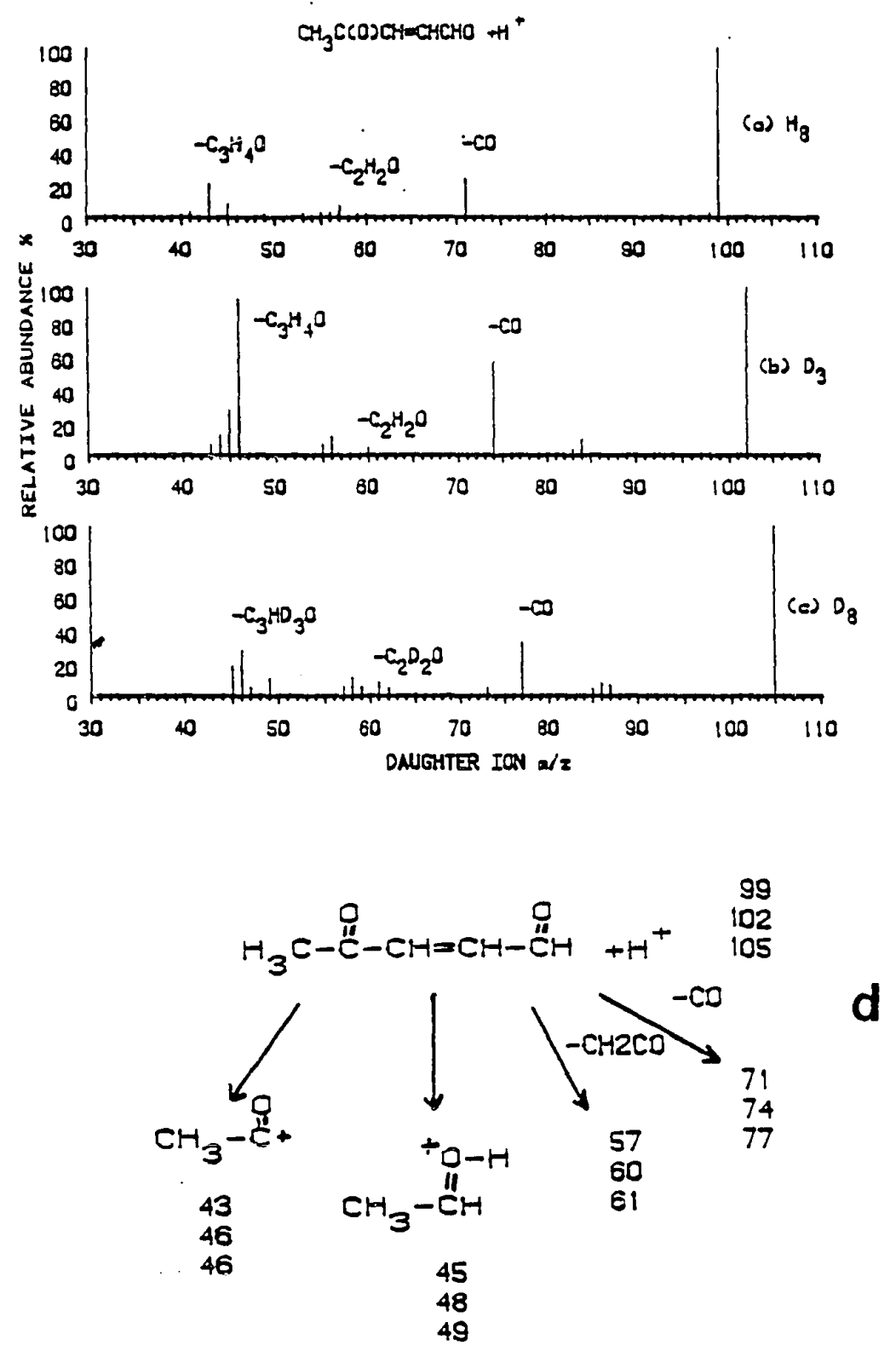

Figure 15. Daughter spectra for 4-oxo-2-pentenal. 

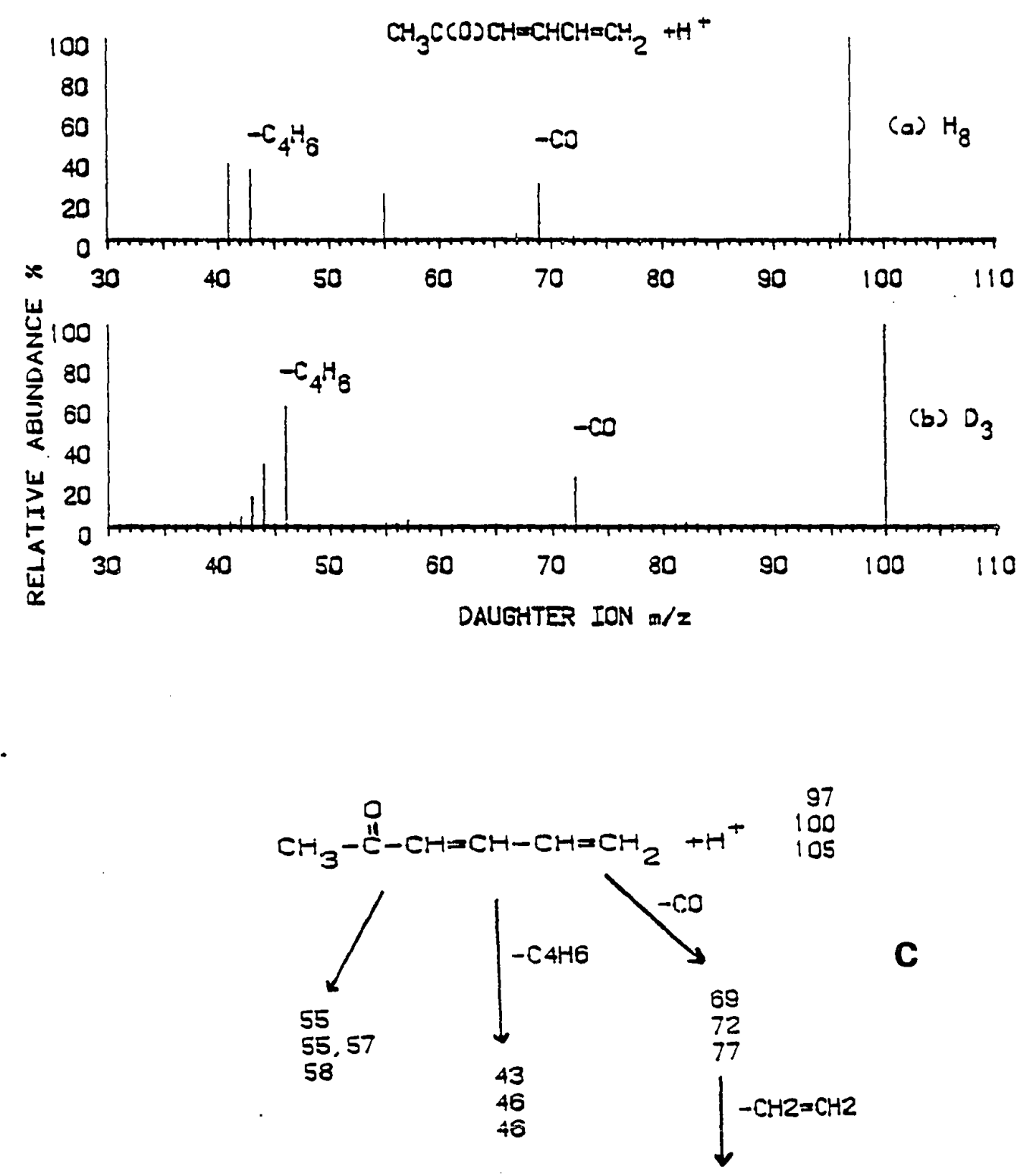

41

43,44

Figure 16. Daughter spectra for 5-oxo-1,3-hexadiene. 
daughter spectra show loss of ketene, butadiene, and $\infty$, followed by loss of ethene. The acetyl fragments indicate the presence of the methylketone isamer. Other peaks in the spectra are better explained by the presence of an aldehyde isomer with the methyl group on the 4 or 5 carbon. In addition to many of the fragments of the ketone isamer, this isamer is expected to account for other fragments in the D3 and D8 spectra by neutral loss of propene $(-42(H 8),-45(D 3),-47(D 8))$ to produce peaks at $m / z=55(H 8)$, 55 (D3), 58 (D8).

The compound 5-oxo-1,3-hexadiene is of special interest as a toluene reaction product since it contains a terminal methylene group which could only have formed by a hydrogen shift in the original atmospheric reaction. However, this compound, while not previously reported, can be rationalized as formed by photolytic loss of $\infty$ from $6-0 \times 0-2,4$-heptadienal $(m / z=125)$ which was also found and identified by its MS/MS spectra. These two compounds point out a potential difficulty with the CI procedure. In addition to its production in the original toluene reaction, 5-oxo-1,3-hexadiene could hav? possibly been produced in the ion source by loss of $\infty$ from the same parent, 6-oxo-2,1-beptadienal. However, the ranghter-ion spectrum of $\mathrm{m} / \mathrm{z}=125$ indicated that while loss of $\infty$ was an important collision-induced dissociation (CID) fragmentation process, there were other fragments which did not appear in the mass spectrum of the sample. Assuming that the CI and CID fragmentation processes are somewhat similar, it is concluded that 5-oxo-1,3-hexadiene is a product of toluene in the 
atmospheric reaction, and not simply an artifact of the CI process. This question could be answered definitively if the reference material were available. The mass spectrum of heptaldehyde did not show extensive $\infty$ loss to be $\propto c c u r i n g$ in the ion-source region.

Butenedial. Figure $17 a-c$ presents the CI/CID daughter spectra for the M+l ions with $\mathrm{m} / \mathrm{z}=85$ (H8), 85 (D3), and 89 (D8). The spectrum for the $\mathrm{m} / \mathrm{z}=85$ parent-ions is dominated by the solvent, dichloromethane. The large peaks at $\mathrm{m} / \mathrm{z}=49$ and 50 are due to loss of $\mathrm{HCl}$ and $\mathrm{Cl}$ respectively. Peaks at $\mathrm{m} / \mathrm{z}=57$ and 43 however cannot be from the solvent. Figure 17d describes the fragmentation process for butenedial. Loss of $\infty$ and ketene are the only major pathways. These are more clearly shown in the D8 experiment where there is no large solvent interference.

Hydroxybutenedial. Figure $18 \mathrm{a}-\mathrm{C}$ presents the CI/CID daughter spectra for the compound identified as hydroxybutenedial. The $\mathrm{M}+1$ ions are at $\mathrm{m} / \mathrm{z}=101$ (H8), 101 (D3), and 104 (D8). The fragmentation pathways are summarized in Figure 18d. For this compound water elimination is the major fragmentation pathway as would be expected (48). The loss of $\mathrm{H} 20$ is possible even in the D8 experiment if the hydroxy group originated from hydroxyl radical (see discussion below). The acid isomer of hydroxybutenedial is not present since acids give large peaks due to loss of 44 mass units ( $\mathrm{CO} 2)$ and these peaks are absent from the spectra.

3-Hydroxy-4-oxo-2-pentenal. The CI/CID daughter spectra for the compound identified as 3-hydroxy-4-oxo-2-pentenal are shown in 

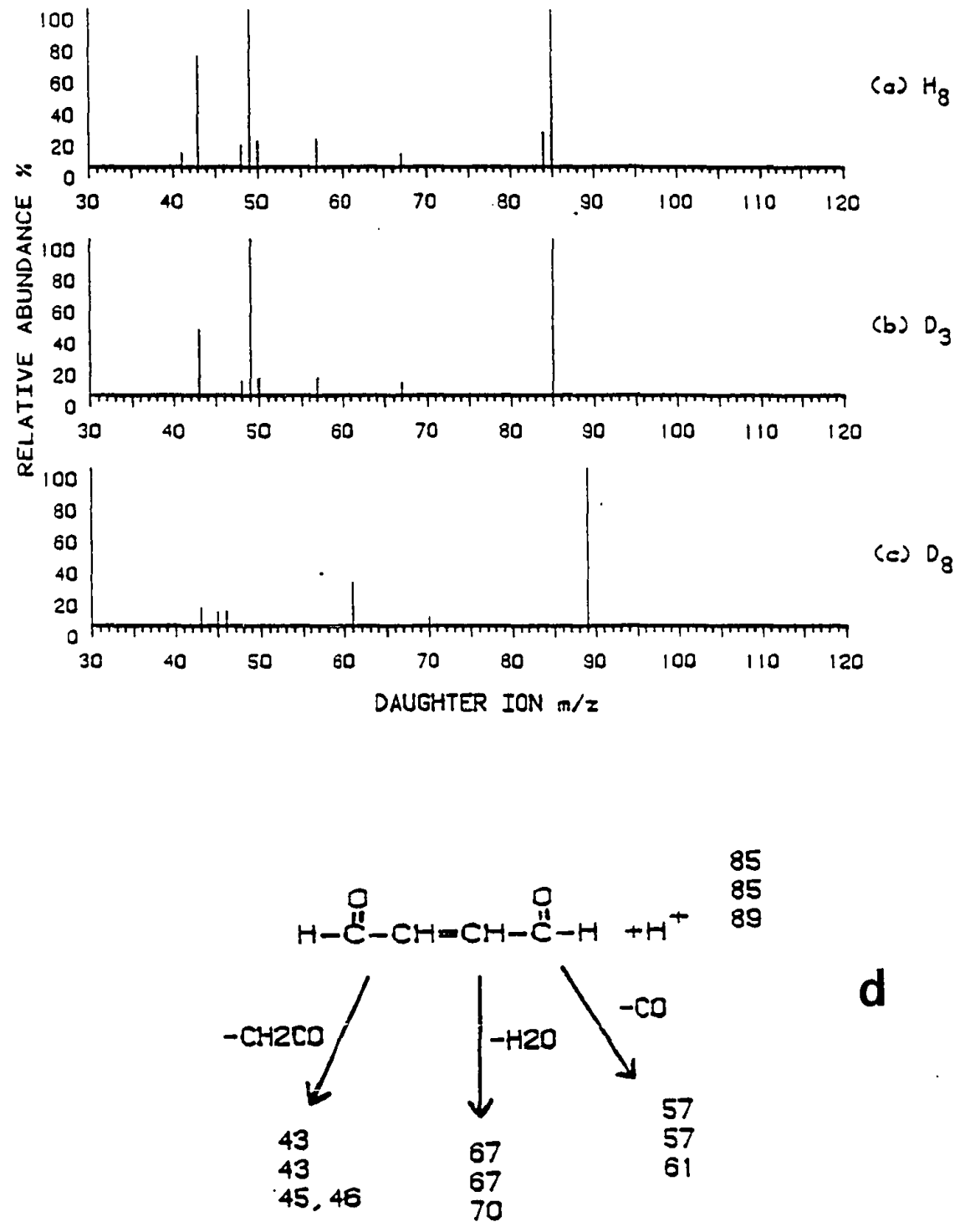

Figure 17. Daughter spectra for butenedial. 

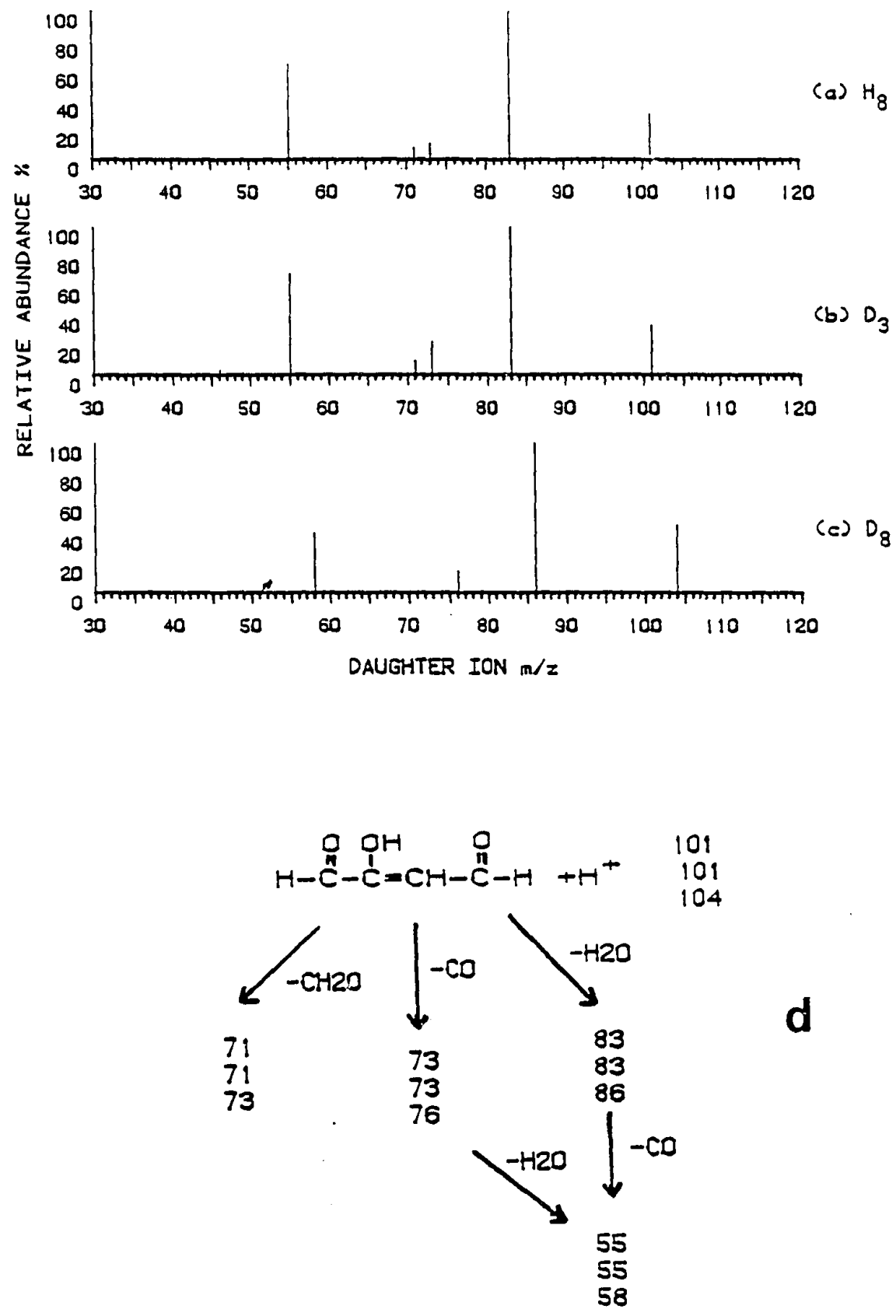

d

Figure 18. Daughter spectra for hydroxybutenedial. 
Figure $19 a-c$. The $M+1$ ions are at $m / z=115$ (H8), 118 (D3), and 120 (D8). Figure 19d outlines the fragmentation pathways consistent with these spectra. The base peak in each spectrum results from the loss of water. The large acetyl ion peak again suggests that the methylketone isomer is the predominate one in the sample. The position of the hydroxyl group is more ambiguous, with the 2-hydroxy isomer being as likely. The acid isomer, however, is not present since there is no $\infty_{2}$ loss as would be expected from an acid.

4-Hydroxy-5-oxo-1,3-hexadiene. The nominal mass of 4-hydroxy-5-oxo-1,3-hexadiene in the D8 experiment is the same as the previous compound. Figure $20 \mathrm{a}-\mathrm{b}$ gives the CI/CID daughter spectra for the $M+1$ ions with $\mathrm{m} / \mathrm{z}=113$ (H8), and 116 (D3). The D8 spectrum clearly resembles that of the previous compound. The $\mathrm{H8}$ and D3 spectra support the identification of the present compound as shown in Figure 20c. The acetyl ion's presence suggests that the methyl ketone isomer is present. Other methyl and hydroxy positional isomers are consistent with the fragmentation pathways. Since the large peak due to $\infty$ loss is more consistent with these isomers, one or more of the aldehyde isomers is likely to be present.

Direct Air Analysis vs. Extraction

Several experiments were performed to insure that the extracted products were characteristic of the gas phase chemistry taking place, not simply of the methods employed. 

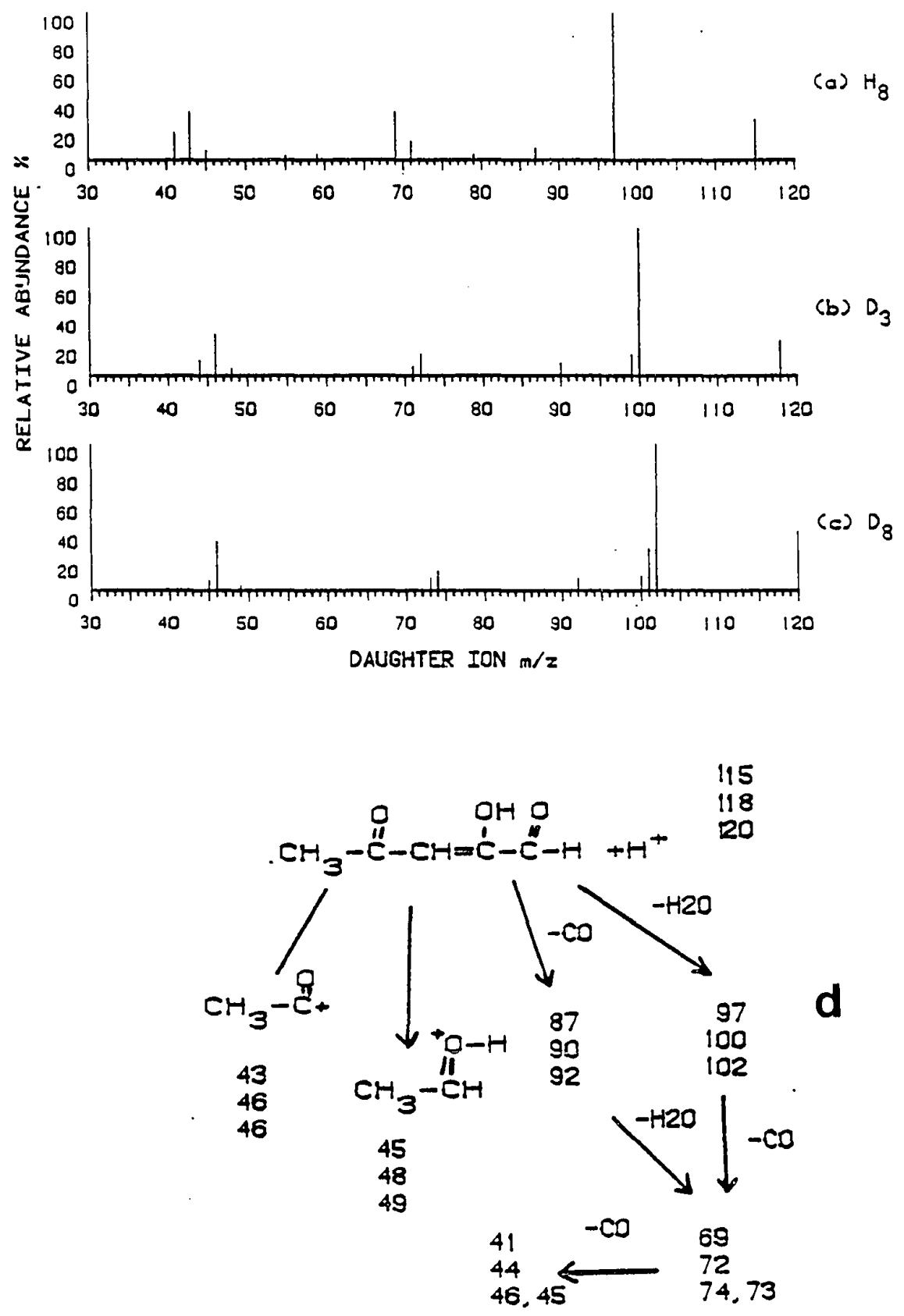

Figure 19. Daughter spectra for hydroxy-4-0xo-2-pentenal. 

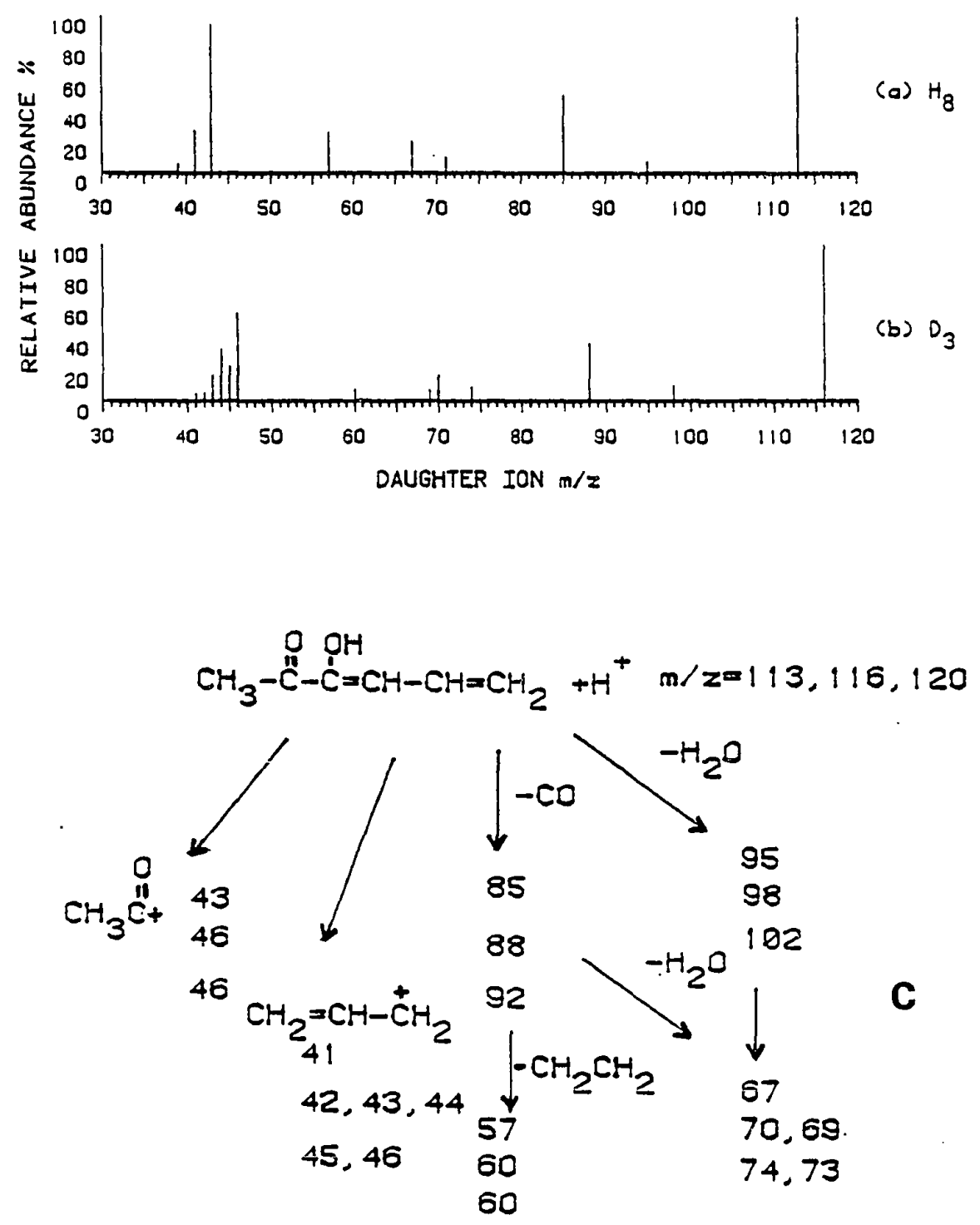

Figure 20. Daughter spectra for hydroxy-5-oxo-1,3-hexadiene. 
Nitric acid is an oxidation product of the nitrogen oxides present in the reaction vessel, nitration of aromatic reaction products occurs to a limited extent in heterogeneous reactions on the walls or during solvent extraction and concentration procedures. In addressing this problem, dark reactions were run with toluene, phenol, m-cresol, and m-nitrotoluene (1-10 ppmV) at 508 relative humidity. Nitration was found to be significant only for phenol and cresol whose substituents activate the aromatic ring to nitration. For these compounds less than one percent of the corresponding nitro-compounds were formed. Nitrotoluenes are well known as bona-fide gas-phase oxidation products of toluene (9-11). Nitrotoluenes were not formed in the dark reactions of nitric acid and toluene. As expected, ring fragmentation products were not produced by nitration reactions under the conditions used. Samples stored in sealed vials at $-10^{\circ} \mathrm{C}$ have renained stable in composition for as long as one year, indicating no significant degradation of products after work-up.

A potentially greater problem is associated with carrying out the reaction in a small vessel, in which there could be significant contribution of wall reactions to the desized gas-phase process. Comparison of product data for carbon monozide from the chamber used in the present study with data from three other "smog chambers", ranging in size from the 22 liter flasks to the roomrsized Teflon-wall outdoor chamber at the University of North Carolina (see dicussion Chapter II). Carbon monoxide is formed directly from toluene, as well as from intermediate toluene 
products. There is guite good agreement of the $\infty$ data from four different chambers. Thus we believe that the walls are not causing any major distortion of the chemical nature of the products formed, but serve chiefly as a precipitation site for these products.

Further confimation of the validity of the extraction procedure for obtaining unmodified products was produced by atmospheric pressure chemical ionization (APCI) MS/MS analysis of the gas-phase reaction products performed by SCIEX. The sample for APCI analysis was prepared by irradiating the toluene/nitrogen oxides mixture in a 100-liter Teflon film bag. The inflated bag was shipped to SCIEX for analysis. Figure $2 \mathrm{la}$ and $2 \mathrm{lb}$ shows the daughter ion spectra of the $\mathrm{m} / \mathrm{z}=99$ and $\mathrm{m} / \mathrm{z}=97$ respectively. These samples were introduced into the SCIEX instrument from the gas-phase. Comparison of Figure 2la with Figure 17a, and Figure $21 b$ with Figure 16a, shows that the fragmentation patterns match very well, for both of these compounds. This confirms the products in the extraction sample are the same as those in the gas-pahse. It also suggests the potential of APCI MS/MS for direct analysis of gas-phase oxidation products, even those partially or largely adsorbed on the reaction vessel surfaces. In the SCIEX sample, when the gas-phase sample was depleted, the bag was reinflated with zero-air, equilibrated, and the analysis continued.

\section{CONCLUSTON}

This study demonstrates the efficacy of MS/MS for the 


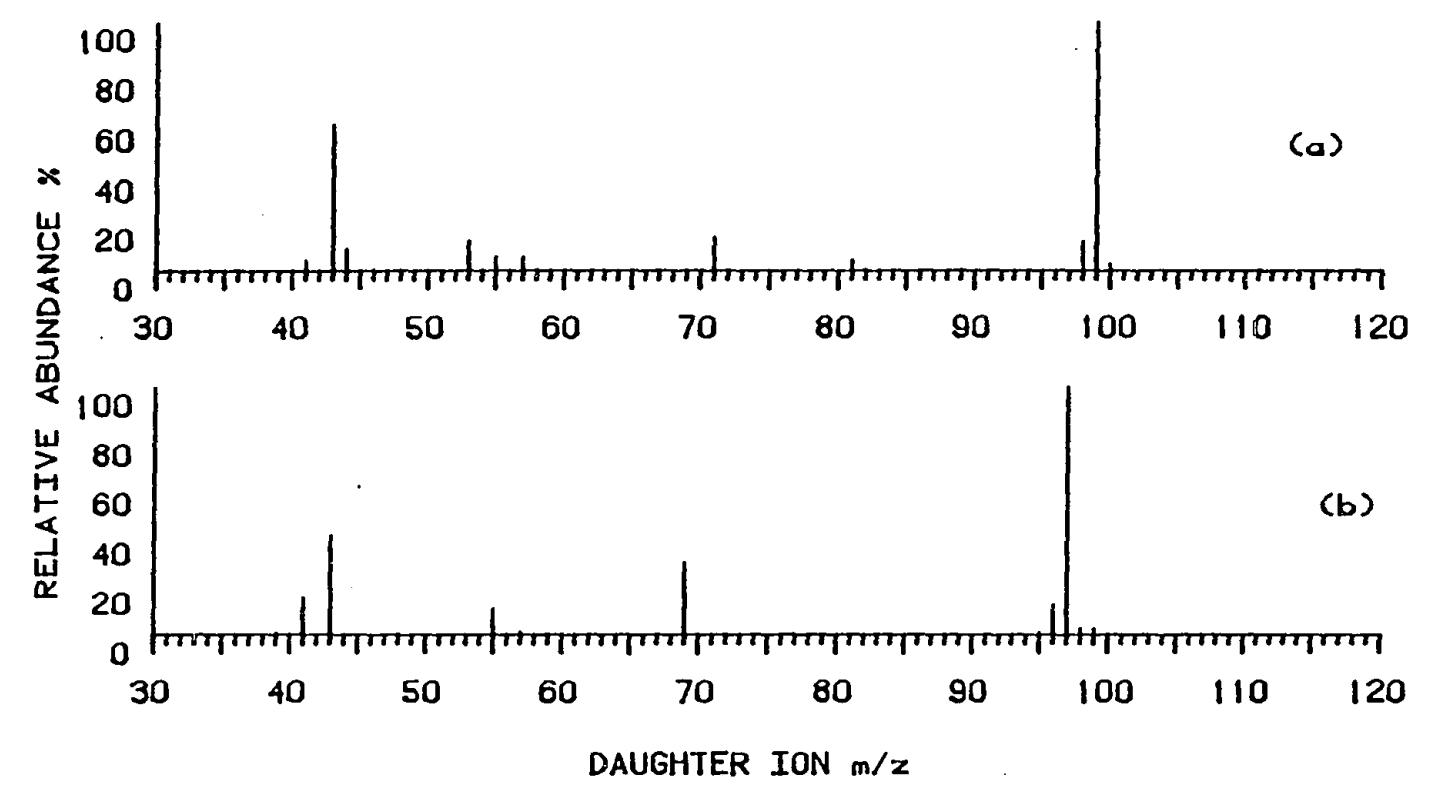

Figure 21. Alil/Daughter spectra for $\mathrm{m} / \mathrm{z}=99$ and $\mathrm{m} / \mathrm{z}=97$. 
separation and identification of the components of a mixture of low molecular yeight oxygenates. The survey methods (neutral loss and parent spectra) allow recognition of the members of a variety of different compound families. The MS/MS daughter ion analysis, especially when performed on products formed fram isotopically labeled parent molecules, allows structure determination. The structures in many cases, however, cannot be selected from several isomeric possibilities, especially since more than one isomer is probably produced as a reaction product. After initial assignments are made, specific experiments (e.g. selective ionization or derivatization) can aid in confimation of the structure, as could reference compounds. If the proposed compounds were available, reference spectra would allow quantification of the various isomers. This would require the fragmentation patterns of the various isomers to be significantly different. Alternatively, chromatography could be used to separate the isomers before mass spectral analysis. (This has been done with same success in experiments descirbed in Chapter IV.)

Isotopic substitution in the reactant molecule has clarified and simplified the product analysis in this study. This procedure should be generally advantageous in any type of reaction product study, including other degradation processes of envirormental conseguence, as well as metabolic processes.

The data required for this study were obtained in a short period, once the sampling and sample introduction procedures were developed. On the other hand, the data analysis itself was a time 
consuming procedure. Computer assisted procedures for analysis of MS/MS data, including searching a library of CID spectra, would be valuable. 
ANALYSIS BY GC, GS/MS, AND HPLC

The major purposes of the gas chromatography and liquid chromatography work were to: 1) confirm identifications made by the MS/MS analysis; 2) help quantitate the reaction product yields; 3) investigate reaction product yield sensitivity to reaction conditions, (to be discussed in Chapter V), and 4) determine whether this technique would be applicable.

\section{EXPERIMENTAL}

Gas chromatography was performed on a Hewlett Packard 5880A gas chromatograph equipped with a Hewlett Fackard crosslinked methyl silicone high performance capillary column. The column was 12 meters long. A flame ionization detector was used, with hydrogen gas provide both as the carrier flow and make-up gas. The chromatograph was temperature programmed from an initial value of $30^{\circ} \mathrm{C}$, with a 2 minute hold, to $140^{\circ} \mathrm{C}$, at $5.0^{\circ} \mathrm{C} /$ minute. Toluene reactions were run as described in Chapters II and III. Generally 
$I_{\mu l}$ of extract was injected with a injection port split ratio of 10:1, thus allowing $0.1 \mu l$ to be injected onto the column.

The GC/MS analysis was performed at the Oregon Gradute Center. A Finnigan 4000 gas chromatograph/mass spectrometer/data system was used. The column used was a 30 meter DB-5 fused silica capillary column obtained fram J W Scientific. The chromatograph was temperature programmed fram $10^{\circ} \mathrm{C}$ to $175 \mathrm{C}$ at $5^{\circ} \mathrm{C} /$ minute. The mass spectrometer was operated in electron impact ionization mode, with ionization energy at 70ev. Mary Stevens of the Oregon Graduate Center, operated the instrument.

The HPLC aralysis was performed on a Spectra Physics SP8700 solvent delivery system eqipped with a SP8440 varible wavelength detector, and a SP4100 computing integrator. A Beckman Ultrasphere ODS 5um $4.6 \mathrm{~mm} \times 250 \mathrm{~mm}$ column was used. Burdick and Jackson HPIC grade methanol and water were used for all analyses. Gradient elution from 1008 water to 25:75 water/methanol over 25 minutes, at $0.8 \mathrm{ml} / \mathrm{min}$. was used for the best separation.

\section{RESULIS AND DISCUSSION}

Capillary GC analissis.

Previous attempts have been made to analyze toluene's atmospheric reaction products by gas chromatography (9-19). These attempts were successful in detecting the major aromatic products, and the final products $\infty$ and $\mathrm{C2}$, (see discussion Chapters I and III). In the present work the wall extracted reaction products 
were analyzed by capillary gas chromatography. The advantage this study had over previous studies is that the extracted material from an entire reaction vessel could be concentrated, enabling the concentrations of the products to reach high enough values to be detected.

A typical resulting gas chromatogram is shown in Figure 22. Initial reaction conditions for the reaction were: 10ppm toluene, 10ppm No, 50o relative humidity, and blacklight irradiation. The reaction was stopped after 48 hours, corresponding to $65 \%$ of the toluene consumed. Peak identifications were made by retention times and mass spectrometry (to be described below). On casual inspection of Figure 22, it is apparent that capillary $\subseteq C$ can separate many of the components of the reaction mixture. This separation is much better than previous GC work on toluene's products, both for the gas phase (10) and the aerosol phase (12). For comparison, Figure 23 shows a gas phase injection of $500 \mu$ in which the products are trapped at the head of the column at liquid nitrogen temperature, and then allowed to elude, at the normal programed race. Only the well known gas phase products, benzaldehyde, cresols, and nitrotoluenes are seen. As noted in Chapter III, both products adsorbed onto the flask walls, and gas phase products are partitioned into the extraction solvent using the methods described in Chapther III. GC analyses were also performed on samples in which the gas phase was first purged from the flask by zero-air. Figure 24 shows an example of the resulting chromatogram. The known gas phase products are greatly reduced or 


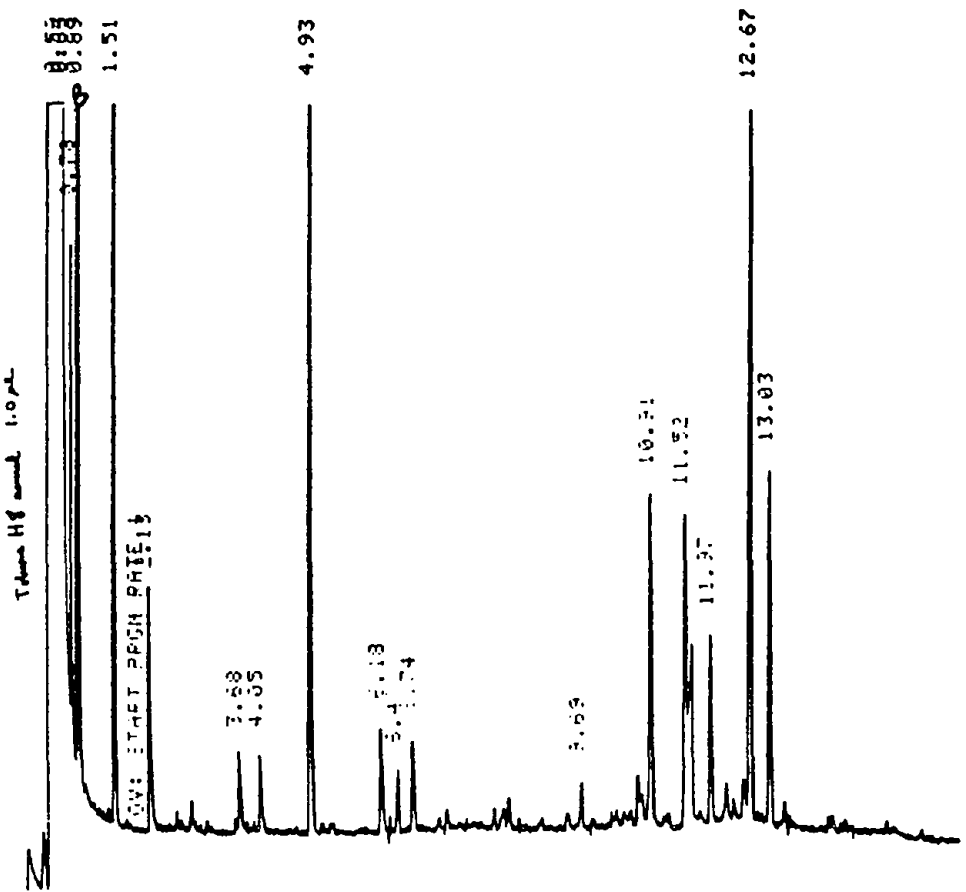

Figure 22. Typical capillary gas chromatogram of toluene's extracted products. 


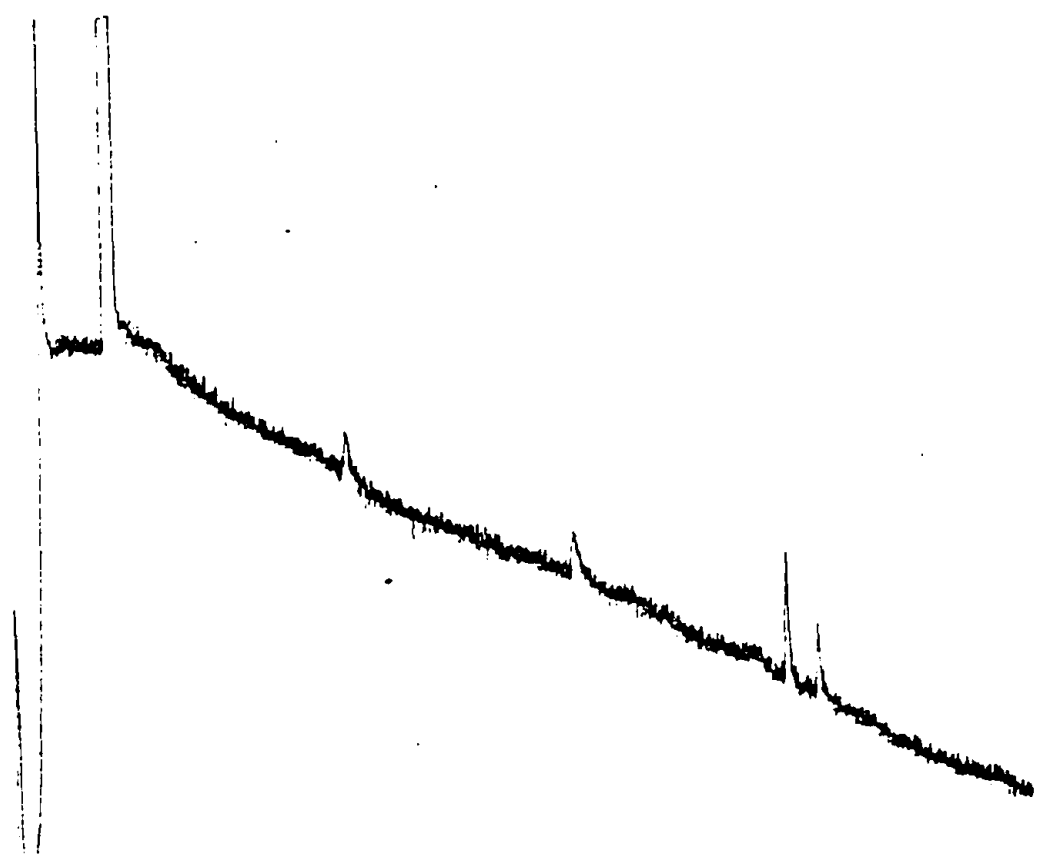

Figure 23. Vapillary gas chromatogram of gas-phase injection of toluene reaction mixture. 


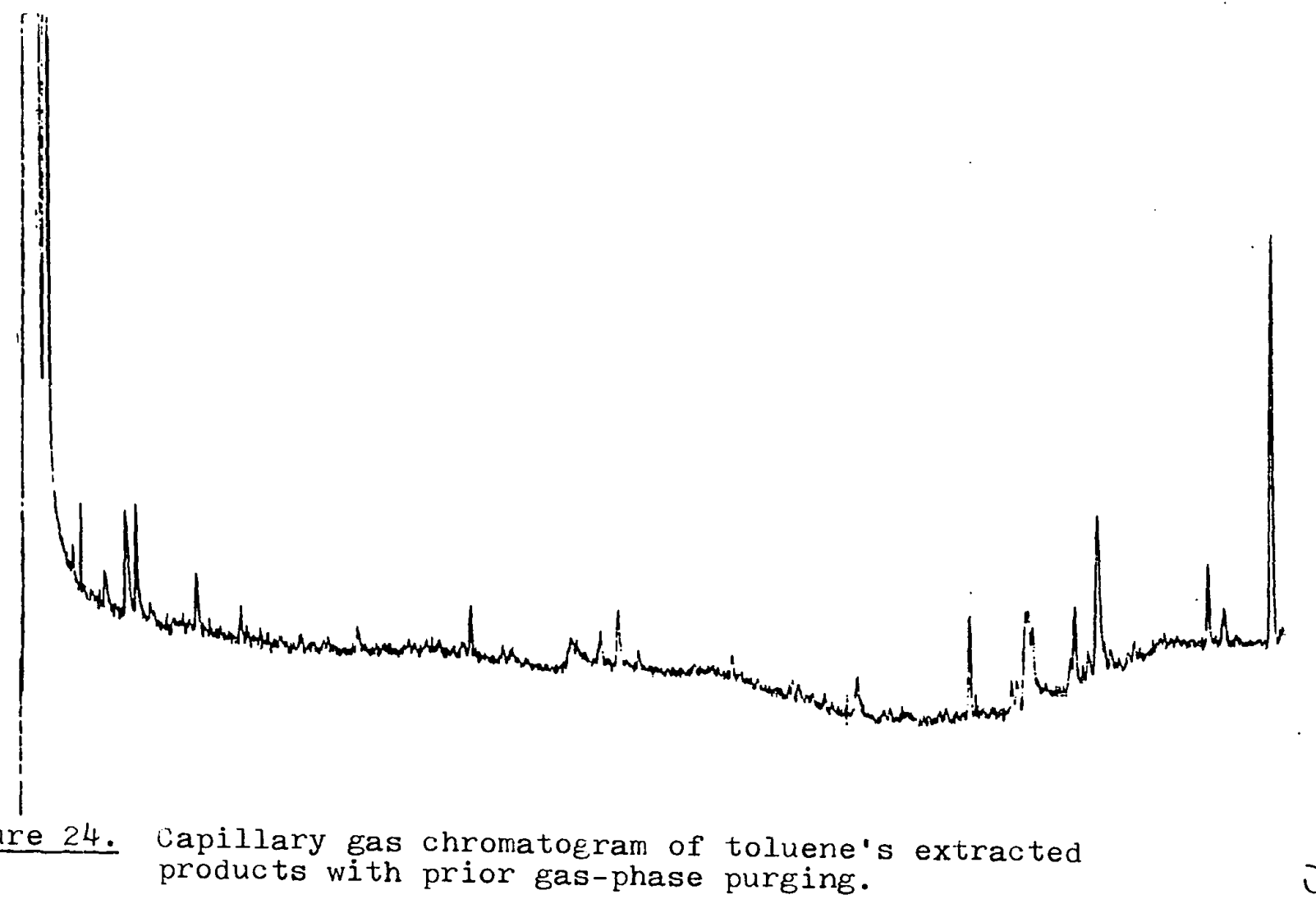


absent, while the assumed fragmentation products are only recuced slightly. It was possible with extensive flushing of the flask to completely eliminate all peaks from the resulting chromatogram. This indicates the products are in equilibrium to a significant extent with the gas phase even though adsorbed on the flask walls. The flasks were not purged under normal operation because product loss could decrease the chance of detection for same of the minor products.

GC runs were made in which a mixture of normal and deuterium labled toluene reaction products were used. This was done as a check that the same deuterium reaction products were produced. The resulting chromatograms are shown in Figure 25a, and 25b, for normal $\mathrm{H} 8$ toluene with D3 and D8 toluene respectively. The resolving power of the capillary column is great enough to partially resolve the deuterated compounds from their nondeuterated counterparts. This confirms that the same products are formed in all three toluene reactions. This analysis lends confidence to the cross-checking scheme assumed in the MS/MS work.

Standards were prepared and analyzed to determine retention times for the identification of the reaction products. The standards were also used to help quantify the product yields. Standards were prepared using the same solvent (dichloromethane), as was used for the extraction of the reaction products of toluene. Independent standards were run to determine retention times. Standards mixtures were used to determine response factors for several standards simultaneously. A typical standards 


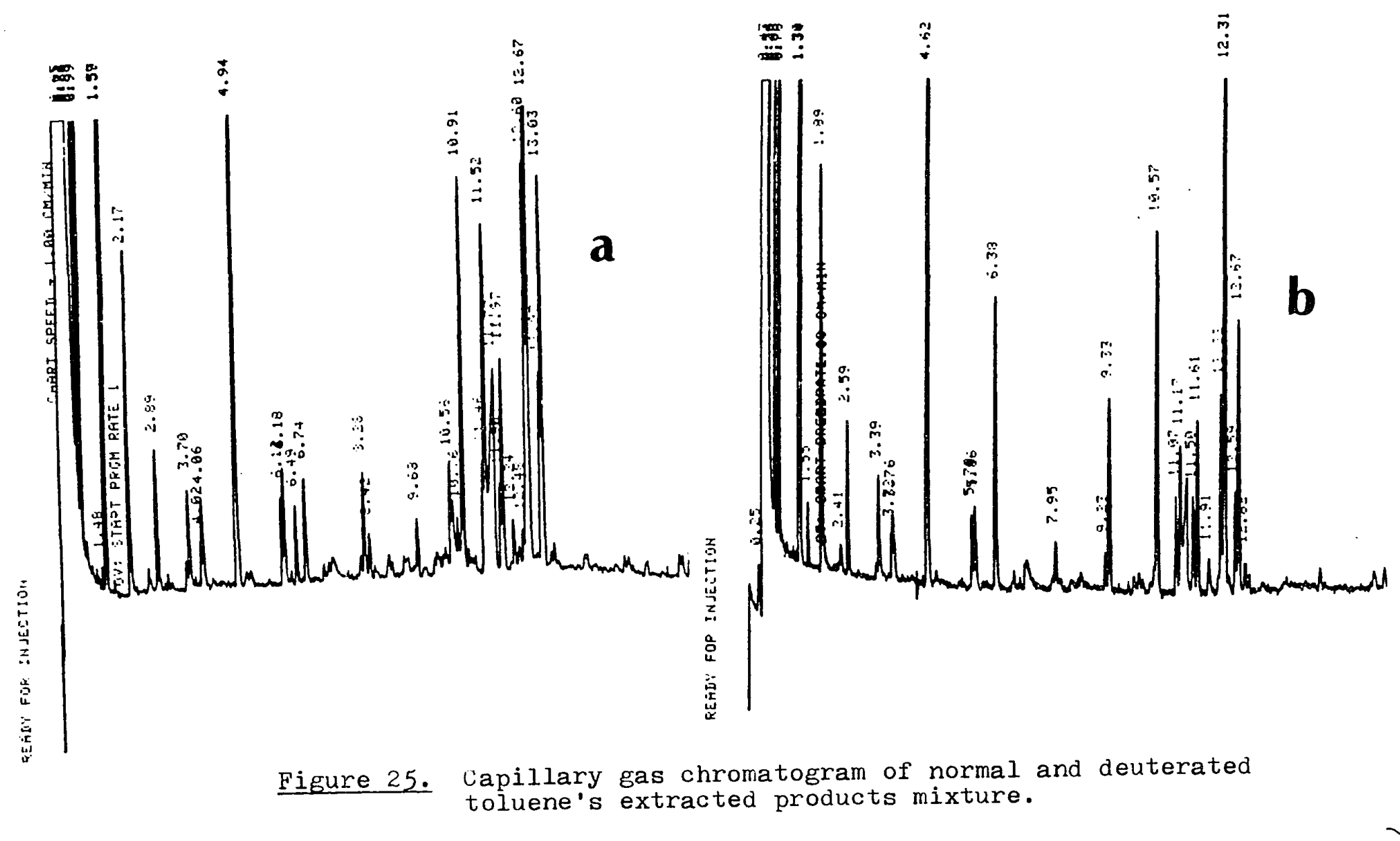


chromatograph is shown in Figure 26. Retention times and reponse factors are shown in Table V. Figure 27 shows the HP5880A output identifying many of the GC peaks from a toluene reaction extract. The numbers under "compound name" correspond to Table V.

\section{Gas Chromatography/Mass Spectrometry Analysis}

Two GC/MS analyses were conducted to confirm GC identifications and to attempt to identify the unknown peaks in the chromatogram. Library matching of spectra was expected to be useful only for the aromatic products, since prior investigation confirmed that many of the ring fragmentation products determined in the MS/MS analysis are not in the EPA/NIH library of spectra (5I).

The total ion chromatograph is shown in Figure 28. Notice the close resemblence to Figure 22. Total ion MS chromatograms often parallel the FID response, since they are actually similar processes. The two columns used are very similar, (both methyl coated fused silica). It is therefore possible to make same corresponding peak identifications based on the GC/MS analysis.

Table VI lists all compounds confirmed by GC/MS analysis. Included in Table VI are compounds such as chlorocyclohexane which derive from the solvent (52). All of the aromatic products found by the MS/MS analysis were confinmed by GC/MS. As mentioned above, many of the fragmentation products were not expected to be found through library matching. However, some of the fragmentation products could be confirmed through analyzing their EI spectra. 
178

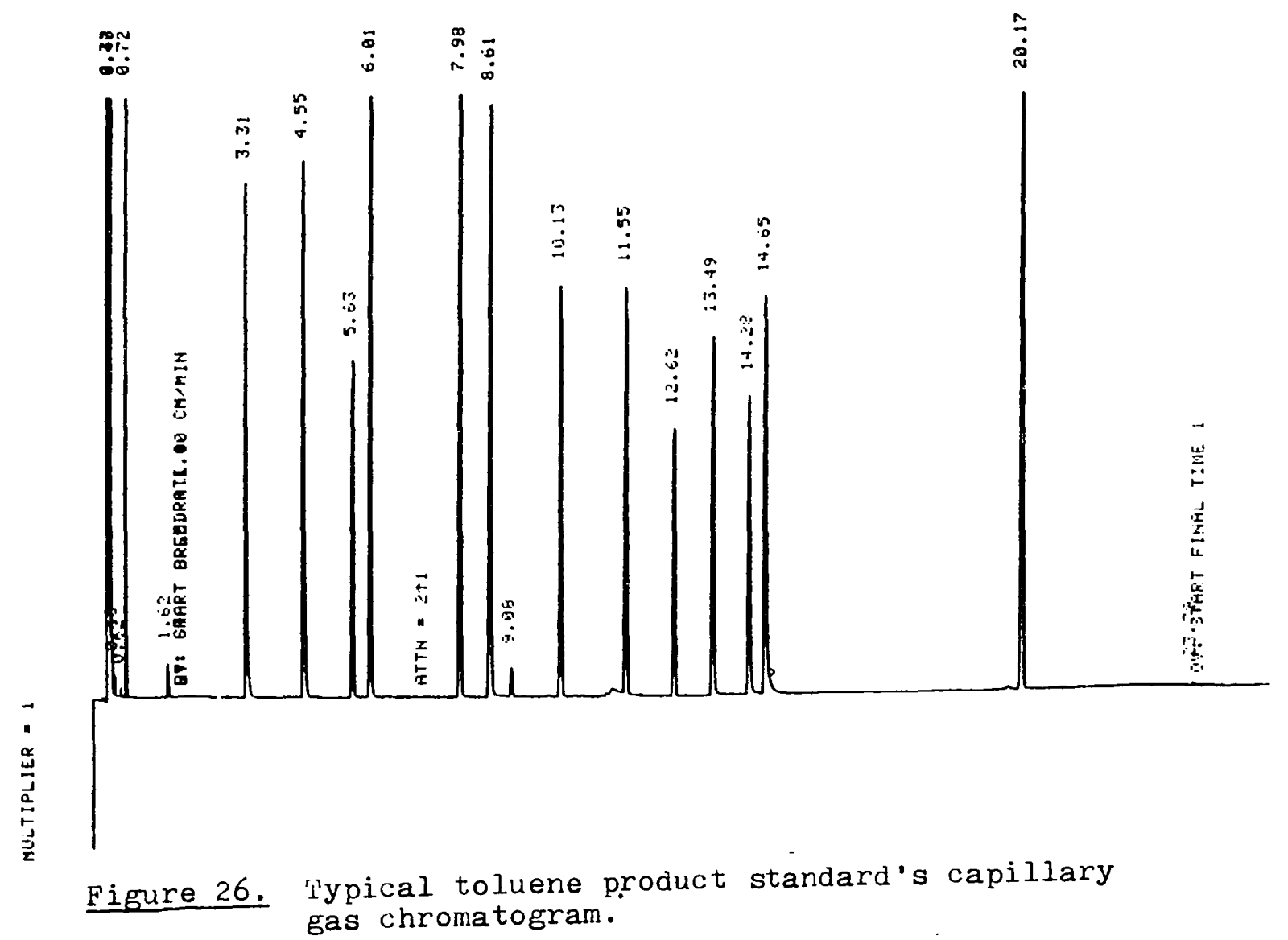


TABLE V

GC/FID RESPONSE FACIORS FOR AROMATIC PRODUCTS

Compound

1. Benzaldehyde

2. Phenol

3. Benzylalcohol

4. o-cresol

5. m-Cresol

6. p-Cresol

7. o-Nitrotoluene

8. m-Nitrotoluene

9. p-Nitrotoluene

10. 4-Hydroxy-3-nitrotoluene

11. o-Nitrobenzaldehyde

12. p-Nitrobenzaldehyde

13. m-Nitrobenzaldehyde

14. 2,6-Dihydroxytoluene

15. 3,4-Dinitrotoluene

16. 4-Hydroxy-2-nitrotoluene

17. 2-Hydroxy-4-nitrotoluene

18. 2-Hydroxy-

4,6-dinitrotoluene 21.14

19. 5-Hyarroxy-2-nitrotolune 21.50

20. Toluene

\begin{tabular}{cc} 
Betention Time \\
\hline (minutes) \\
\hline 4.43 \\
5.83 \\
6.78 \\
7.89 \\
8.52 \\
8.61 \\
9.98 \\
10.95 \\
11.60 \\
12.46 \\
13.34 \\
14.12 \\
14.49 \\
20.01 \\
20.34 \\
20.38 \\
uene \\
21.13 \\
\\
\\
uene 21.14 \\
21.50 \\
1.21
\end{tabular}

\begin{tabular}{l} 
Response Factor \\
\hline (ng/pa min.) \\
0.17 \\
0.035 \\
0.19 \\
0.11 \\
0.08 \\
0.08 \\
0.18 \\
0.20 \\
0.24 \\
0.34 \\
0.37 \\
0.51 \\
0.54 \\
N.D. \\
N.D. \\
0.35 \\
N.D. \\
N.D. \\
0.39 \\
O.20
\end{tabular}

(N.D. not determined) 


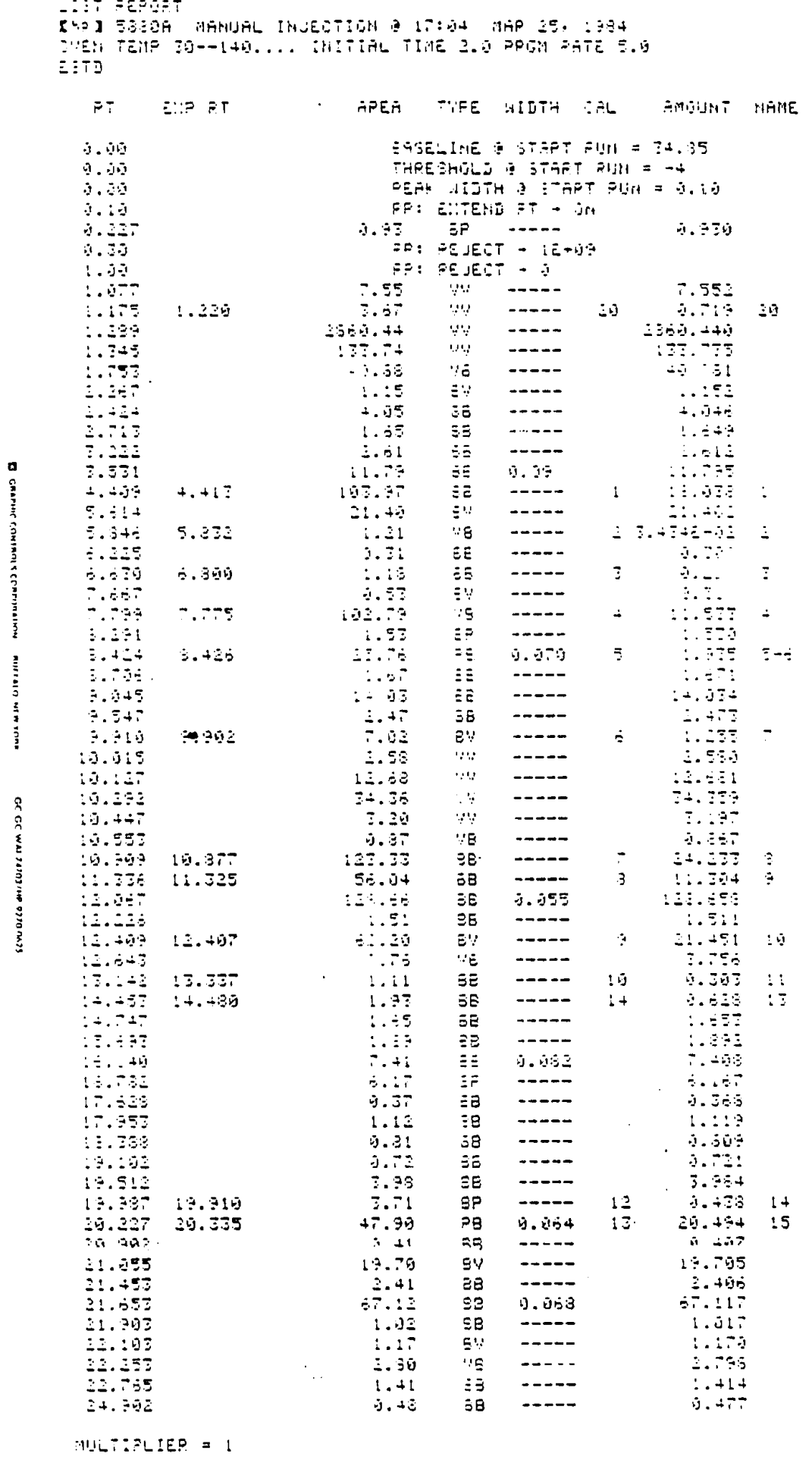

Figure. 27. Example of data output from HP5880A showing aromatic products identified in the mixture. 


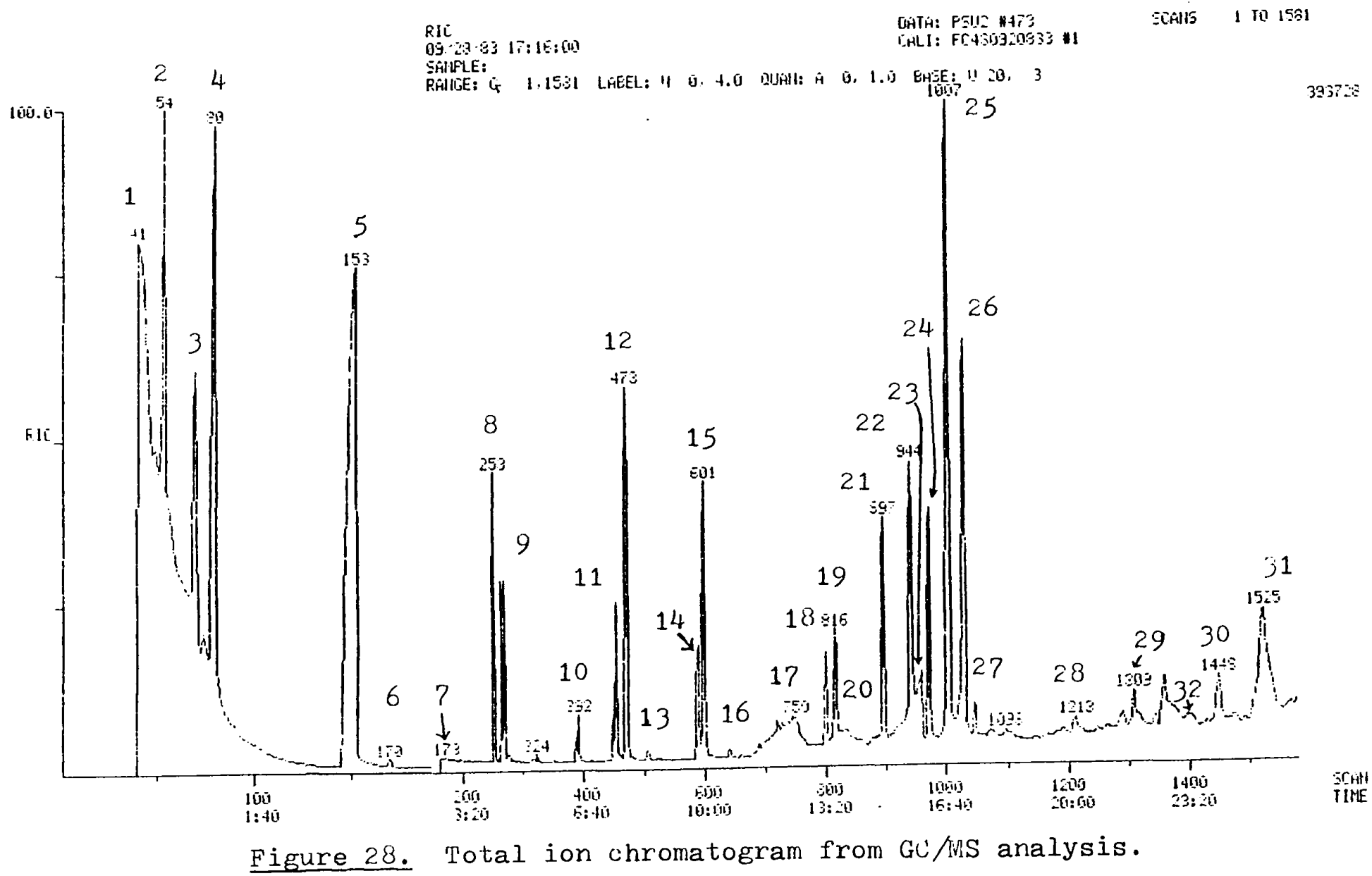


TABLE VI

PRODUCTS DETERMINED BY GC/MS

PEAK\# NAME

1 Dichloromethane

2 Trichloromethane

3 Cyclohexane

4 Cyclohexene

5 Toluene

6 3-Methyl-2,4-pentadienal

7 2-Methyl-butendial

8 4-Oxo-2-pentenal

9 2,5-Furandione

10 2,5-Cyclohexadiene-1,4-dione

11 Hydroxymethylbutendial

12 Benzaldehyde

13 4,5-Dioxo-2-hexenal

14 6-Oxo-2,4-heptadienal

15 Chlorocyclohexanol

16 2-Hydroxybenzaldehyde

17 Nitrobenzene

18 Hydroxy-4-oxo-2-pentenal

19 p-Nitrophenol

20 Hydroxy-4-oxo-2-pentenal

21 Benzalnitrate

22 m-Nitotoluene

23 Benzoic acid

24 p-Nitrotoluene

25 Nitrocresol

26 Nitrocresol

27 Nitrocresol

28 Nitrobenzaldehyde

29 Hydroxy-nitrobenzaldehyde

30 Dinitrophenol

31 Nitrophenol

32 Nitrocresol
COMMENTS

solvent

from solvent

from solvent

from solvent

reactant

confirms MS/MS

confins MS/MS

confirms MS/MS

confins MS/MS

confirms MS/MS, GC

confirms MS/MS

confirms MS/MS

from solvent

confinms MS/MS

confins MS/MS

confirms MS/MS

confins MS/MS

confins MS/MS, GC

confirms MS/MS, GC

confirms MS/MS

confirms MS/MS, GC confirms MS/MS, GC confiums MS/MS

confims MS/MS, GC

confirms MS/MS, GC

confirms MS/MS

confirms MS/MS, GC 
The closest match made from the library was often useful even though not correct. Individual cases are now described.

Peak \#6. Figure 29 shows the EI spectra of peak \#6, and the best library match of 2-vinyl crotonaldehyde. The peak, however, is more likely 3-vinyl crotonaldehyde, (which is 3-methyl-2,4-pentadienal) and the isomer of 5-oxo-1,3-hexadiene identified by MS/MS. As stated in Chapter III the methyl positional isomers were suggested by the CID spectra. The EI spectra of 2-vinyl crotonaldehyde and 3-vinyl crotonaldehyde should be very similar.

Peak \#I and \#8. The spectra of peaks \#7 and \#8 are shown in Figures $30 \mathrm{a}$ and $30 \mathrm{~b}$ respectively. They are identified as 2-methyl-2-butendial and 4-oxo-2-pentenal. There was no good library match found for these compounds. The molecular weights and fragmentation patterns are consistant with the identifications proposed. These compounds were identified in the MS/MS study as well. They are the two possible methyl-positional isomers described in Chapter III. The difference in the relative intensities of the -15 mass units peak and the -29 mass units peak allow distinguishing which chromatographic peak is which (48). Loss of the methyl radical is expected to be much greater for the 4-oxo-2-pentenal since it leaves a stable carbonyl cation, whereas loss of the methyl group from 2-methyl-2-butendial leaves a vinylic cation. The MS/MS CID spectra suggested 4-oxo-2-pentenal was the major isomer. This is in agreement with the relative intensities of the two chromatographic peaks. 

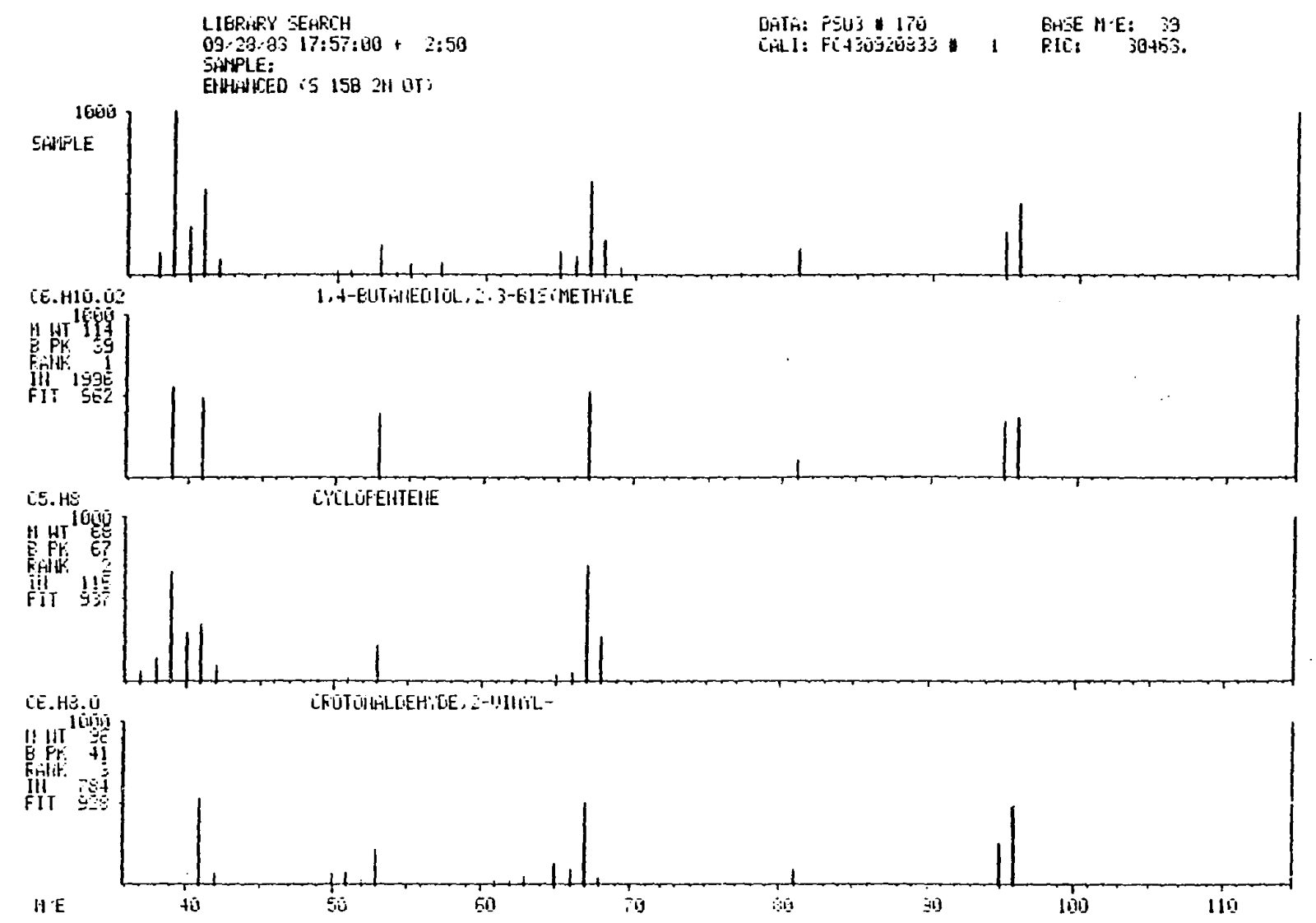

Figure 29. Sample and library spectra for GC/MS peak \#6. 

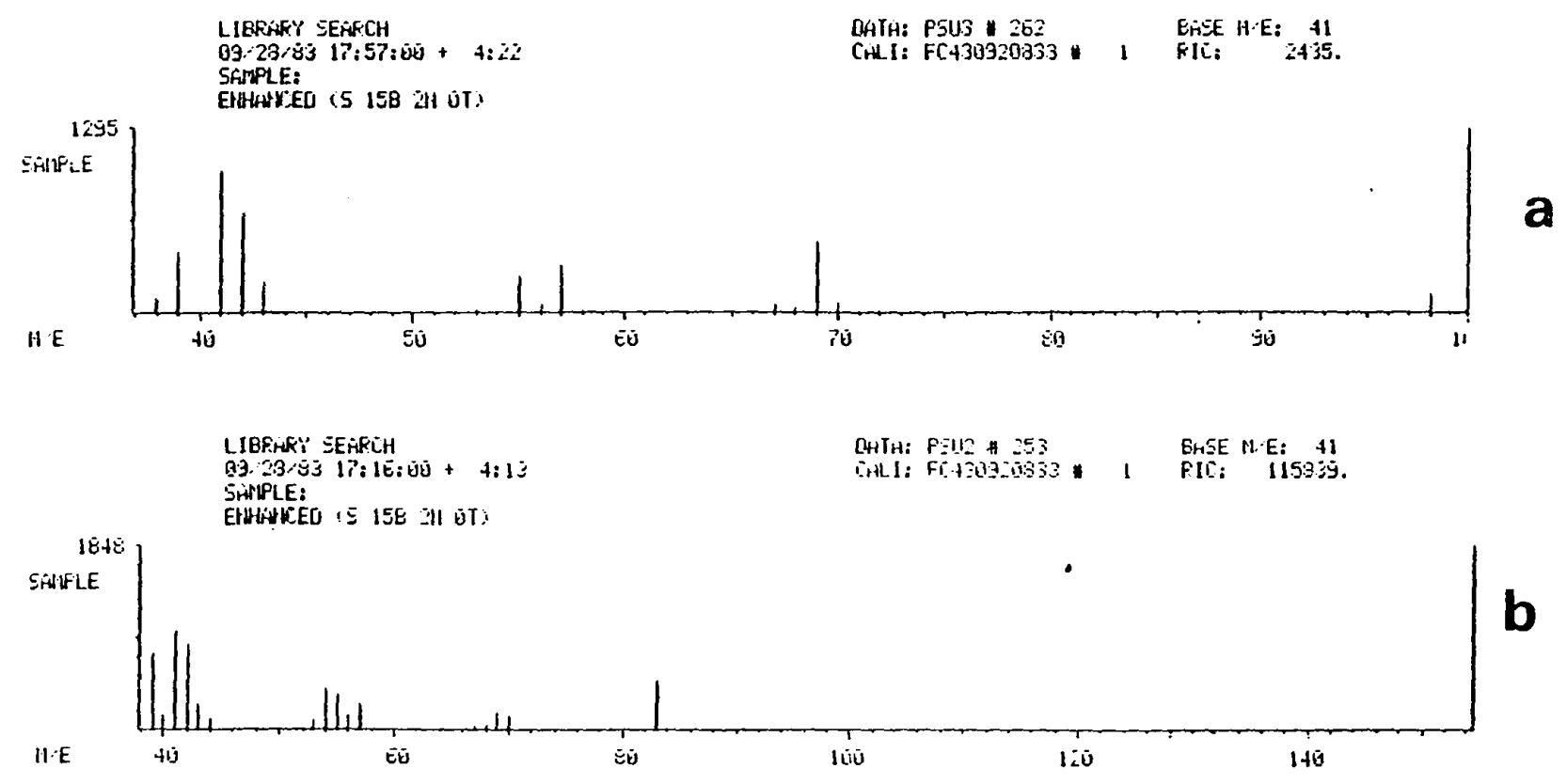

Figure 30. Sample and library spectra for GC $/ \mathbb{N}_{1}$ a) \#7; b) \#8. 
Peaks \#9 and \#10. The EI spectrum of peaks \#9 and \#10 matches very well with the library spectra of 2,5- furandione, and 2,5-cyclohexadiene-1,4-dione, respcetively. These are shown in Figures 31 and 32. These compounds are not confinmed by MS/MS analysis. They are conceivable but improbable toluene reaction products. More analyses would need to be done in order to over come the negative evidence in the MS/MS studies.

Peaks \#11, \#18, and \#20. Figure 33a and 33b, show the EI mass spectra for peak \#18 and peak \#20 respectively. There were no library matches for these compounds, but the spectra are consistant with the two different hydroxy-4-oxo-pentenal isomers. Figure 33c shows the EI mass spectrum for peak \#Il. Again there was no library match for this compound. The spectra are consistent with 2-methyl-4-oxo-butenoic acid. All three compounds are isomers of the MS/MS identified product hydroxy-4-oxo-pentenal. The three isomers can be distinguished fram one another on the basis of the intensities of different peaks in the spectra. 2-Hydroxy-4-oxo-pentenal would be expected to show the largest $-\mathrm{OH}$ and $-\mathrm{CH} 3$ peaks since both leave a stable cation. This compound should also have a large $\mathrm{m} / \mathrm{z}=43$ peaks from the acetyl ion. The acid isomer is the only compound which should show a-coll peak at $\mathrm{m} / \mathrm{z}=68$.

Peak \#13. Figure 34 shows the weak spectrum for peak \#13. There doesn't appear to be an intact molecular ion (M+), since all high $\mathrm{m} / \mathrm{z}$ peaks are odd. The large $\mathrm{m} / \mathrm{z}=43$ peak and $\mathrm{m} / \mathrm{z}=97$ peak suggest the compound could be the MS/MS identified compound 


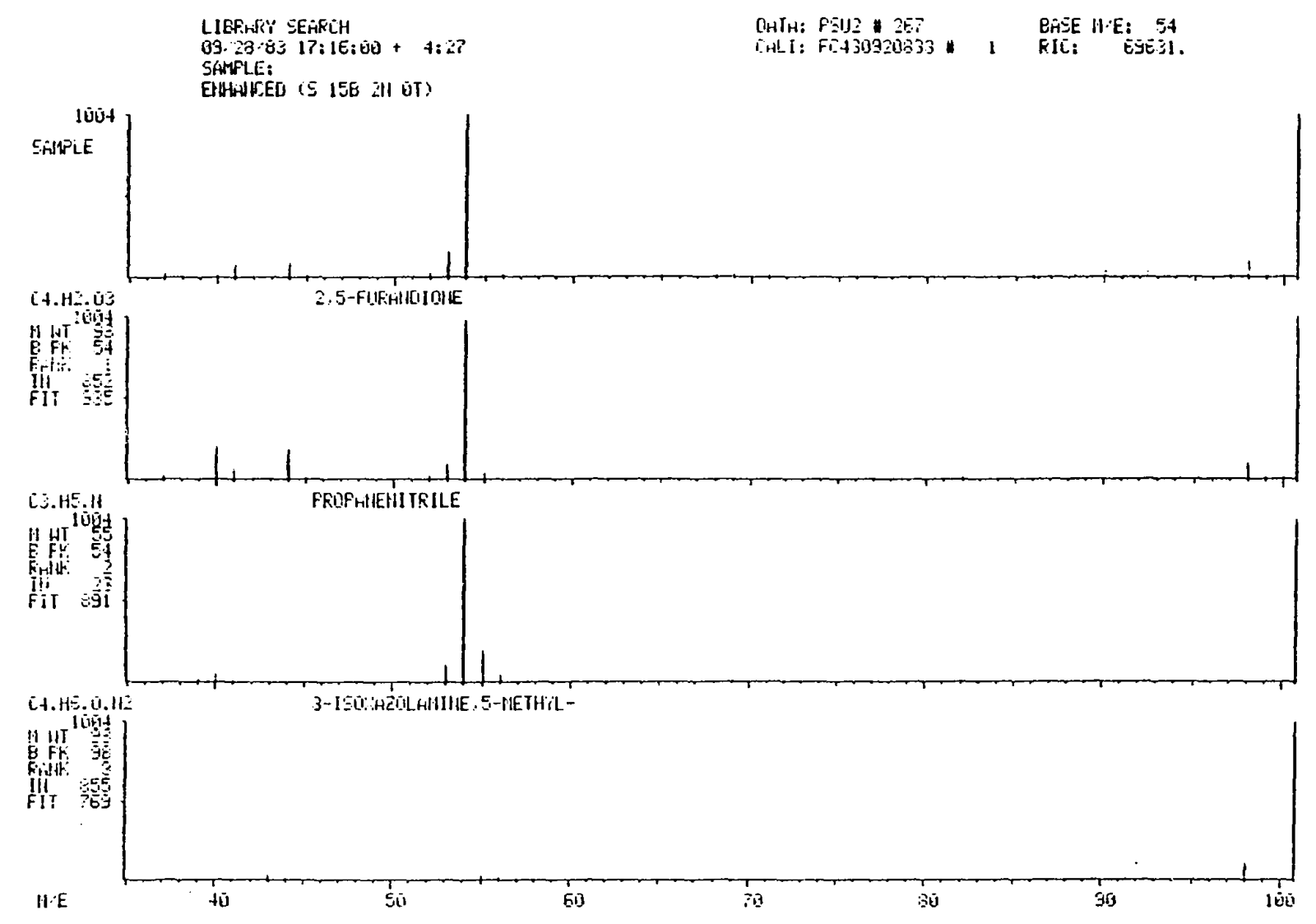

Figure 31. Sample and library spectra for Gu/NS peak \#9. 


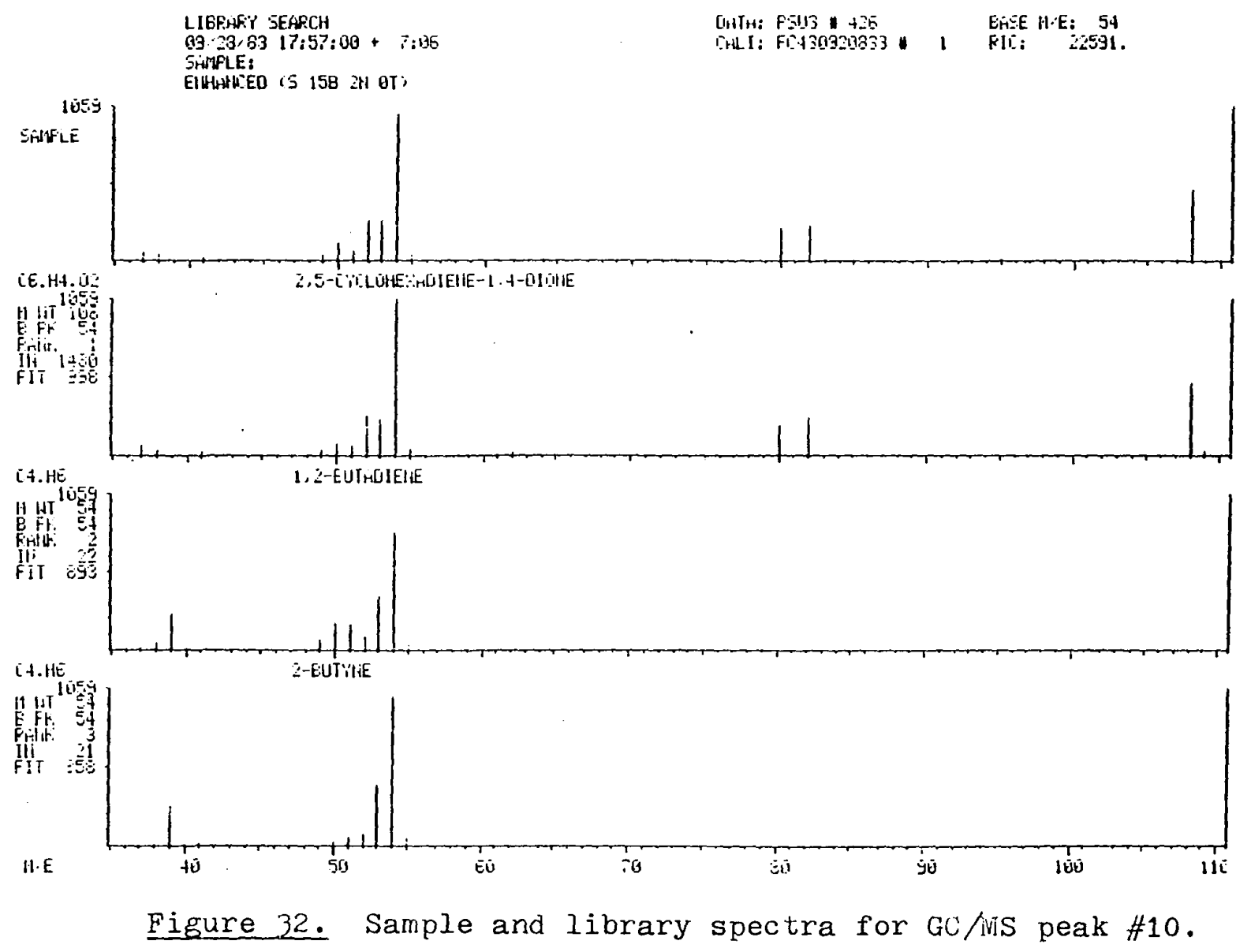



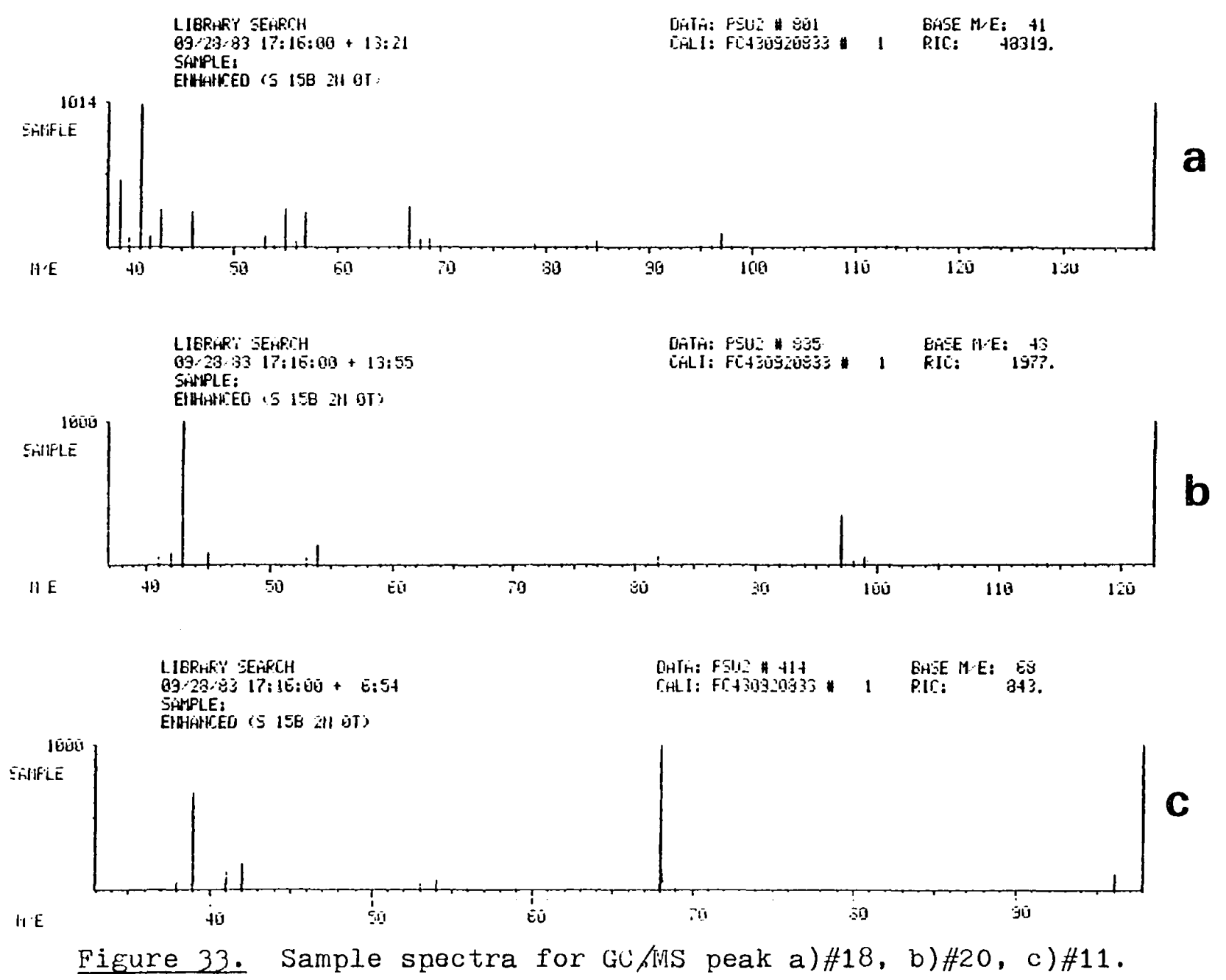


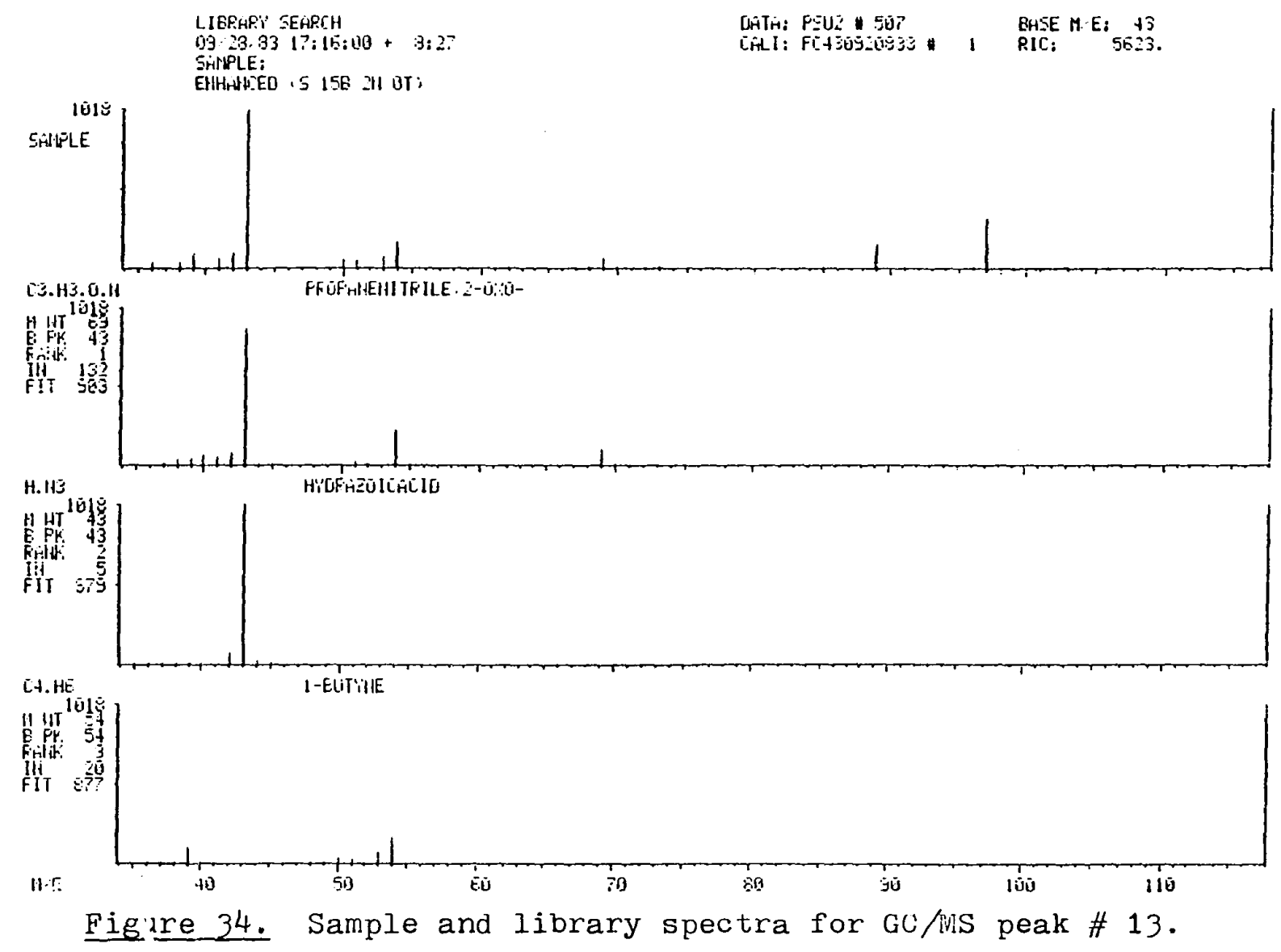


4,5-dioxo-hexenal, which has lost formyl radical (126-29=97).

Peak \#14. Figure 35 shows the EI mass spectrum for peak \#14. The spectral library made a match with methly-quinone. Notice however, the molecular ion in 35 is at $\mathrm{m} / \mathrm{z}=124$ not $\mathrm{m} / \mathrm{z}=122$ as in the known. The MS/MS identified compound 6-oxo-2,4-heptadienal would be expected to give a very similar spectrum to methyl-quinone (48-49) except with a small molecular ion at $\mathrm{m} / \mathrm{z}=124$ instead of $\mathrm{m} / \mathrm{z}=122$ ! It is quite likely therefore that peak \#14 is 6-oxo-2,4-heptadienal.

Peak \#17. Peak \#17 is a poorly resolved peak containing many components. The peak contains the compound nitrobenzene (at scan 728). Other portions of the peak propably consist of ring fragmentation products, but the spectra are not interpretable because they contain several compounds. This is a more severe problem in EI spectra than CI or CID spectra because of the very large number of peaks in the mass spectrum.

As noted above, the GC/MS analysis did not do very well in identifying the hydroxy compounds which were found in the MS/MS portion of this work. Hydroxy compounds are very often difficult to determine by EI mass spectrometry because they lose the hydroxy group so easily (48). The GC/MS identifications probably could have been futher clairified if a GC/MS instrument had been availible for full time use on this project. The GC/MS analysis did however verify the presence of several isomers of the products suggested by the MS/MS work, which was not possible with out chromatographic separation. 


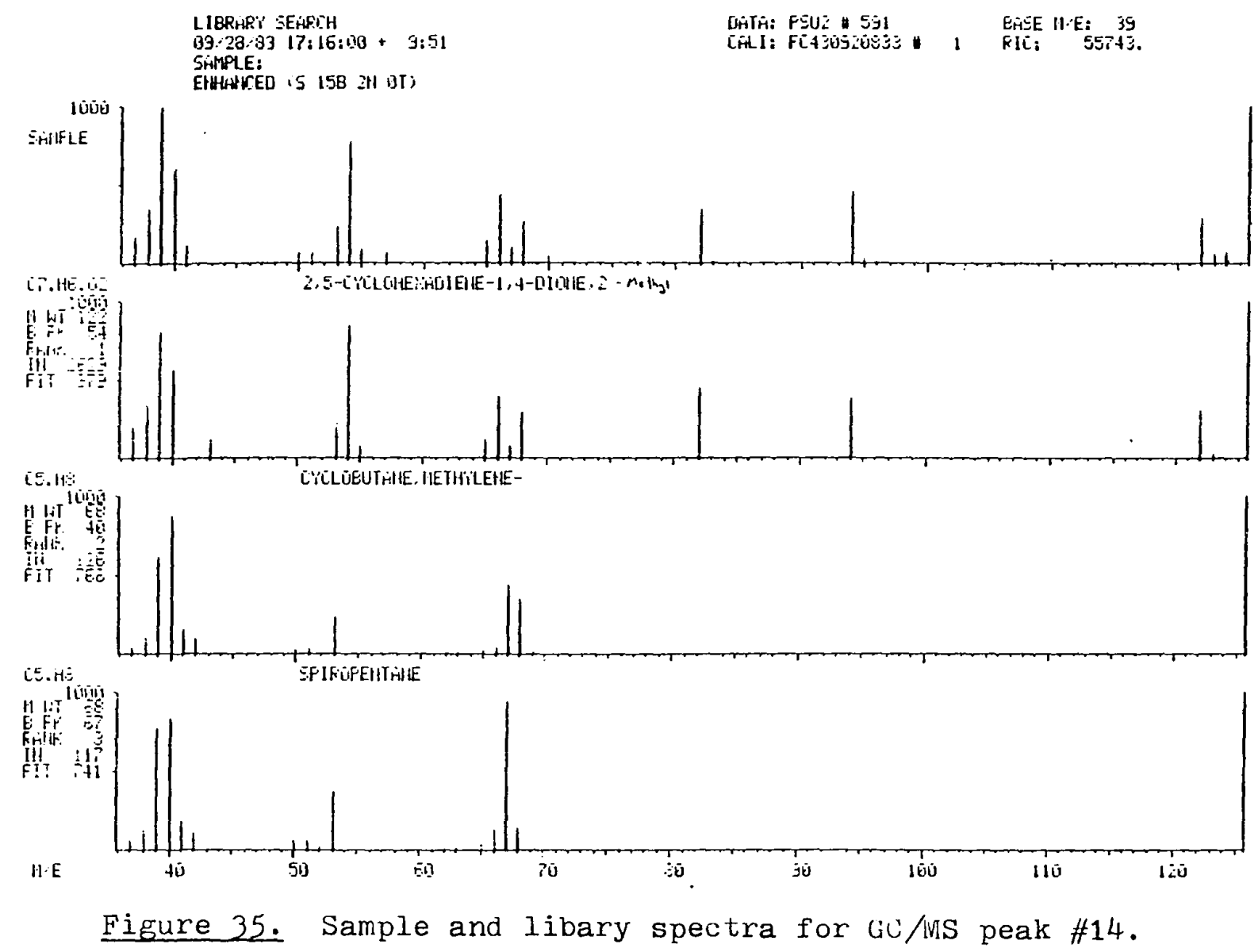


Quantification from $Q C$ analysis

Gas chromatography is more suitable for quantification of the products than MS/MS. THe FID molar response does not vary more than a factor of five for the compounds of interest, and is roughly correlated with molecular weight. As stated in Chapter II, it is important to keep a carbon balance for the reaction under study. Experiments were run under the same conditions described above for this purpose. The extraction solvent was carefully concentrated to known volumes, measured by calibrated glassware. Known fractions of this solution were then analyzed by $G C$. Since many of the aromatic products are in fact in the gas phase, the partitioning "efficiency" was measured for these compounds. Known amounts (ppon level) of toluene and the other major aromatic products were extracted from the same 22 liter flasks as were used for the toluene reactions. The amount of each compound recovered was calculated. Much of this work was performed by Thuy-Trang Dang, as part of a senior research project. These extraction efficiences were applied to an actual toluene reaction. At the time the reaction was stopped, the toluene was $52 \%$ reacted. This agrees with the calculated recovery from the extract, of 468 . Total carbon can be calculated in two ways. If the ring framentation product's peaks are calculated with the same extraction effiency as the aramatic products the total carbon yield is $96 \%$. If the fragmentation products are assumed to be 1008 extracted then the over all yield is reduced to 908 . This is still much better than previous gas sampling results (9-11), as 
described in Chapter II. In both cases the fragmentation products are assumed to have FID responces the same as the average of the other products.

HPIC analysis of extracted products

High performance liguid chramatography studies were performed on the toluene reaction products as extracted by dichloromethane. These studies were performed mainly as a preliminary check of the samples before they were sent for MS/MS analysis. In the early stages of research they were also used to prove reproducibility of the extraction procedure, and the toluene reactions themselves. HPLC proved to be useful for the separation of the toluene products, but far less useful than MS/MS for their identification. Retention times were determined for the known aromatic products from standards. Gradient elution using the SP8100, under the conditions given in the experimental section was optimal for the separation of the detected products. An example of a resulting chromatogram is shown in Figure 36. Standard toluene reaction conditions were used in all HPLC work. Table VI lists the identified products. It is clear the modern high resolution reverse phase columns are a powerful tool for the separation of these relatively polar compounds. The method is limited however since general product identification was not possible. The new technique of liquid chromatography/mass spectrometry could prove to be very effective in the analysis of these reaction products as well as other model or real aerosols. 


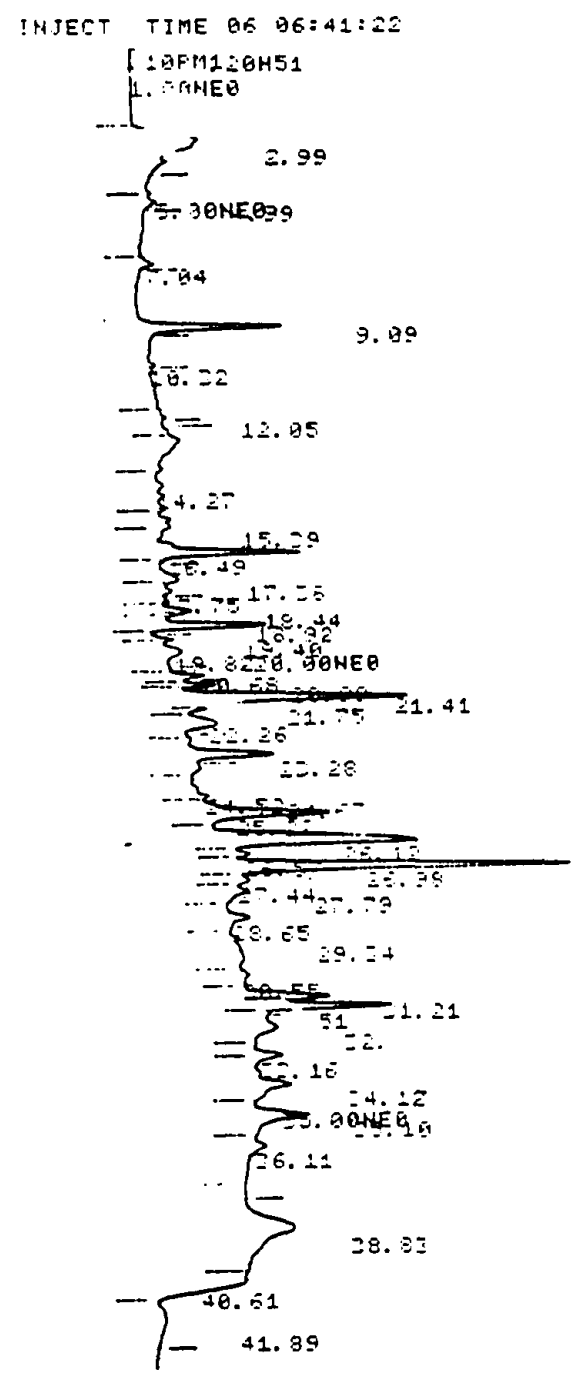

Figure 36. Typical high performance liquid chromatography chromatogram for toluene's extracted products. 
CHAPTER V

MECHANISM FOR TOLUENE'S ATMOSPHERIC DEGRADATION

Current models of tropospheric chemistry either do not include reactions of aromatics (53), or treat them very simply (54). These comprehensive computer models are used by air quality planners to develop control strategies for an airshed. Billions of dollars are spent annually, based on what these models predict. Even small improvements in the accuracy of these models is therefore useful. Aromatics make up a large portion of the ambient hydrocarbon content of air, as described in Chapter I. Inclusion of reliable aromatic hydrocarbon chemistry in the tropospheric models would be a great aid in their improvement.

Although several mechanisms specific to toluene's atmospheric oxidation have been proposed, these contain a great degree of uncertainty because of the lack of information on the relative yields and even the identities of many of the products. These mechanisms depend mainly on curve fitting the experimentally observed profiles for toluene, nitric oxides, and ozone. Since 
many factors influence the time dependent behavior of these species it is relatively easy to compensate an inaccuracy in one portion of the mechanism through an assumption made in another portion of the mechanism. Indeed, the disagreements between the three most developed toluene mechanisms $(9,26,34)$ are largely due to differences in assumptions made about unmeasured processes.

The major unknown in all previous toluene mechanisms concerns the formation and reaction of the intermediate products. These reaction products have been included or excluded as necessary to make the proposed mechanisms fit the experimental data. For example Atkinson (9) considers several ring fragmentation pathways to produce methyl glyoxal, while whitten and killus (26) limit their mechanism to just one. Both groups however simulate the same experimental data, and both obtain comparible fits to the data for their models. The product determinations presented in this thesis indicate that the atmospheric chemistry of toluene is more complex then proposed by any previous mechanism.

TOLUENE REACTIONS

All of the compounds proposed by this study have reasonable production pathways from toluene reacting under simulated atmospheric conditions. Toluene, like most hydrocarbons, is initially attacked by hydroxyl radical(2). Subsequently, reactions with molecular oxygen and nitrogen oxides produce stable oxygenated products and regenerate hydroxyl radical. The general 
mechanism involved is shown in equations $i-8$.

$$
\begin{aligned}
& \mathrm{R}-\mathrm{H} \quad+\cdot \mathrm{OH} \longrightarrow \mathrm{R} \cdot+\mathrm{H} 2 \mathrm{O} \text { (I) } \\
& \mathrm{R} \cdot \quad+\mathrm{O} 2 \longrightarrow \mathrm{RO} 2 \text {. } \\
& \mathrm{RO} 2 \cdot+\mathrm{NO} \longrightarrow \mathrm{RO} \cdot+\mathrm{NO} 2 \\
& \mathrm{RO} \cdot \quad+\mathrm{O} 2 \longrightarrow \mathrm{RC}(\mathrm{O}) \mathrm{R}^{\prime}+\mathrm{HO} 2 \cdot(4) \\
& \mathrm{HO} 2 \cdot+\mathrm{NO} \longrightarrow \mathrm{NO} 2+\mathrm{OH} \text {. } \\
& \mathrm{NO2}+\mathrm{hv} \longrightarrow \mathrm{NO}+\mathrm{O} \\
& \mathrm{O}+\mathrm{O} 2 \longrightarrow \mathrm{O3} \\
& \mathrm{O} 3+\mathrm{NO} \longrightarrow \mathrm{NO} 2+\mathrm{O} 2
\end{aligned}
$$

Reactions 6-8 comprise the photo-stationary state for ozone and the nitrogen oxides. The building up of ozone is produced through the perturbation of this null cycle, by reactions $3-5$, the interaction of hydrocarbon chemistry with the NOx chemistry.

The specific reactions to produce the aromatic products fram toluene's degradation are understood (10). These reactions are shown in Figure 37. Reactions $a$ and $b$ are initial attack on toluene through abstraction and addition respectively. Abstraction leads to the products benzaldehyde or benzyl nitrate. Ring addition of hydroxy radical leads to the aromatic products cresol and nitrotoluene. Reactions similar to these can be used to explain the other aromatic products: hydroxybenzaldehydes, dihydroxytoluenes, nitrobenzaldehydes, nitrocresols, and dinitrotoluenes. The minor product phenol probably results fram secondary reactions of benzaldehyde (26) .

The ring fragmentation products result from a more complex sequence of reactions. The reactions presented below are largely 


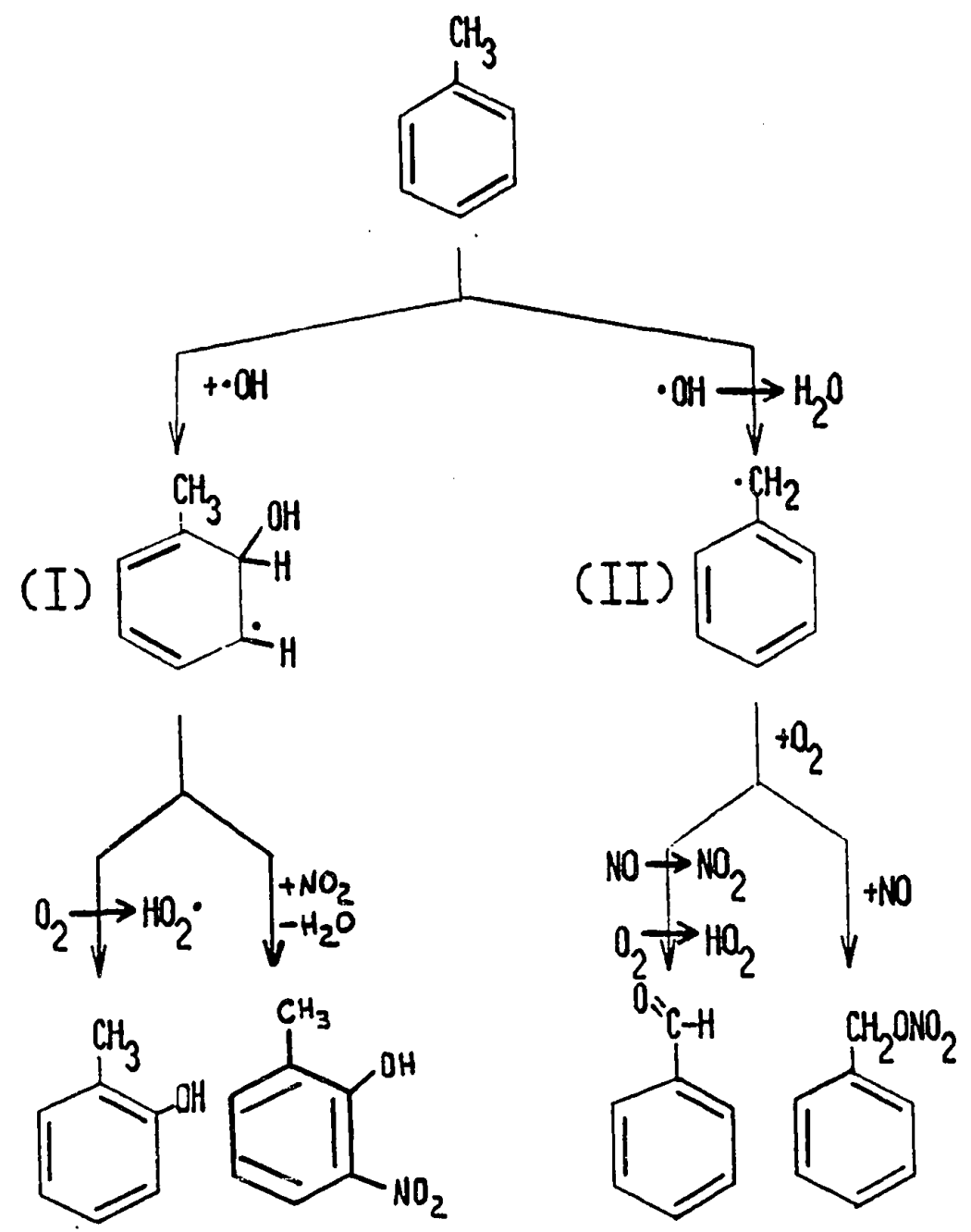

Figure 37. Aromatic products of toluene formation Nechanism. 
based on reactions proposed by Atkinson et al. (9). Newly determired products from the present work are proposed to be formed following similar mechanistic pathways. The important reaction sequences for the fragmentation products are shown in Figures 38-40. A complete mechanism written in four letter code suitable for computer modelling is presented in Appendix B. As shown by the examples in Fiures 38-40, there are many interrelationships between the products. A significant feature relating to toluene's importance in ozone formation is the number of NO to $\mathrm{NO2}$ conversions for each pathway. The larger the number of NO converted to $\mathrm{NO} 2$ by hydrocarbon radicals, the more ozone formation is enhanced (2). Different products can form while converting the same number of $\mathrm{NO}$ to $\mathrm{NO2}$, as in Figure 38. The same products can form through different pathways with a different number of $\mathrm{NO}$ to $\mathrm{NO} 2$ conversions. Notice methyl glyoxal is formed with two NO to $\mathrm{NO} 2$ conversions in Figure 38, and six NO to $\mathrm{NO} 2$ in Figure 39. The same products can also be formed through completely different pathways yet produce the same net $\mathrm{NO}$ to $\mathrm{NO} 2$ conversions, Figure 39, vs. Figure 40, for methyl glyoxal. It should be clear that only monitoring the nitrogen oxides and ozone profiles can not discriminate between possible pathways unless something is known about the intermediate products. Ozone reactions with the unsaturated products is a potentially important process. These products would then serve both as sources and sinks for ozone. The overall ozone forming potential of the products is therefore not easily predicted. The organic products from the reaction with 


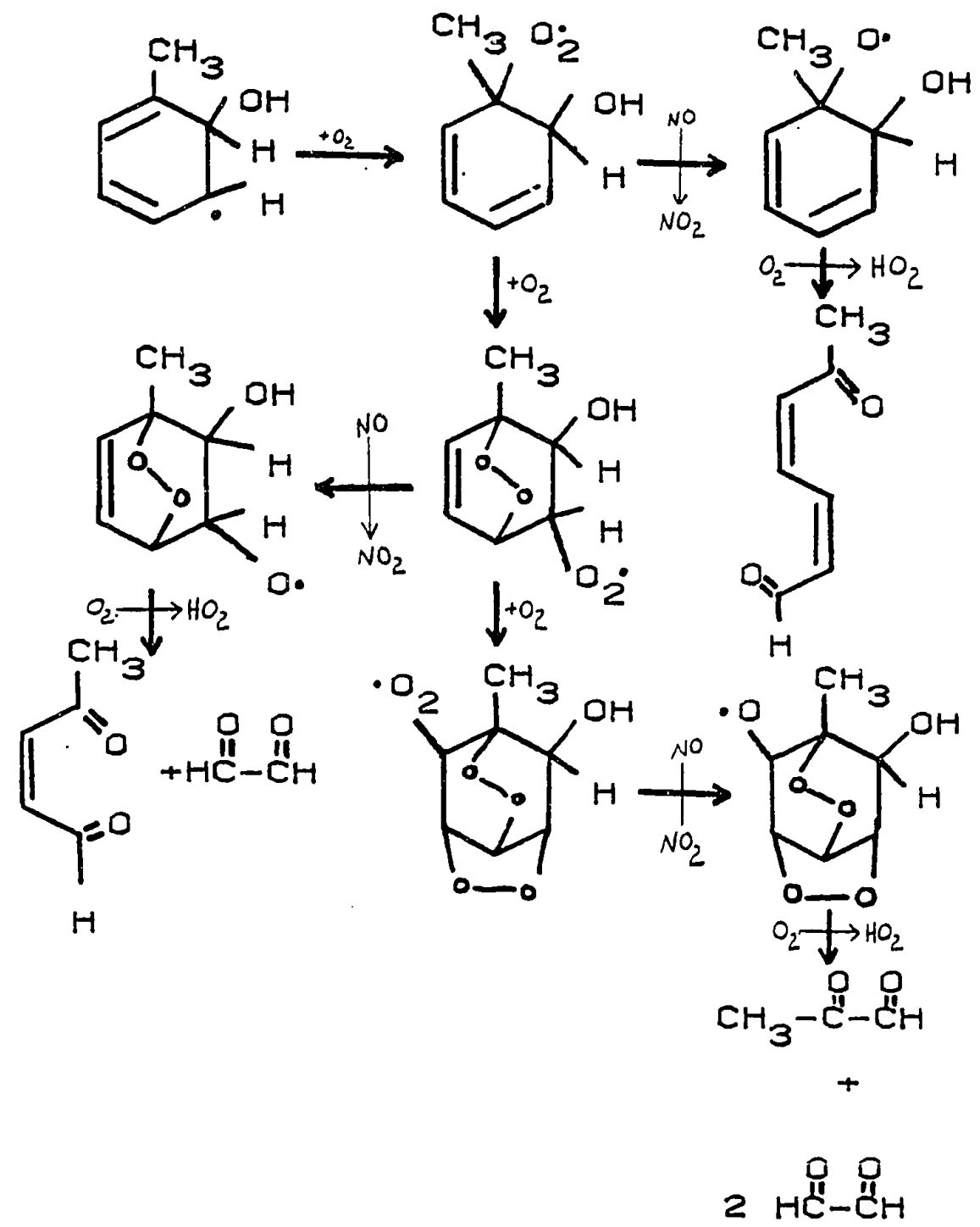

Figure 38. Ring fragmentation products formation which convert two NO to NO2. 


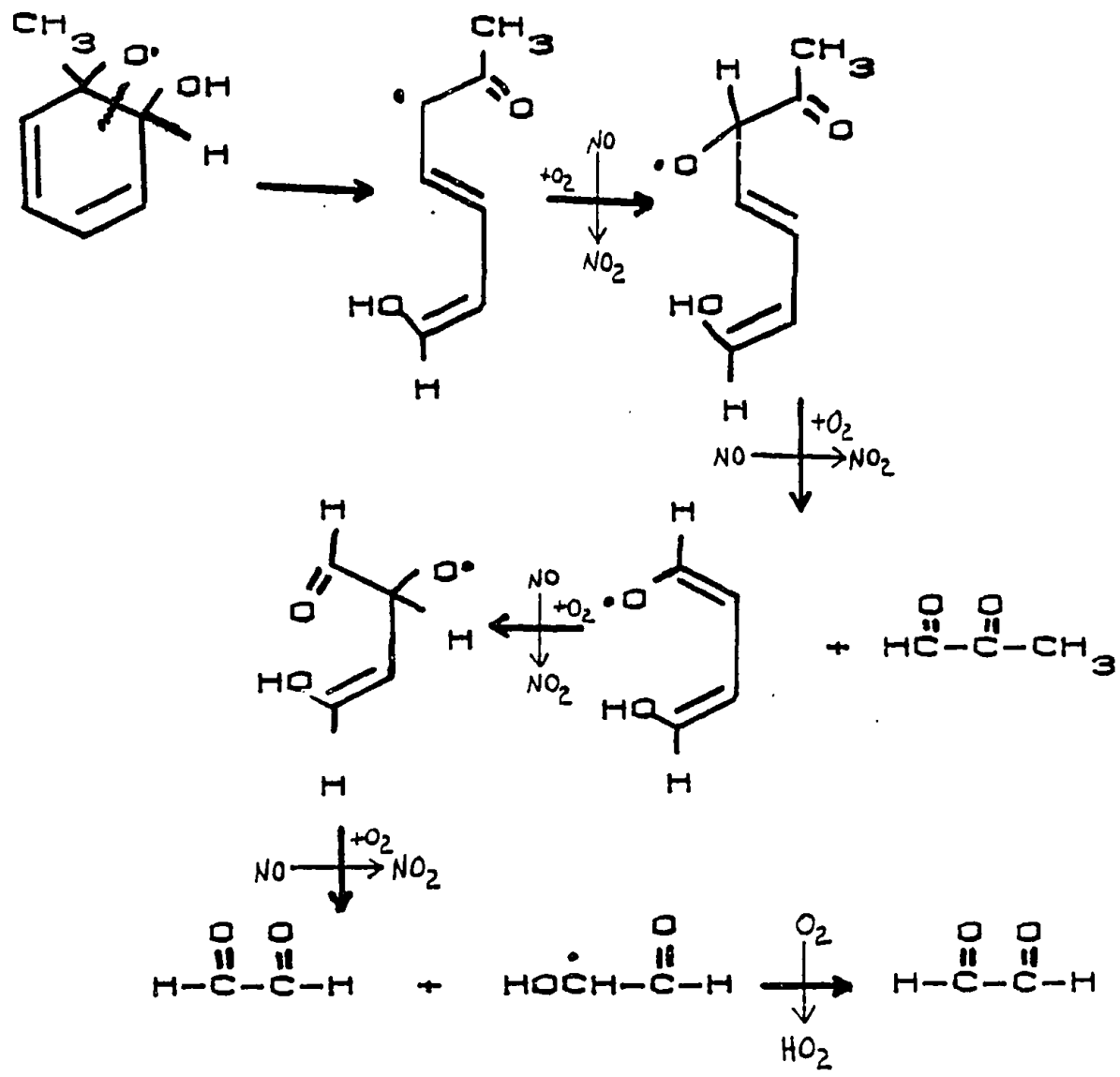

Figure 39. Ring fragmentation products formation which convert six NO to NO2. 


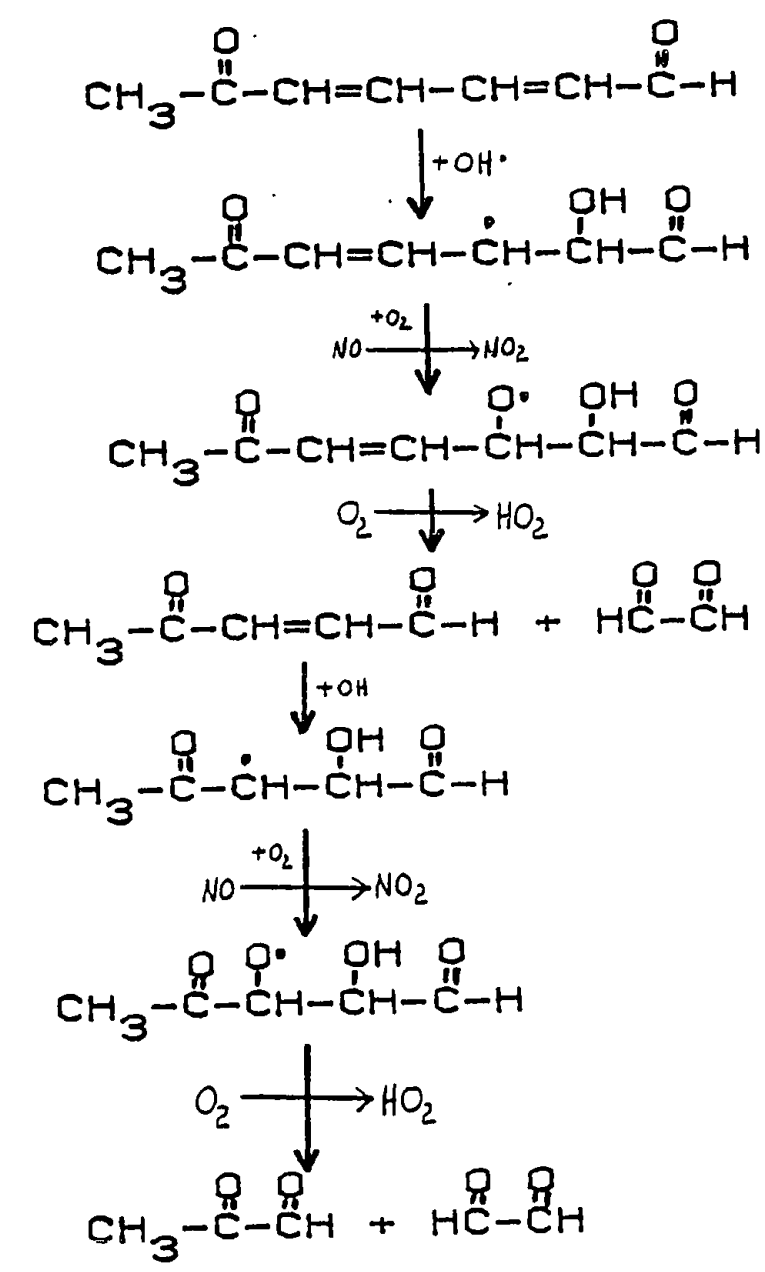

Figure 40. Seaction of 6-0xo-2,4-heptadienal to produce methyl glyoxal and glyoxal. 
ozone are expected to be much the same as those from hydroxyl radical reactions. The only additional products expected are organic acids formed from the rearrangement of Criegee intermediates, such as (I) in Figure 4I. As noted in Chapter III few acids were found in the present work, possibly because the reactions were generally run under ozone suppressing conditions (high NOx concentrations).

A major difference between the overall chemistry in the present mechanism and that of previous workers $(9,26,34)$, is the formation ratio of carbon dioxide to carbon monoxide. Previous mechanisms have the seven carbon atoms of toluene producing approximately five carbon monoxide and two carbon dioxide. The present work has approximately three carbon monoxide and four carbon dioxide overall. This prediction better agrees with the overall measured yields of $15 \% \mathrm{CO}$ and $85 \% \mathrm{CO} 2$, given in Chapter II.

Figure 42 presents a sumnary of probable pathways for the production of the major ring fragmentation products. Although many of the compounds in Figure $\mathbf{4 2}$ have not been identified previously, several of the pathways presented have been proposed. These pathways are reactions a-e. Killus and Whitten (26) base their mechanism largely upon butenedial and methylglyoxal. Butenedial has been tentatively identified by Besemer (18). Atkinson et al. (9) base their mechanism upon this pathway plus glyoxal and 4-oxo-2-pentenal, although the latter compound has not been previously identified. The other ring fragmentation products 


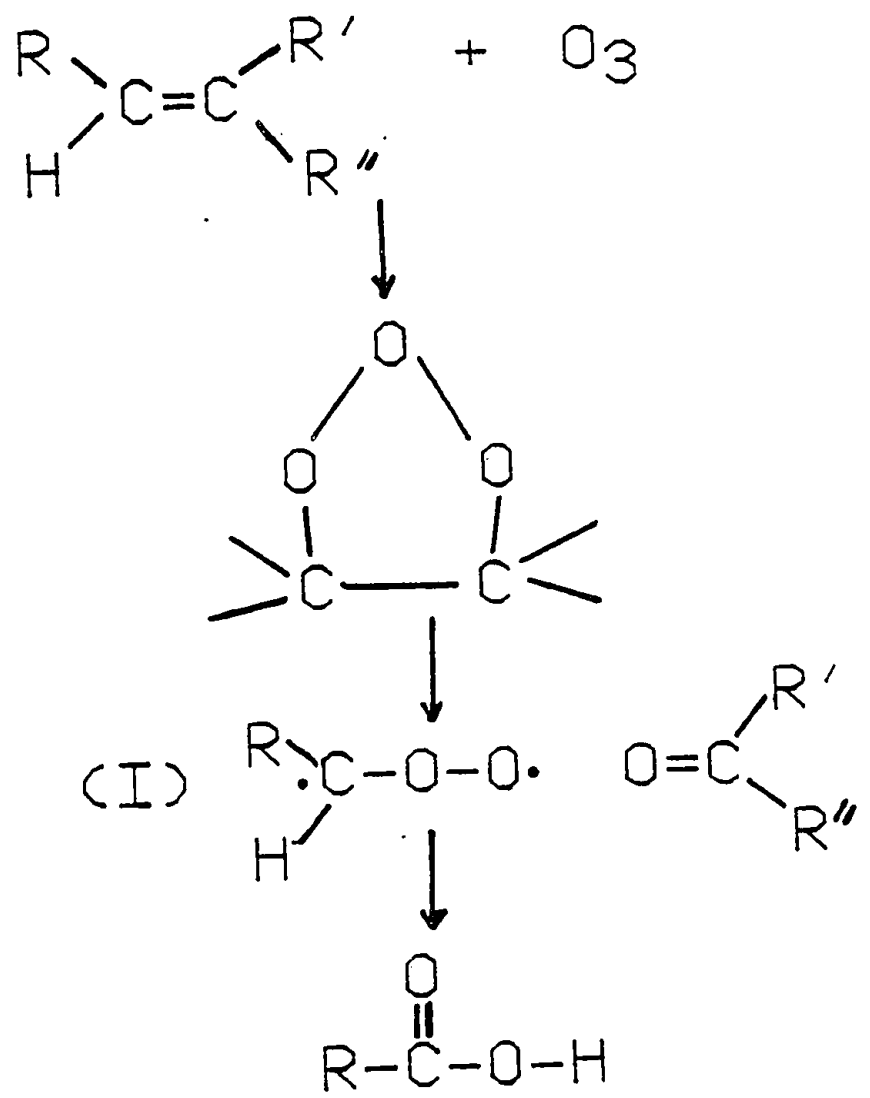

Figure 41. Criegee intermediate formation and rearrangement to produce organic acids. 


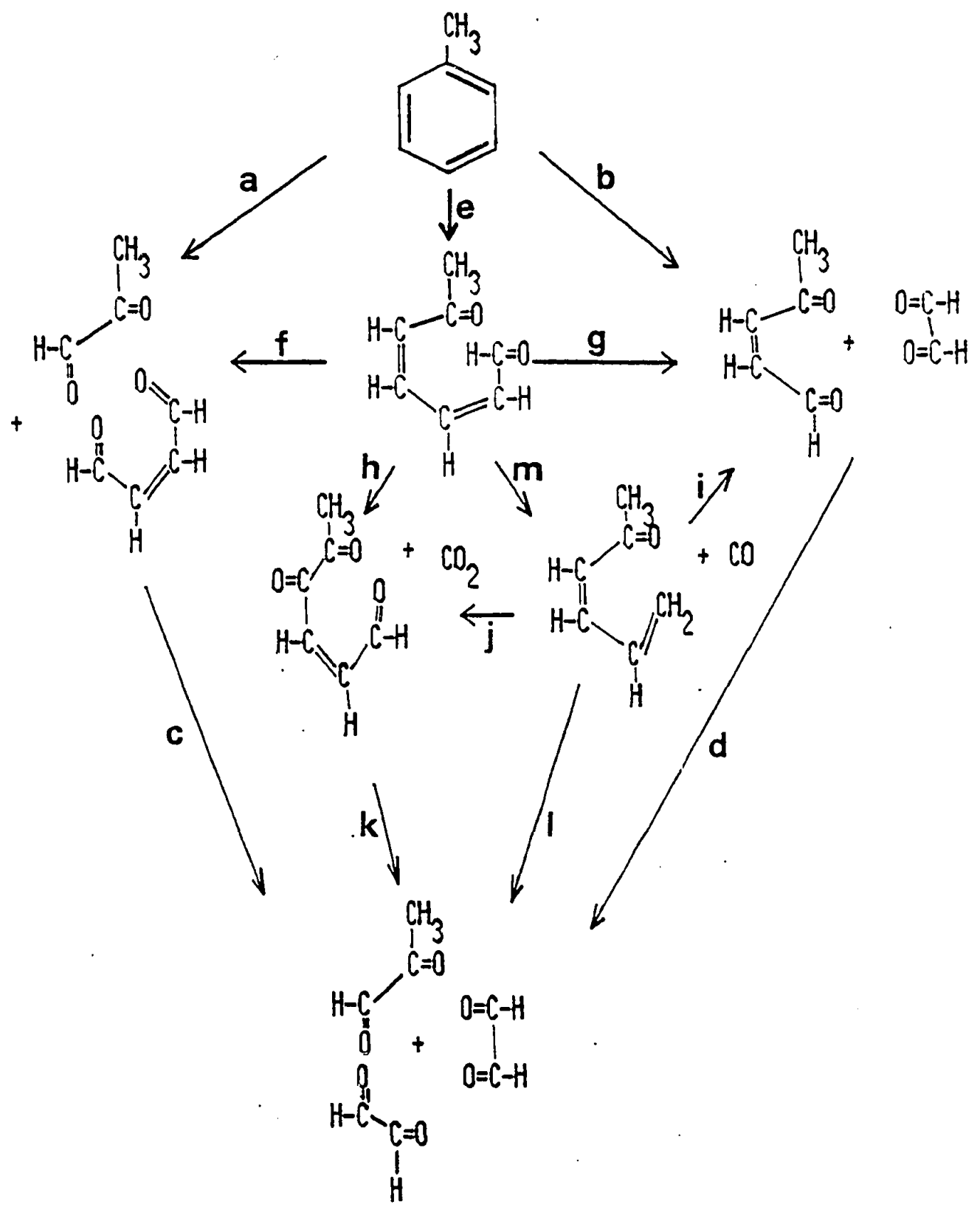

Figure 42. Summary of ring fragmentation mechanism. 
determined in Chapter III have been presumed by other workers to play no major role in toluene's atmospheric oxidation. References for the proposed formation of these and other compounds can be found in Table II in Chapter III. Reactions $f-l$ have not been previously proposed. They involve reaction sequences similar to those in a-e. Reaction $\mathrm{m}$ is photolytic loss of carbon monoxide from 6-oxo-2,4-heptadienal. Similarly, hydroxy 5-oxo-1,3-hexadiene, 3-oxobutene, and hydroxy-3-oxobutene are possible photoylsis products of hydroxy-6-oxo-2,4- heptadienal, 4-oxo-2-pentenal, and hydroxy-4-oxo-2-pentenal respectively. The photochemistry of these molecules is presently unknown. Photolytic loss of $\infty$ occurs for some aldehydes, but propenal and trans-2-butenal do not show significant $\infty$ production at normal (25 C) temperatures $(55-56)$. Coomber and Pitts found that $\infty$ yields in trans-2-butenal did significantly increase at higher temperatures. They also observed a pressure and wavelength dependance on $C$ yields (56). Extending the conjugation of the carbonyl beyond that found in 2-butenal will have a large effect on the absorption spectrum. Although this pathway could explain the formation of products containing a terminal methylene group, the measured carbon monoxide yields are only 15\%. Since carbon monoxide can be largely accounted for in other reaction pathways, a significant photolysis process would require a major modification of these more established reactions.

An alternative mechanism which would lead to these products is a 1,2-hydrogen shift after initial hydroxyl radical attack. 
This mechanism is shown in Figure 43a. This type of 1,2-shift has been observed (57-58). Takamuku et al found a 1,2 shift occurs with a closely related reaction, $O$ (3P) attack on toluene (58). In Figure $43 a$, the hydrogen shifted adduct (I) proceedes through reaction sequences similar to those proposed for the other ring fragmentation products. This reaction pathway leads to the production of 5-oxo-1,3-hexadiene and carbon dioxide. Immediate formation of carbon dioxide upon toluene reaction has been observed. The reactions in Fig.43a would help explain this initial carbon dioxide yield. Similar reaction sequences can be formulated for the other products containing a terminal methylene group.

The hydroxy products identified in this study have two reasonable formation mechanisms. They may be formed as a result of the reaction of the primary product cresol reacting along similar fragmentation pathways as toluene. Since the primary cresol yield is low, only small amounts of these products would be expected from this route. An alternative reaction mechanism is shown in Figure 43b. The hydroxy product results from hydrogen abstraction from the oxygen cyclized adduct (II), rather than oxygen addition leading to methyi giyoxal and glyoxal formation. It is likely that this mechanism dominates over cresol reactions for formation of products with the alcohol group.

EFFECT IF REACTION CONDITIONS ON PRODUCT YIEIDS

Qualitative experiments were performed to check on product yield sensitivity to reaction conditions, and to ensure the 

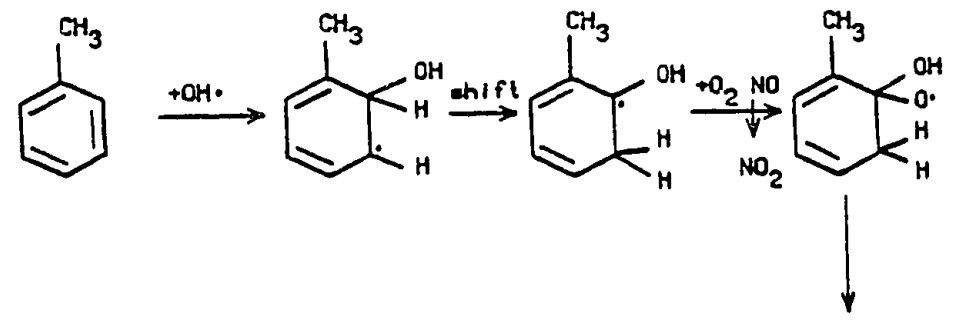

a)

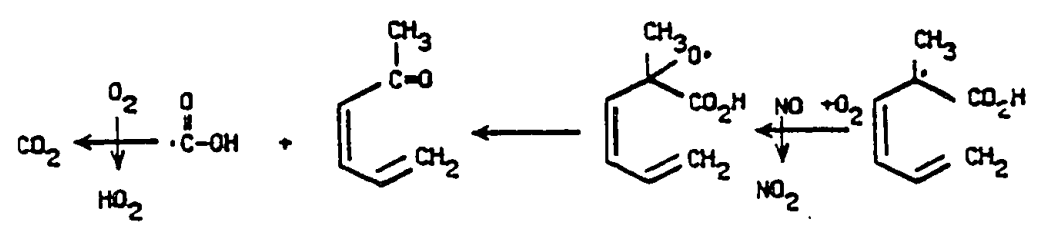<smiles>Cc1ccccc1CCCCC1C=CC(C)C=C1</smiles>

b)

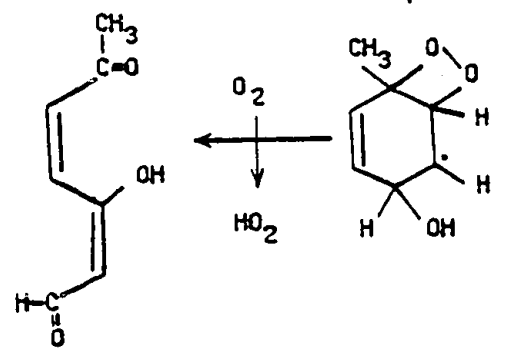

Figure 43. Alternate reactions to produce toluene products with a) terminal methylene grouo, b) hydroxy group. 
proposed mechanism was consistent with the observed atmospheric chemistry. Reactions were normally run with high initial concentrations of nitric oxide. As stated above, this suppresses ozone formation and thus reduces complications form ozone reacting with the intermediate products. However, high concentrations of ND increase the formation of the relatively uninteresting nitroaromatic products. It was expected that lower concentrations of NOx would reduce the proportion of the nitroaromatics. It was also expected that this would reduce the overall reactivity of the system. These expectations were confirmed by reactions at low initial NO concentrations. For example, reactions run at initial concentrations of $0.5 \mathrm{ppm} \mathrm{NO}$ and $5 \mathrm{ppm}$ toluene, instead of the normal 10 and 10, did produce 108 of the normal yield of nitroaromatics (nitrotoluenes and nitrocresols). The rate of the reaction decreased also. Work is currently underway by Dr. Robert O'Brien to elucidate the exact relationship between initial no concentrations and nitroaromatic yields. Under abient conditions where there is a low concentration of $\mathrm{NOx}$, the nitroaromatics would be relatively unimportant. 
CHAPTER VI

CONCLUSTONS

The product determinations made in this study indicate that the atmospheric chemisty of toluene is more complex than previously thought. Twentyseven reaction products of toluene were determined by MS/MS. Of these, only eight had been previously identified. Another five had been previously proposed but not identified. Several ring fragmentation products were determined. These products are of key importance to the understanding of toluene's atmospheric degradation. The use of deuterium labeled toluene greatly aided the research. It added confidence to the structural determinations made with the use of "authenic" standards which were not availible for many of the products. Even with the labeled toluene experiments, in some cases the fragmentation patterns did not allow unique assigmments to be made between several methly or hydroyl positional isomers. Undoubtedly more than one isomer was often present, as would be expected.

An atmospheric pressure CI MS/MS instrument confirmed the 
wall extracted products are also in the gas phase. This instrument would be the most powerful tool in the further study of this or similar systems.

This particular chemical reaction system is complicated by its heterogeneous nature. However, this problem is associated with the process itself, and not with the methods used. Precipitation of the reaction products on the vessel walls is actually an advantage for the direct probe introduction procedure used in the MS/MS analysis. Carbon balance measurements were very useful for the confinmation of wall precipitated products. This type of measurement was the first of its kind taken. Total gas-phase carboñ measurements would be useful for all simulated atmospheric chamber experiments.

The other analytical techniques used in the study supplemented the MS/MS work. The GC/MS work help confirm the MS/MS identifications, including all the aromatic products, and many of the major fragmentation products. It also confirmed the presence of more than one iscmer for many of the products, as was suggested from the MS/MS studies. The use of the livrary search method for the identification was of limited value because many of the compounds of interest were not in the library. In some cases the best library match was an aid in the interpretation of the spectrum.

The capillary gas chromatography work allowed approximate quantification of the products collected. Calculated carbon balances were much better than previously reported. Relative 
yields of the products indicate that several pathways of ring fragmentation are of equal importance. This is in disagreement with all of the current toluene mechanisms. A detailed mechanism has been proposed in this work. It is presented in a four letter code suitable for computer modeling studies. Results from the product determinations are incorporated into this mechanism. Several new pathways were developed to account for the new products identified. The overall chemistry is similar to previous pathways except that the overall yields of carbon monoxide and carbon dioxide are in better agreement with measured yields. Much more work is needed to varify a mechanism as complex as the one proposed for toluene's atmospheric degradation. Now that many of the other ring fragmentation products have been determined, their individual atmospheric chemistry's can be investigated. When the reactions of the products are understood, the accuracy of toluene's mechanism will be increased. The results presented in this thesis should be large step in this process.

When aromatic hydrocarbon atmospheric chemistry is well understood, it will be possible to incorporate the affects of this important class of hydrocarbons in general tropospheric models. As a result better predictions can be made about the potential pollution problems in an urban area, and better control strategies can be developed to decrease any potenial harm to man and his environment. 
REFERENCTS

1. O'Brien, R. J.; Hightower, J., and Crocker, T.D. In "The Alkylbenzenes"; Peter, F.M., Ed.; National Academy of Sciences: Washington, D.C., Chapter I, (1981).

2. O'Brien, R. J.; Johnson, J.E.; Wilkerson, C. In "The Alkylbenzenes"; Peter, F.M., Ed.; National Academly of Sciences: Washington, D.C., Chapter IV, (1981).

3. Sexton, K॰; Westberg, H. Environ. Sci. Technol. $17,329-332$, (1980).

4. Cox, R.A.; Derwent, R.G.; Williams, M.R. Environ. Sci. Technol. 17, 57-61, (1980).

5. Altshuller, A.P.; Cohen, I.R. Int. J. Air Water Pollut. 7, 787-797, (1963).

6. Kopczynski, S.L. Int. J. Air Water Pollut. $8,107-120,(1964)$.

7. Heuss, J.M.; Glasson, W.A. Environ. Sci. Technol. 2, 1109-1116, (1968).

8. Glasson, W.A.; Tuesday, C.S. Environ. Sci. Technol. 4, 916-924, (1970).

9. Atkinson, R.; Carter, W.P.L.; Darnall, K.R.; Winer, A.M. ; Pitts, J.N., Jr. Int. J. Chem. Kinet. 12, 799-836, (1980). 10. O'Brien, R.J.; Green, P.J.; Doty, R.A.; Vanderzanden, J. W.; Easton, R.R.; Irwin, R.P. "Nitrogenous Air Pollutants", D. Grosjean, Ed., Ann Arbor Press, Ann Arbor, MI Ch. 11, (1979). 11. Nojima, K.; Fukaya, K.; Fukui, S.; Kanno, S. Chemosphere, 5, 247-252, (1974). 
12. Schwartz, w. "Chemical Characterization of Model Aerosols", report to U.S. E.P.A., Avail. NIS PB-238 557, (1974).

13. Akimoto, H.; Hoshino, J.; Inone, G.; Okuda, M.; Washida, N. Bull. Chem. Soc. Japan, 51, 2496-2502, (1978).

14. Hoshino, J.; Akimoto, J.; Okuda, M. Bull Chem. Soc. Japan, 51, 718-724, (1978).

15. Ishikawa, J.; Watanabe, K.; Ando, W. Bull. Chem. Soc. Japan, 51, 2174-2174, (1978).

16. Pate, C.T॰; Atkinson, R.; Pitts, J.N. Jr. J. Environ. Sci. Health-Environ. Sci. Eng., All(1), 1-10, (1976) .

17. Slcane, T.M. Chem. Phys. Letters, 54, 269-272, (1978).

18. Besemer, A.C. Atmospheric Envirorment, 16, 1599-1602, (1982)

19. Takagi, H. Washida, N.; Akimoto, H.; Nagasawa, K.;

Usui, Y.: Okuda, M. J. Phys. Chem. 84, 478-483, (1980).

20. Darnall, K.R.; Atkinson, R.; Pitts, J.N., Jr. J. Phys. Chen.

83, 1943-1946, (1979).

21. Takagi, H.; Washida, N.; Akimoto, H; Okuda, M.

Spect. Lett. 15, 145-152, (1982).

22. Nicovich, J.M.; Thompson, R.L.; Ravishankara, A.R.

J. Fhys. Chen., 85, 2913-2916, (1981).

23. Ebata, T.; Obi, K.; Tanaka, I. Chem. Phys. Letters,

$77,480-483$, (1981).

24. Atkinson, R.; Darnall, K.R.; Pitts, J.N. Jr.

J. Phys. Chem., 82, 2759-2761, (1978).

25. Carter, W.P.L.; Winer, A.M.; Pitts, J.N. Jr.

Environ. Sci. Technol., 7, 829-831, (1981). 
26. Killus, J.P.; Whitten, G.Z. Atmos. Environ. 16, 1973-88, (1982).

27. Davis, D.D.; Bollinger, W.; Fuher, S. J. Phys. Chem. 79, 293-294, (1975).

28. Atkinson, R.; Pitts, J.N. Jr. Chem. Phys. Letters, $63,485-489$, (1979).

29. Kenley, R.A.; Davenport, J.E.; Hendry, D.G. J. Phys. Chem., 82,1095-1096, (1978).

30. Tully, F.P.; Ravishankara, A.R.; Thompson, R.L. ;

Nicovich, J.M.; Shah, R.C.; Kreutter, N.M.; Wine, P.H.

J. Phys. Chem., 85, 2262-2267, (1981).

31. Perry, R.A.; Atikinson, R.; Pitts, J.N. Jr. J. Phys. Chem. $81,296-304$, (1977).

32. Gaffney, J.S.; Atkinson, R.; Pitts, J.N. Jr. JACS, 98, 1828-1832, (1976).

33. Atkinson, R.; Carter, W.P.L.; Winer, A.M. J. Phys. Chem., $87,1605-1610,(1983)$.

34. Leone, J.A.; Seinfeld, J.H. Int. J. Chem. Kinet. 16, 159-193, (1984).

35. Cater, W.P.L.; Lloyd, A.C.; Sprung, J.L.; Pitts, J.N., Ir. Int. J. Chem. Rinet. 11, 45-101, (1979) .

36. Altshuler, A.P.; Kopcynski, S.L.; Lonneman, W.A.; Sutterfield, F.D.; Wilson, D.L. Environ. Sci. Technol. 4, 44-46, (1970). 37. Iehmann, H.W.; Widmer, R.J. Vac. Sci. Tech. 17, 1177-86, (1980). 38. Holmes, J.R.; O'Brien, R.J.; Crabtree, J.H.; Hecht, T.A.; Seinfeld, J.H. Environ. Sci. Technol. 7, 519-523, (1973). 
39. Huntzicker, J.J.; Johnson, R.L. "program and Summaries of Presentations", Conference on Carbonaceous Particles in the Atmosphere, March 20-22, 1978; National Science Foundation and Lawrence Berkley Laboratory: Berkley, CA; paper no. 2.

40. O'Brien, R.J. Portland State University; unpublished data, 1984.

41. Cooks, R.; Glish, G.L. Chem. Eng. News 59,40, (1981).

42. Yost, R.A.; Fetterolf, D.D. Mass Spectrom. Rev.

$2,1-45,(1983)$.

43. Slayback, J.R.B.; Story, M.S. Ind. Res. Dev.

Feb., 129-139, (1981).

44. Buckley, J.A.; French, J.B.; Lawson, P.H.; Reid, N.M.;

MS/MS Conference, Asilamar, CA, September 21-24, 1980.

Sciex TAGA 6000 MS/MS Applicatios Note 4680-P, Specification

Bulletin 3780-T.

45. Hunt, D.F. Sethi, S.K. J. Am, Chem. Soc. 102, 6953-63, (1980).

46. Hartman, K.N.; Lais, S.; Ausloss, P.; Rosemtoch, H.M.;

Schroyer, S.S.; Schmidt, C.; Martinsen, D.; Milne, G.W.A.

"A Compendium of Gas Phase Basicity and Proton Affinity

Measurements". U.S. National Bureau of Standards, (1979).

47. Henderson, T.R.; Sun, J.D.; Royer, R.E.; Clark, C.R.;

Li, A.F.; Harvey, T.M.; Hunt, D.H.; Fulford, J.E.; Lovette, A.M.

Davidson, W.R. Environ. Sci. Technol. 17, 443-449, (1983).

48. MaLafferty, F.W. "Interpretation of Mass Spectra", 3rd. ed. University Science Books: Mill Valley, CA. (1980).

49. Walther, H.J.; Eyer, H.; Schlunegger, U.P.; Porter, C.J.; 
Larka, E.A.; Beynon, J.H. Org. Mass Spectrom. 17, 81-85, (1982). 50. Bachiri, M.; Perros, P.; Verneuil, B.; Mouvier, G.; Carlier, P. $15,84-89$, (1980).

51. Heller, S.R. EPA/NIH mass spectral data base. US Department of Commerce, National Bureau of Standards. v.1-4. (1978).

52. Burdick and Jackson's Solvent guide, Second ed. (1982). Burdick and Jackson Laboratories, Inc. pages 82-83.

53. Office of Air Quality Planning and Standards. "Uses, Limitations and Technical Basis of Procedures for Quantifying Relationships Between Photochemical Oxidants and Precursors". EPA-450/2-77-021a. U.S. Enviromental Protection Agency, (1977). 54.Killus, J.P. and Whitten, G.Z., "A New Carbon-Bond Mechanism for Air Quality Simulation Modeling", EPA 600/3-82-041, U.S. Environmental Protection Agency, (1982). 55. Lee, E.K.C.; Lewis, R.S. Advances in Photochemistry, $12,53-55,(1980)$.

56. Coomber, J.W.; Pitts, J.N. Jr. J. Amer. Chem. Soc., 91, 4955-4960, (1969). 57. Szirovicza, I, and Szilagyi, I. Int. J. Chem. Kinetics XII, 113-122, (1980). 58. Takamuku, S., Matsimoto, H., Hori, A., and Sakurai, H. J. Am. Chem. Scc. 102, 1441-1443, (1980). 
APPENDIX A

MS/MS DAUGHIER ION SPECIRA FOR REMAINING PRODUCTS

$\begin{array}{lcccc}\text { Compeund } & \text { H8, } & \text { D3, } & \text { D8 } & \text { Page } \\ \text { glyoxal } & 59 & 59 & 61 & 121 \\ \text { acetic acid } & 61 & 64 & 64 & 122 \\ \text { 3-oxo-butene } & 71 & 74 & (77) & 123 \\ \text { hydroxy-3-oxo-butere } & 87 & 90 & 92 & 124 \\ \text { phenol } & 95 & 95 & & 125 \\ \text { 3-oxo-2-hydroxy-butanal } & 103 & 106 & 108 & 126 \\ \text { benzaldehyde } & 107 & 108 & 113 & 127 \\ \text { cresol } & 109 & 112 & 116 & 128 \\ \text { benzoic acid } & 123 & 123 & 127 & 129 \\ \text { hydroxybenzaldehyde } & (123) & 124 & (127) & 130 \\ \text { dihydroxytoluene } & (125) & (128) & 131 & 131 \\ \text { nitrotoluene } & 138 & 141 & 145 & 132 \\ \text { nitrophenol } & 140 & 140 & 144 & 133 \\ \text { hydroxy-6-oxo-2,4- } & & & & \\ & 141 & 144 & 148 & 134 \\ \text { nitrobenzaldehyde } & 152 & 153 & 157 & 135 \\ \text { nitrocresol } & 154 & 157 & 160 & 136 \\ \text { benzalnitrate } & (154) & 156 & 161 & 137 \\ \text { dinitrotoluene } & 183 & 186 & 189 & 138\end{array}$

spectra in () have been presented previously 


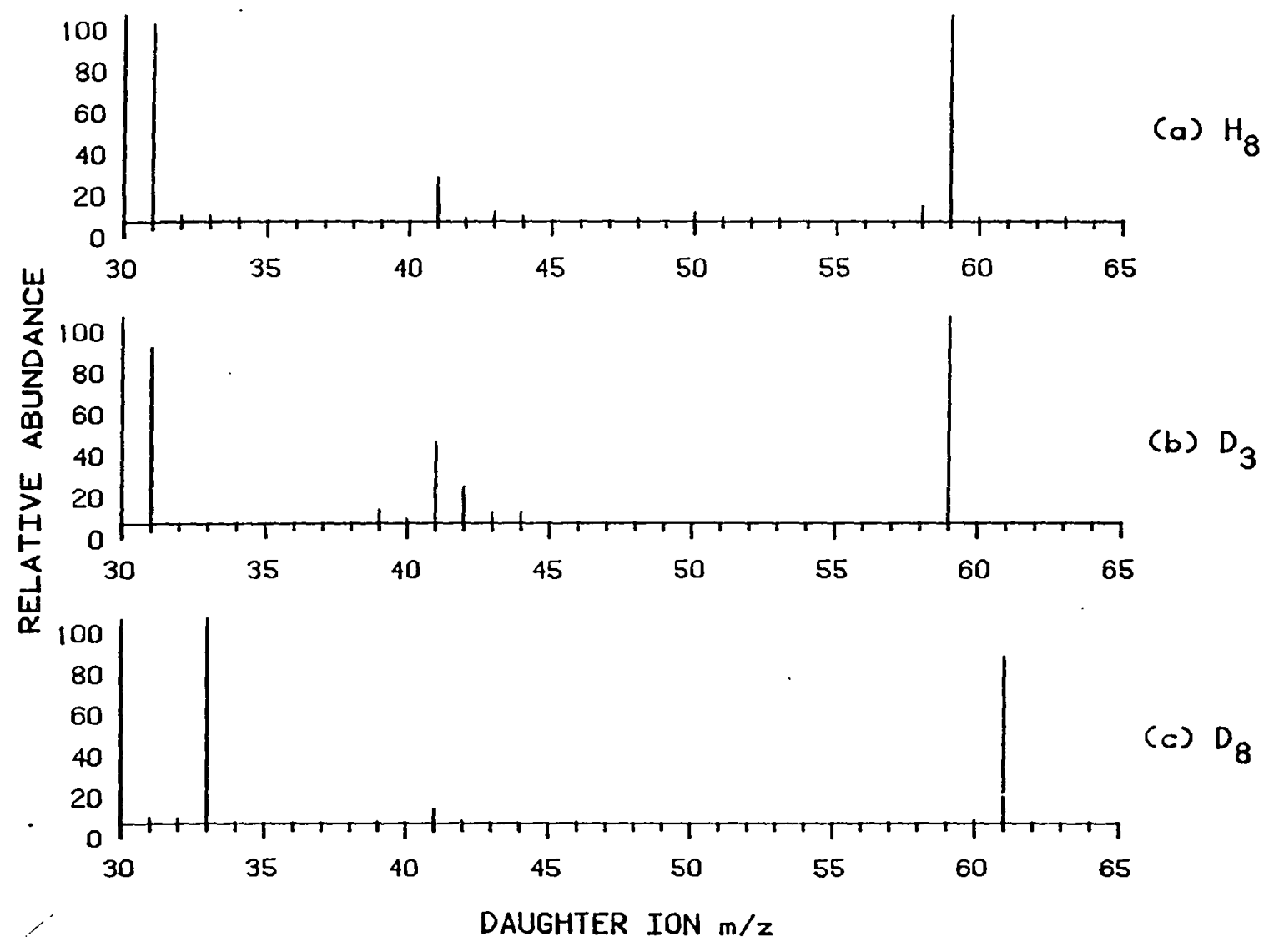




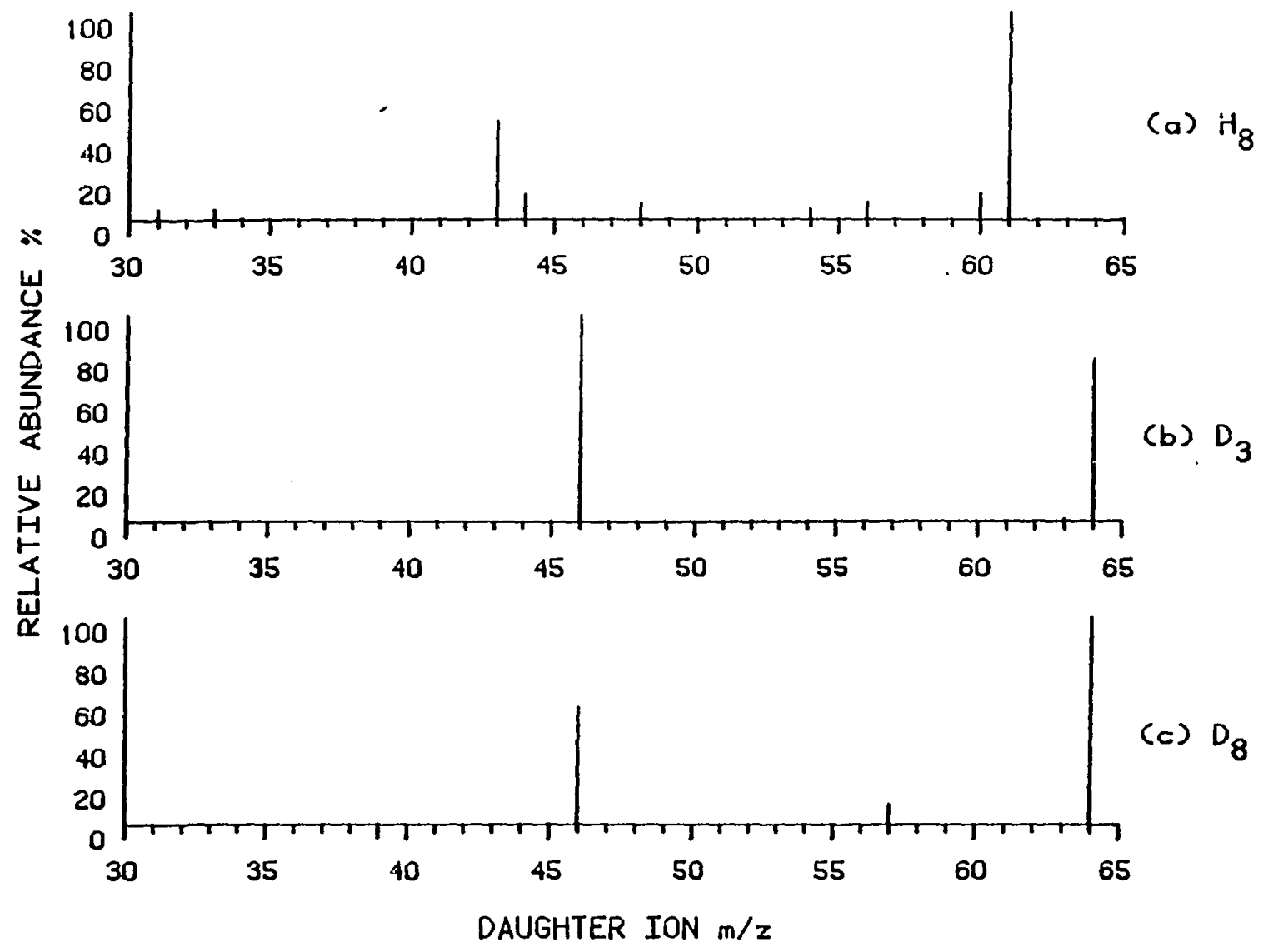




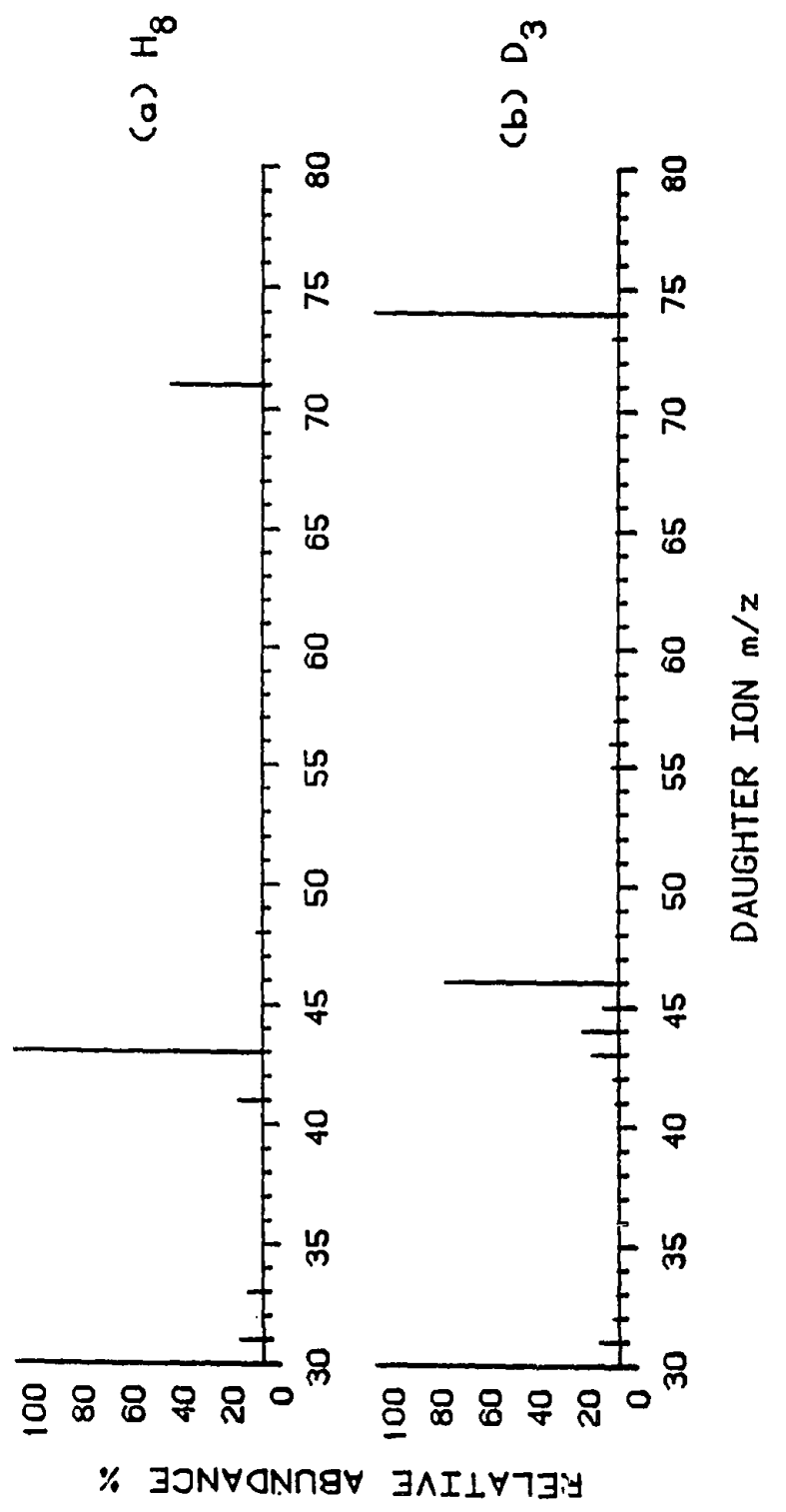




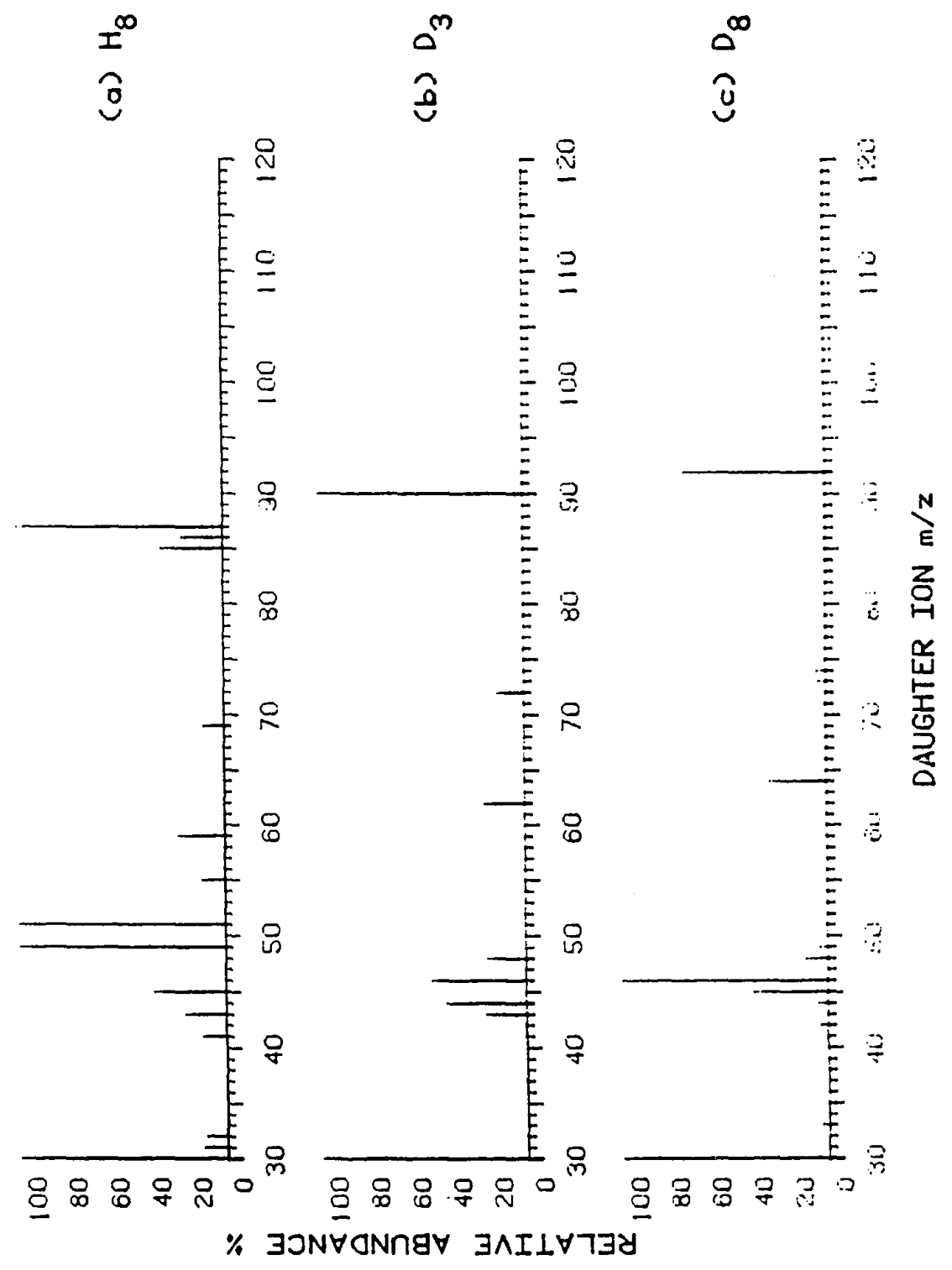




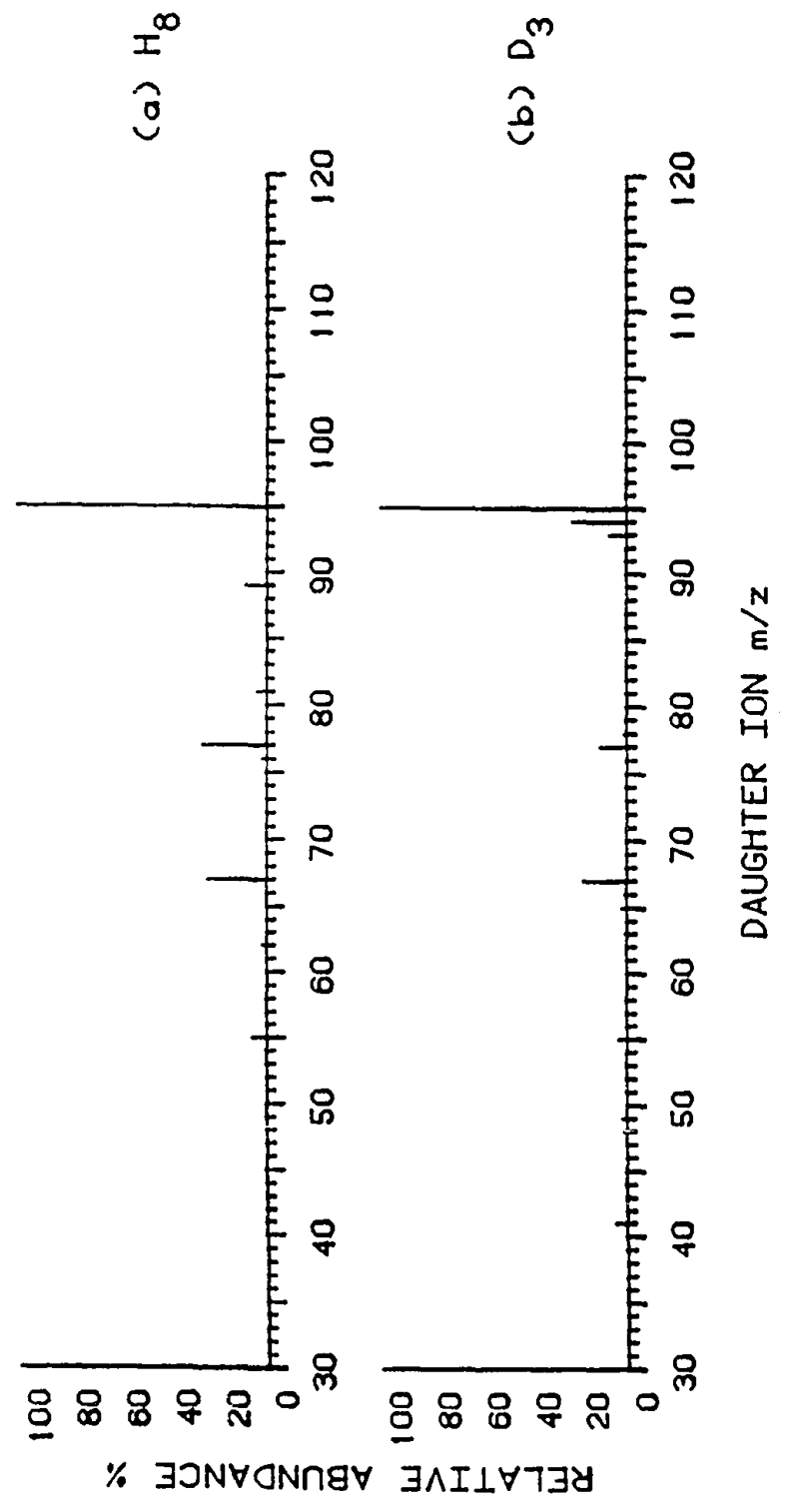




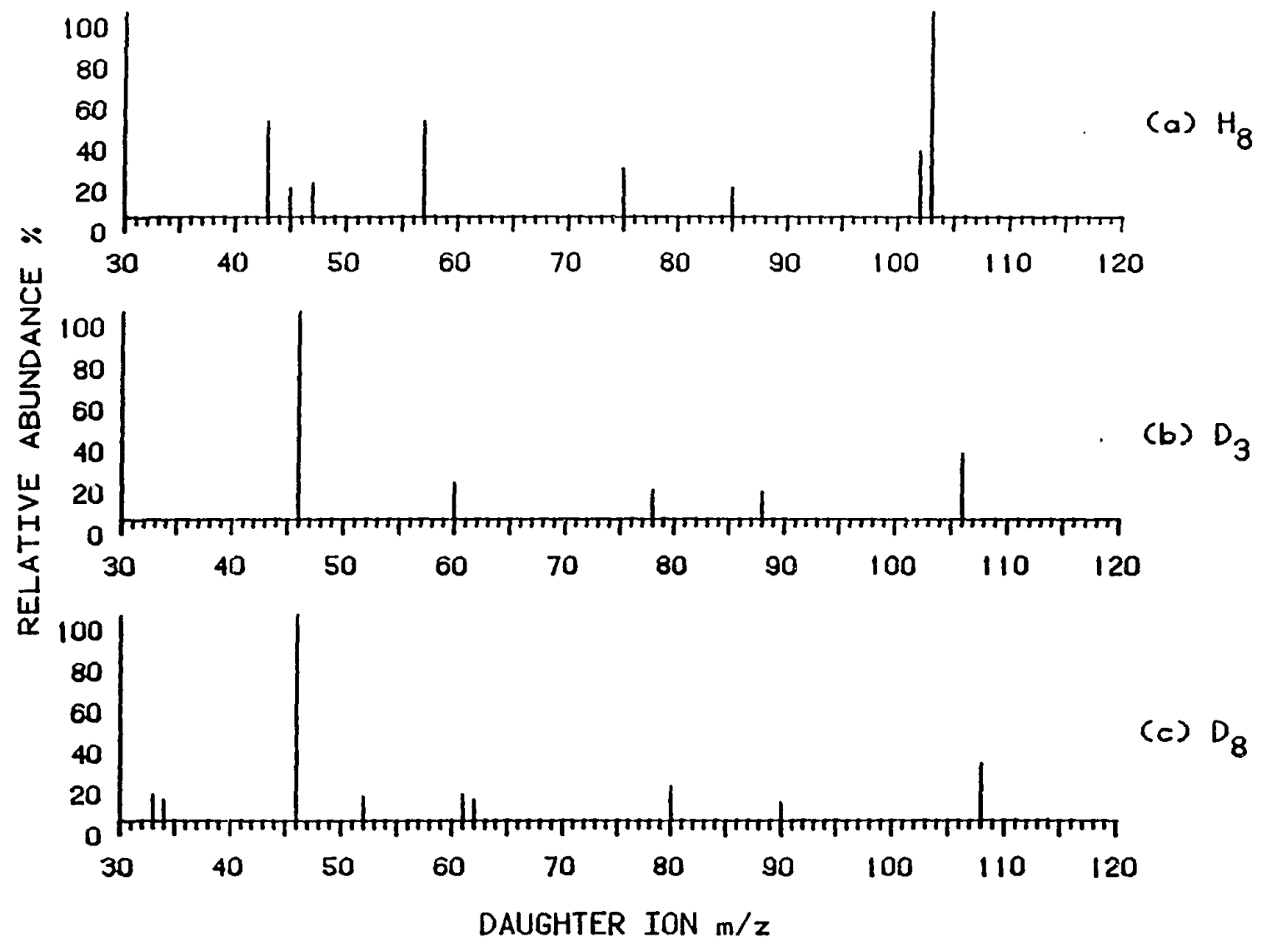




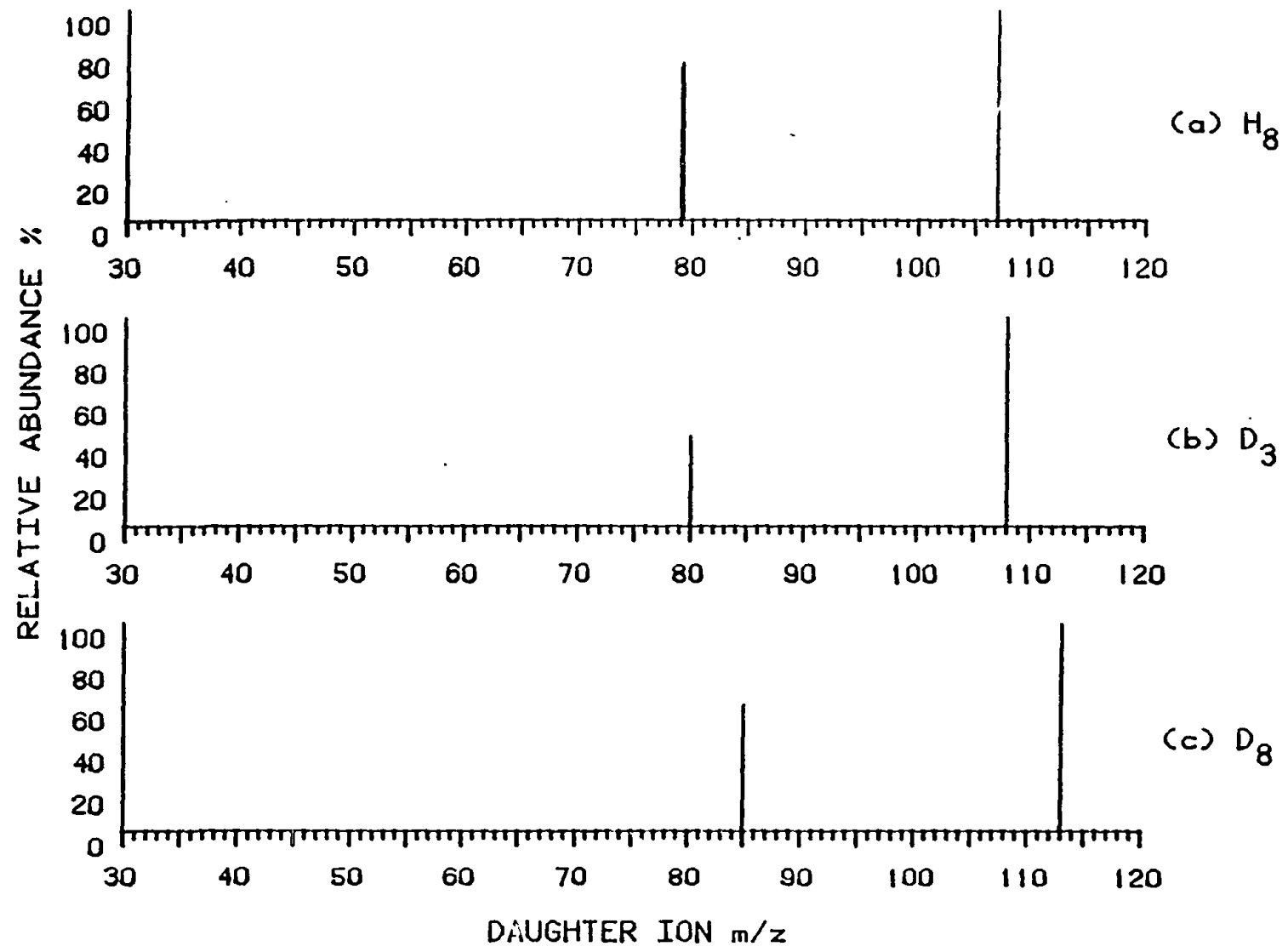




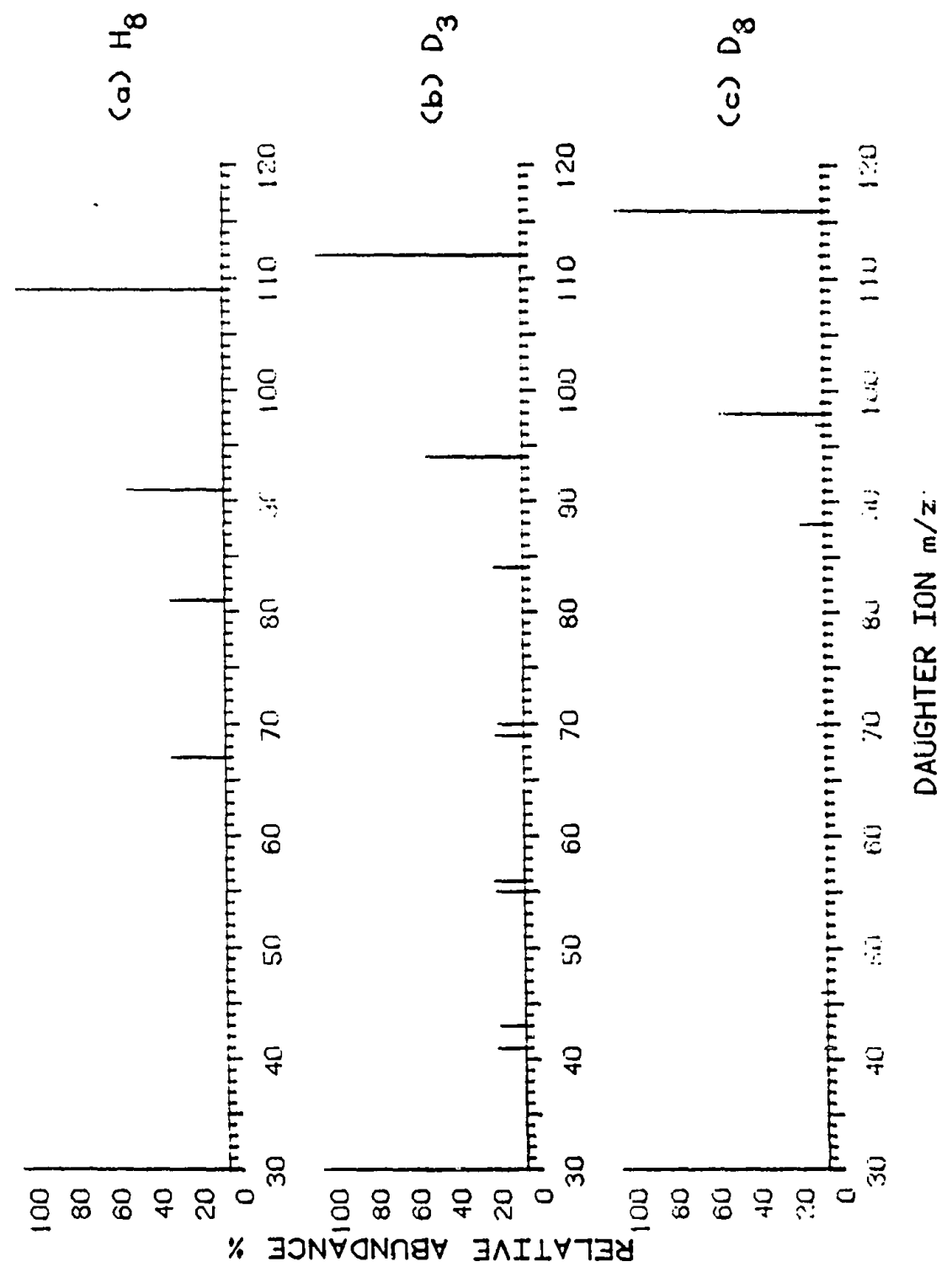




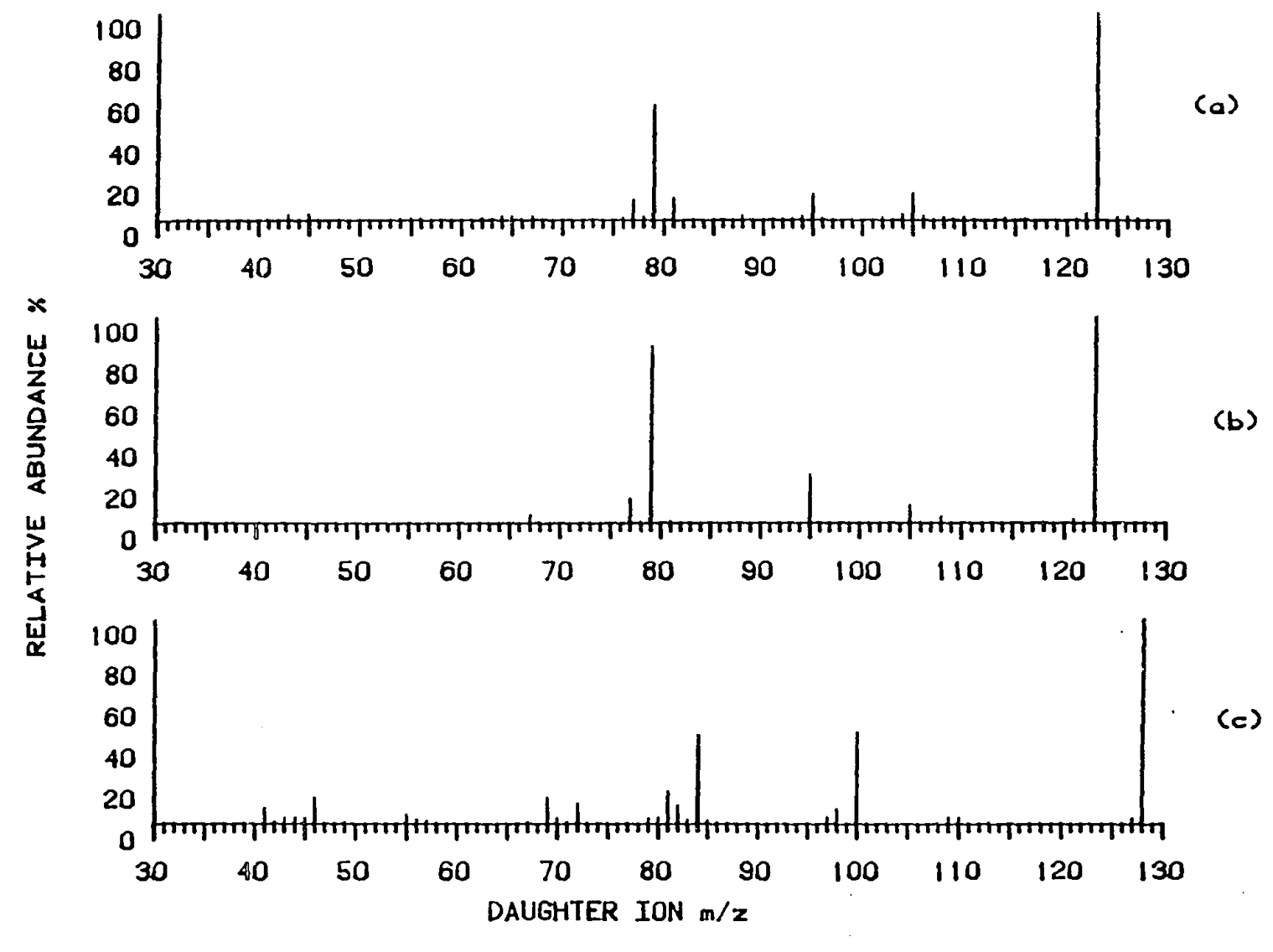




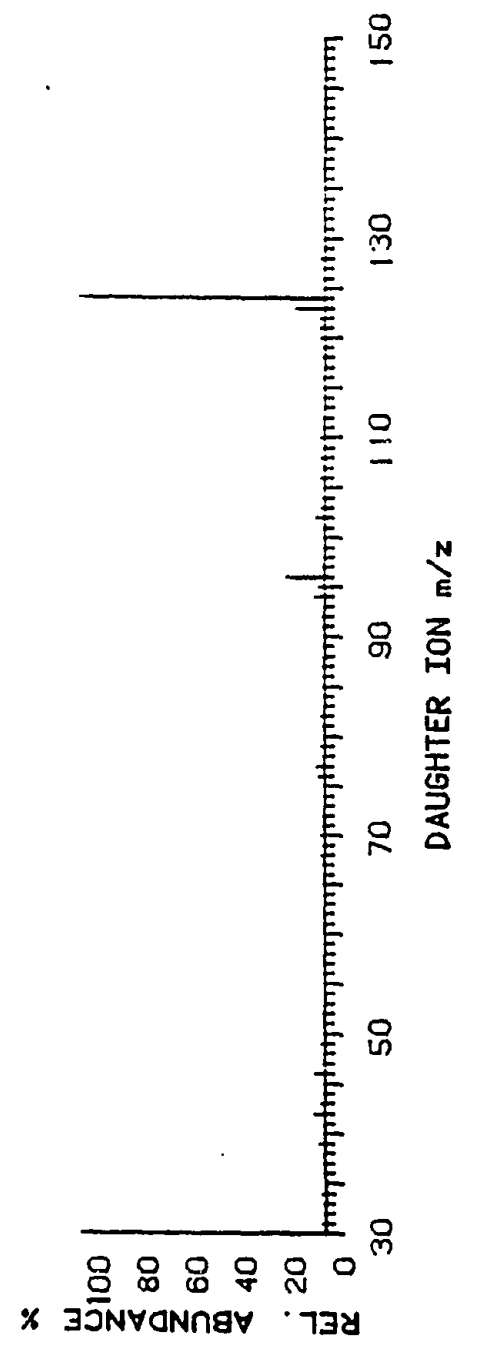


131

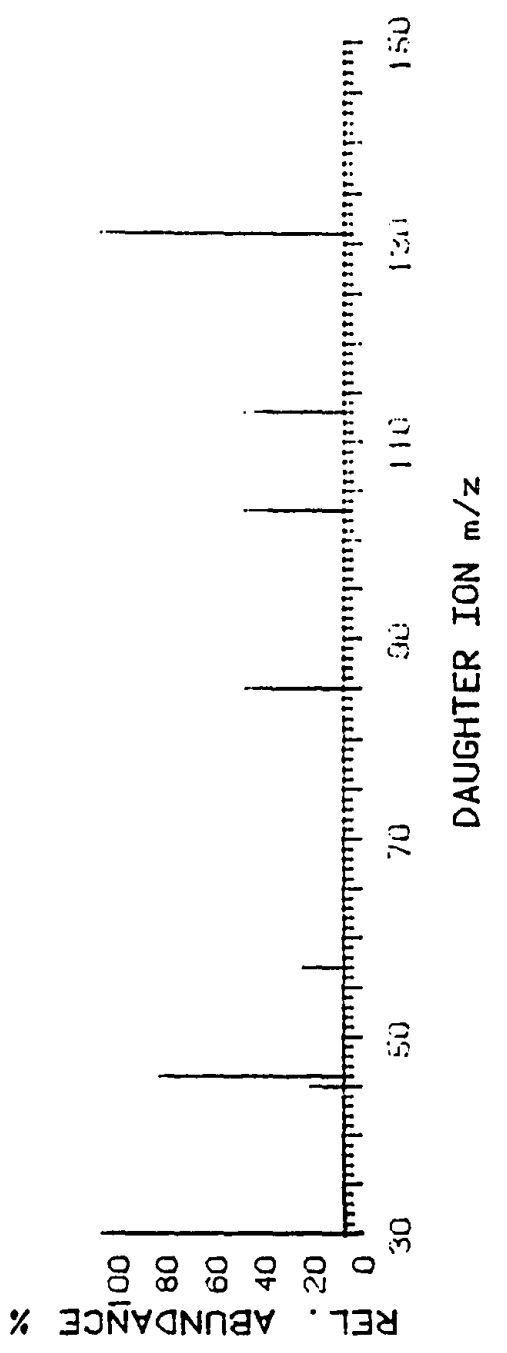




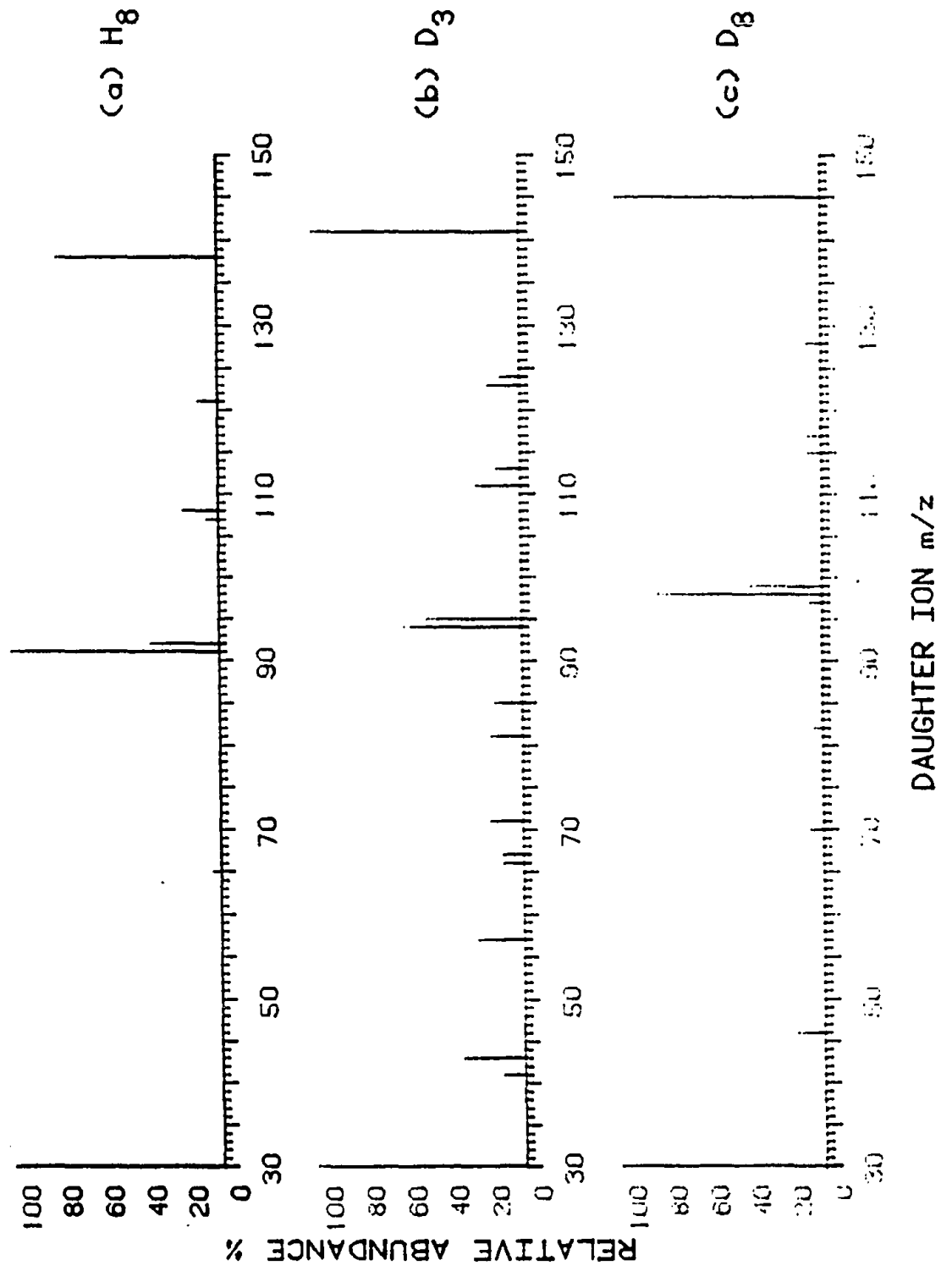




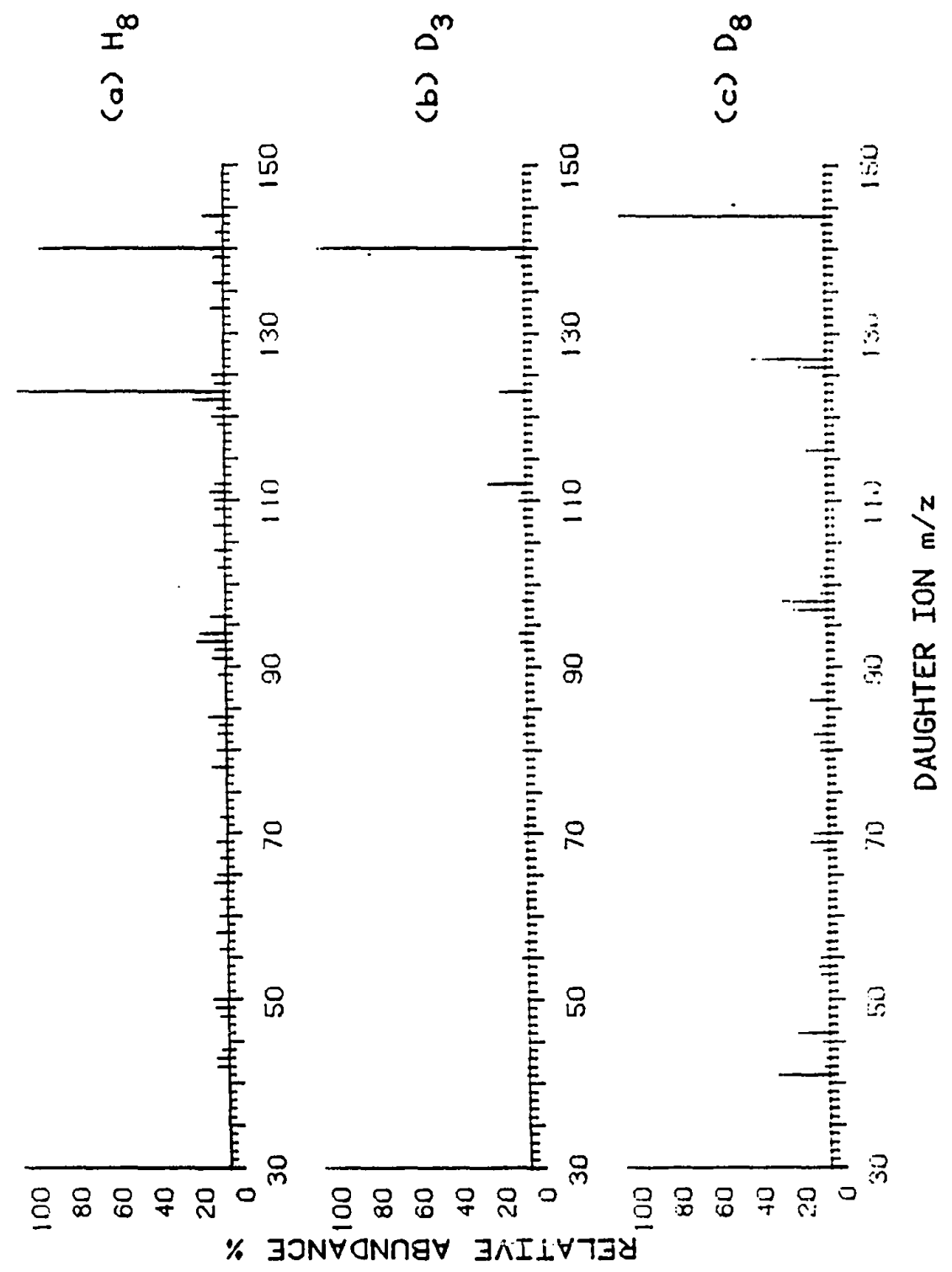




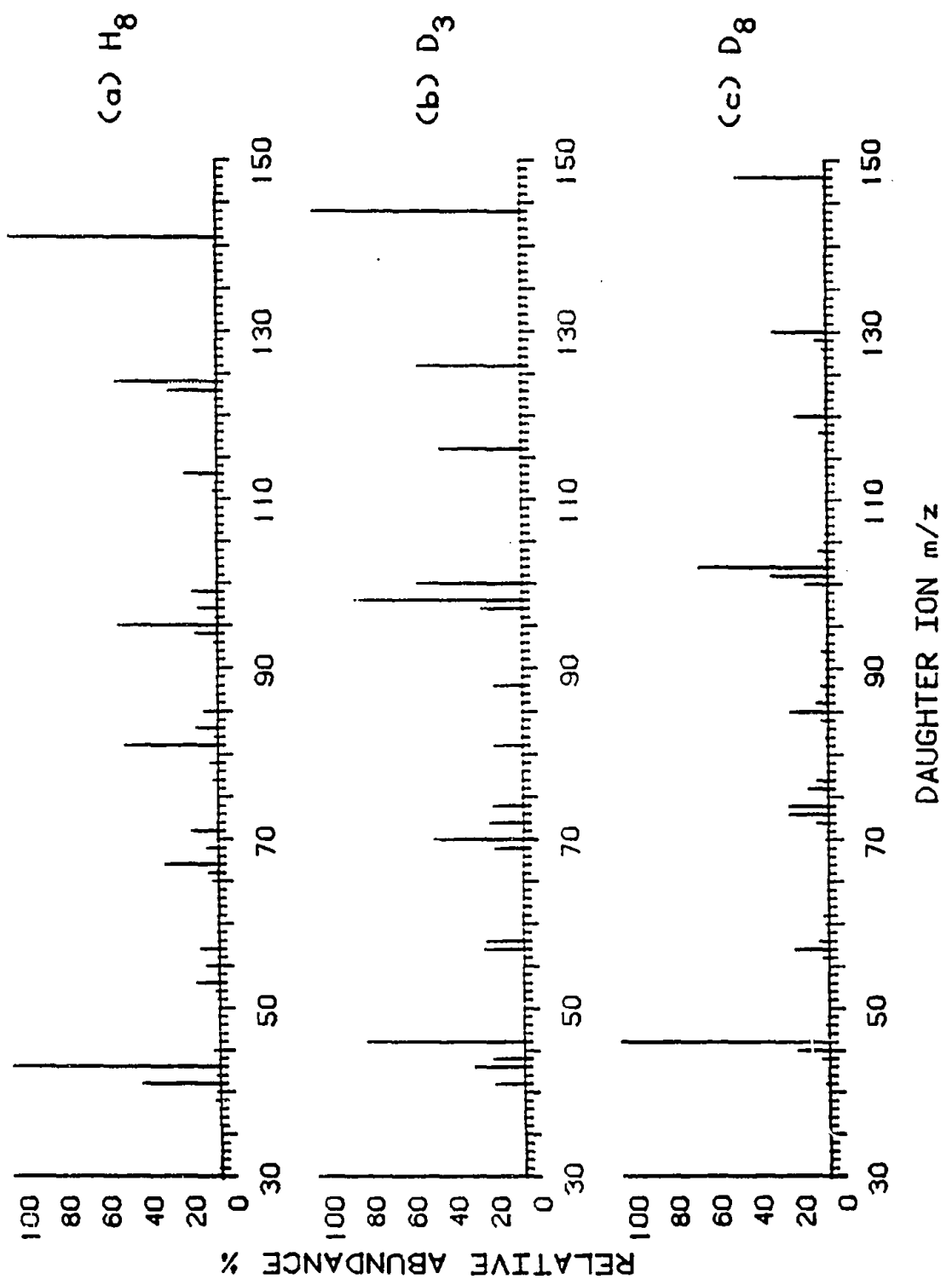




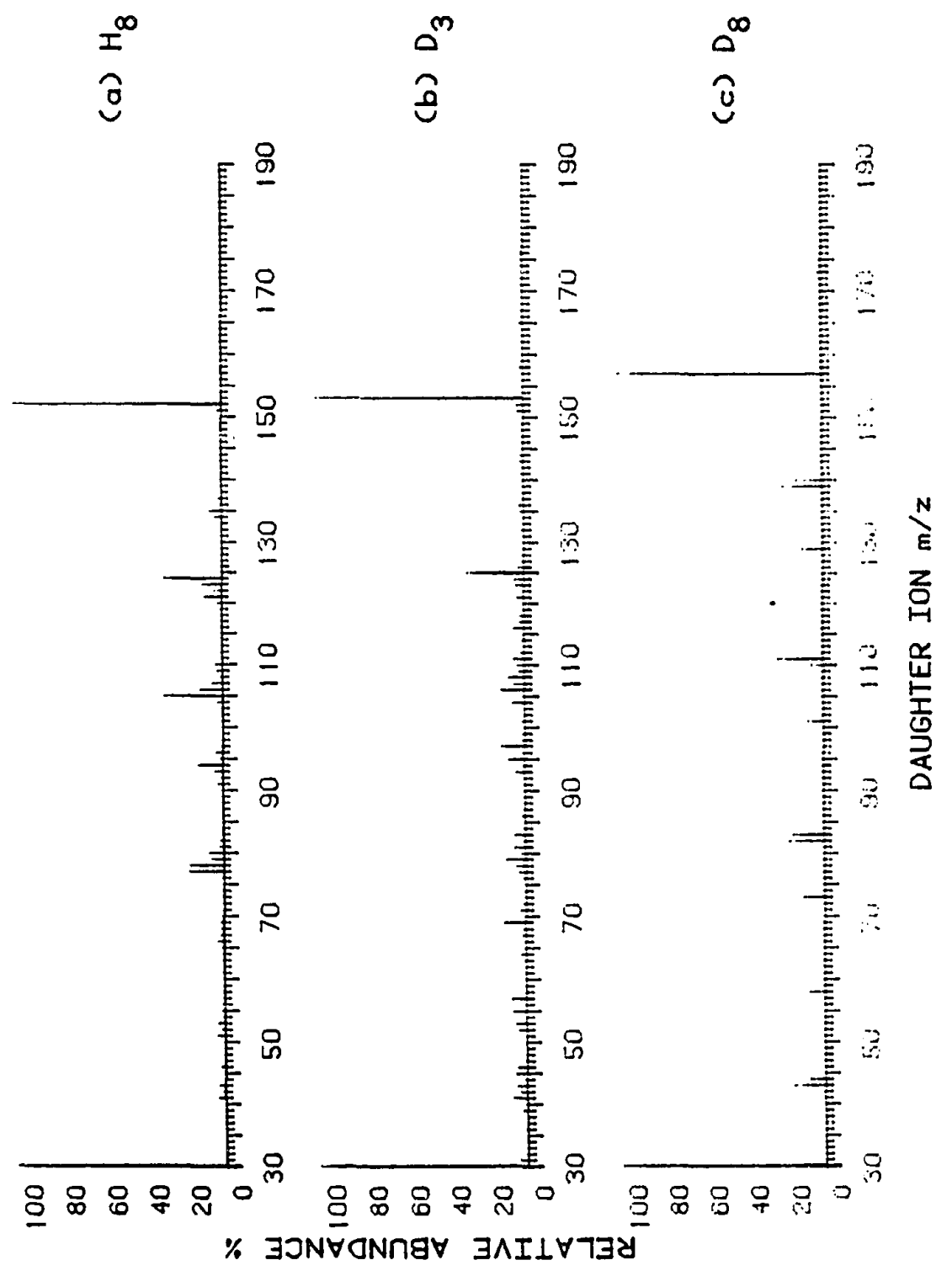




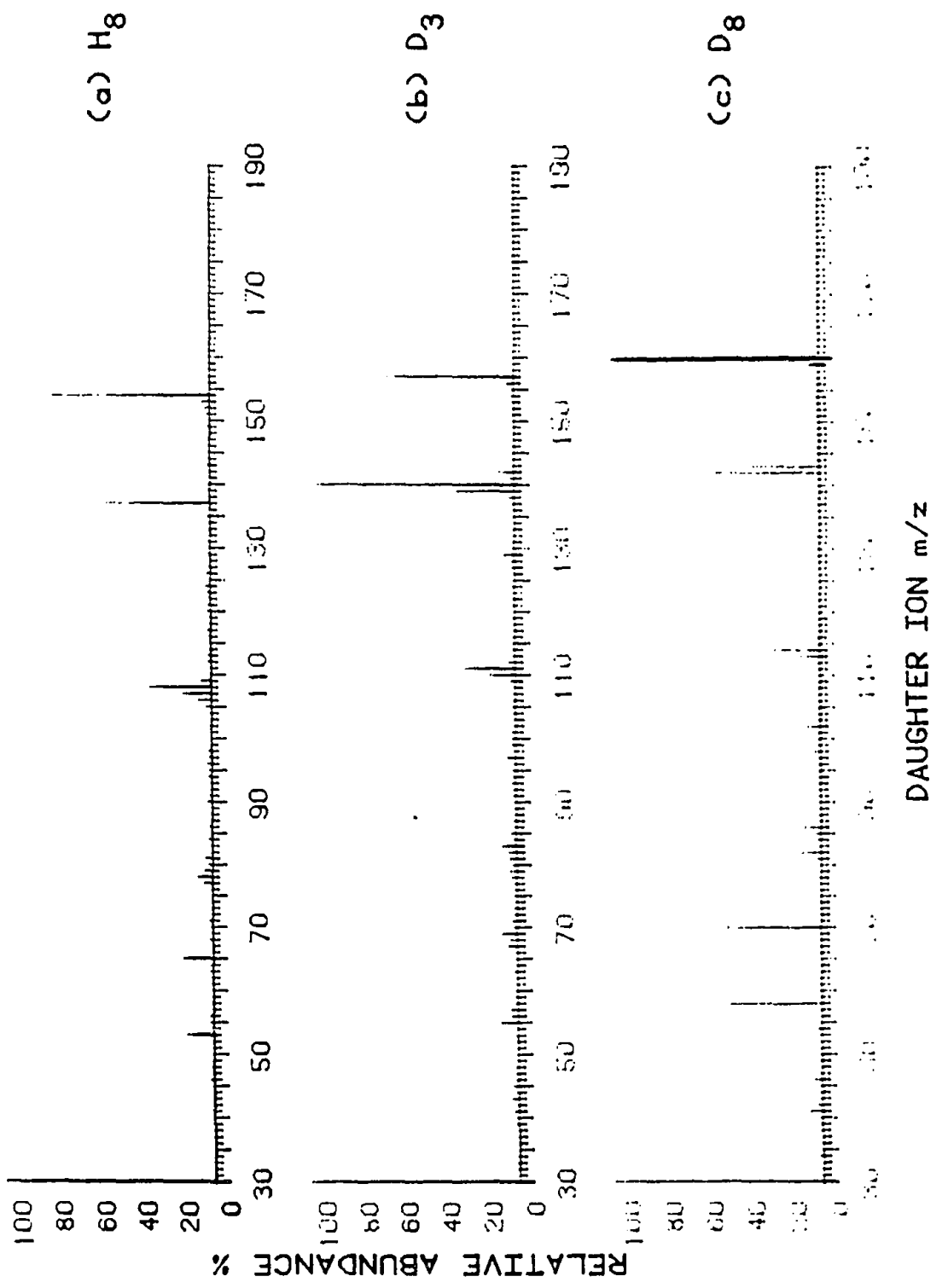




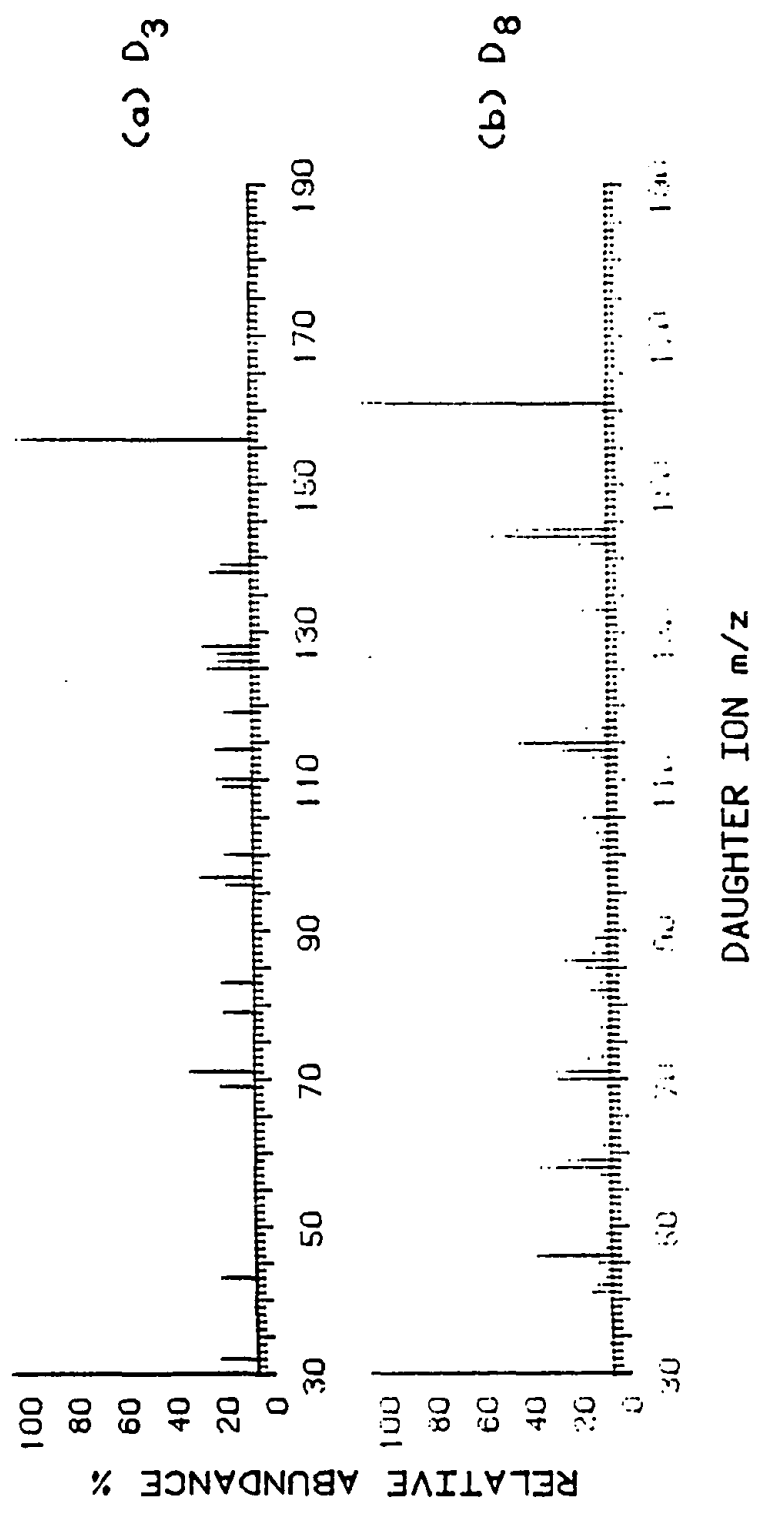




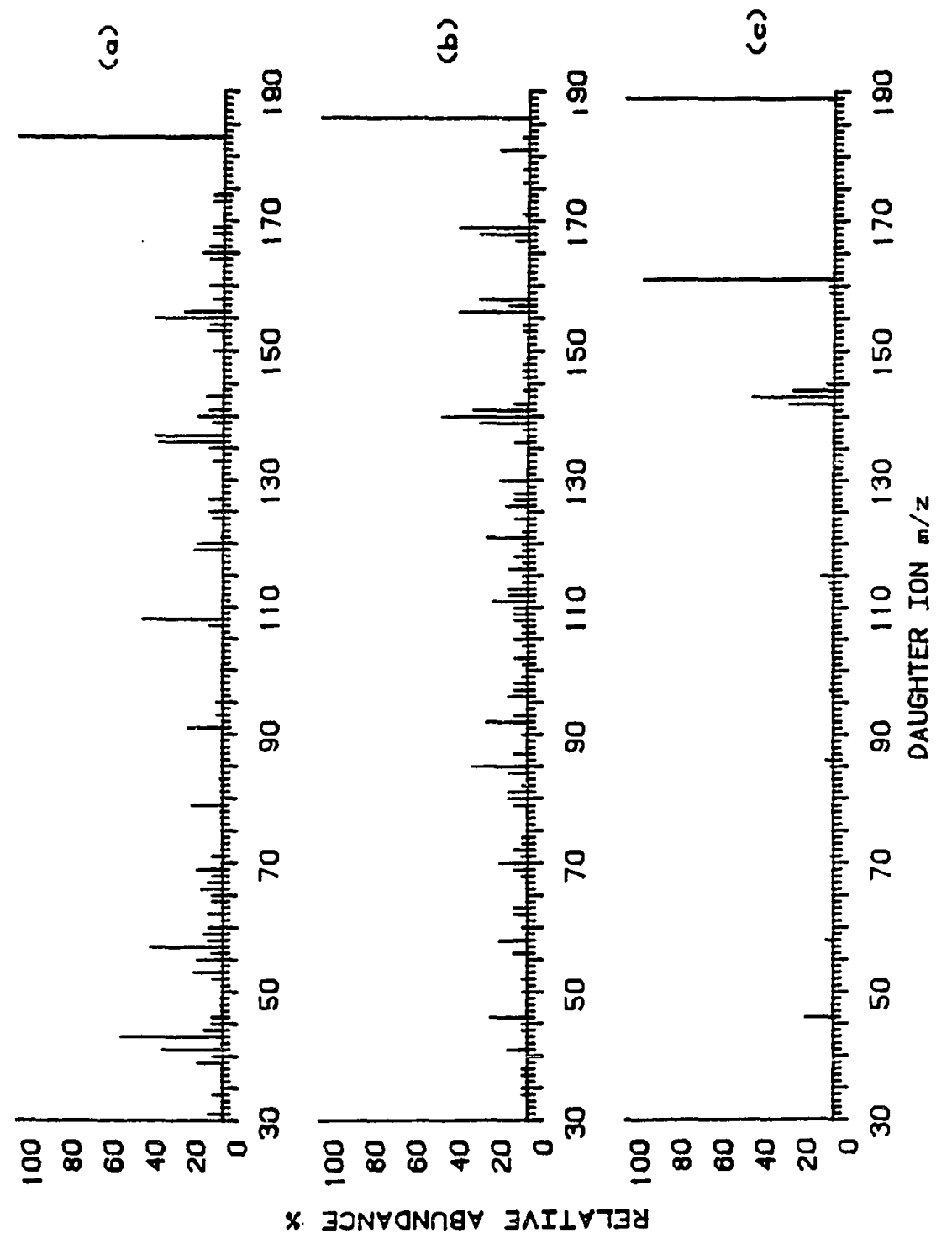


APPENDIX B

FOUR LETTER CODED TOLUENE MECHANISM

FOR COMPUTER SIMULATION

Beaction Rate constant (ppow/min)

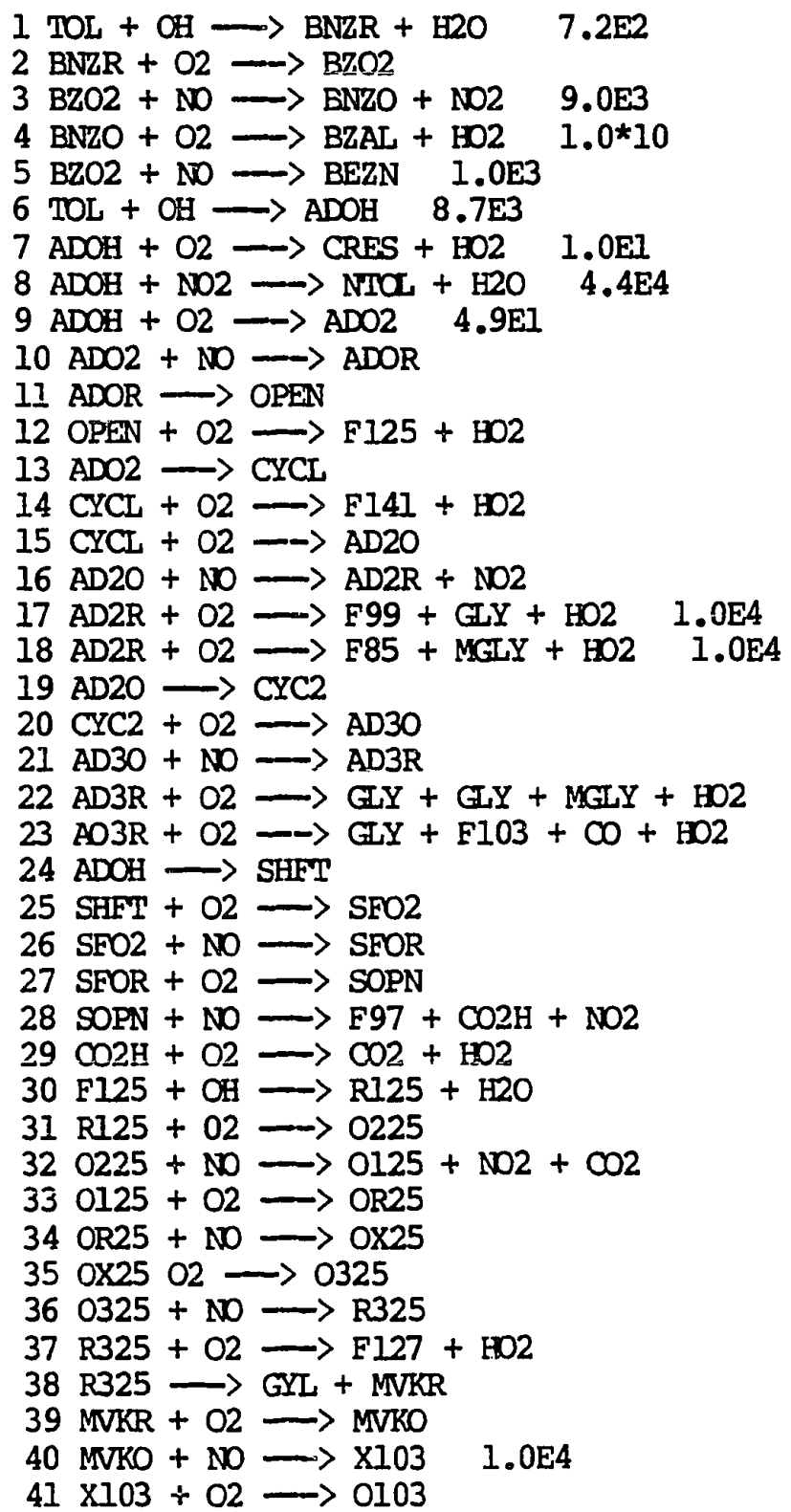




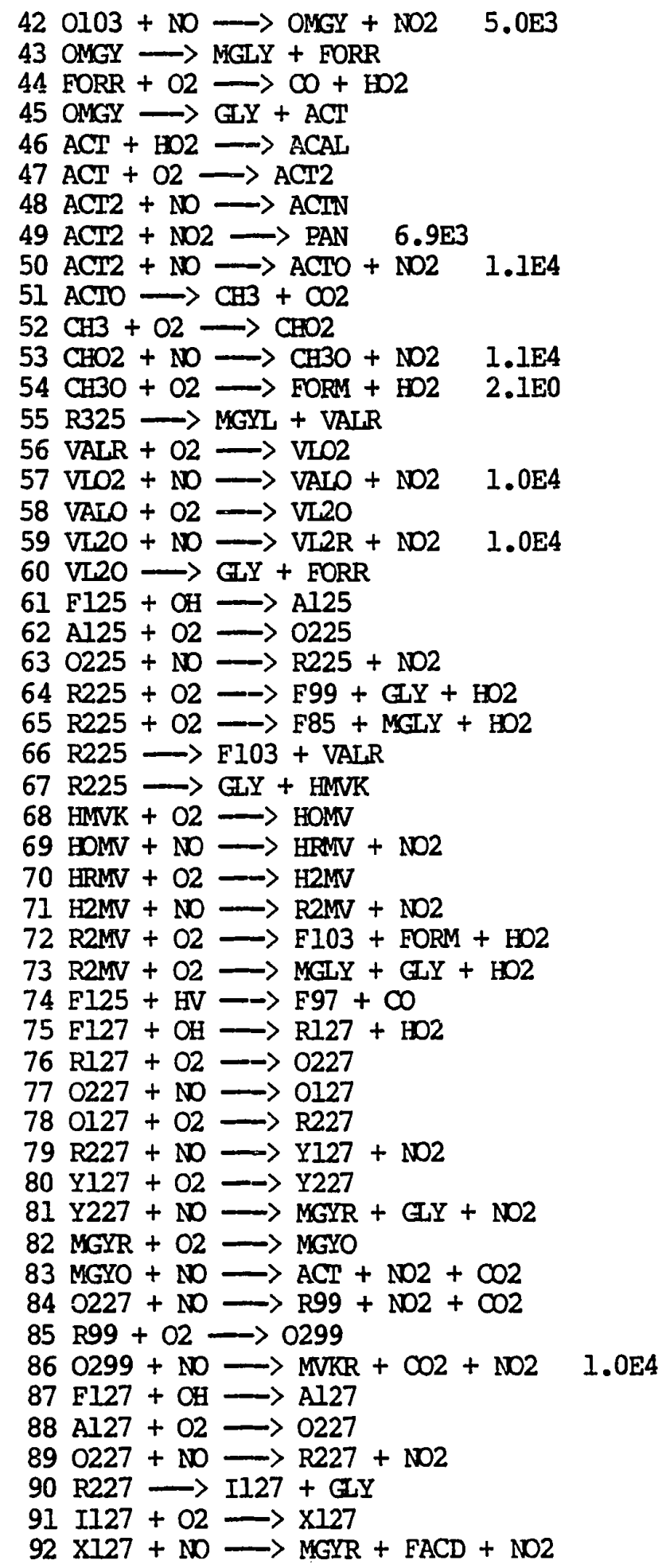




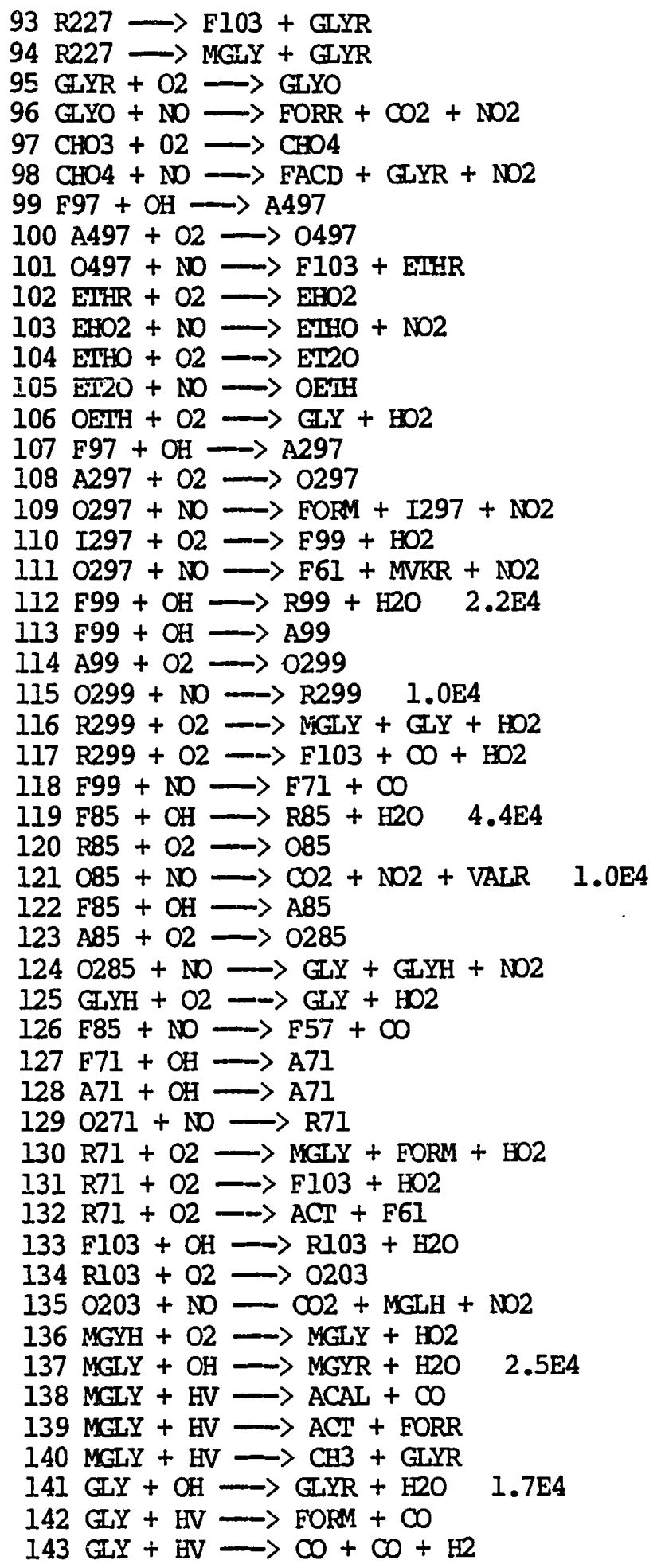




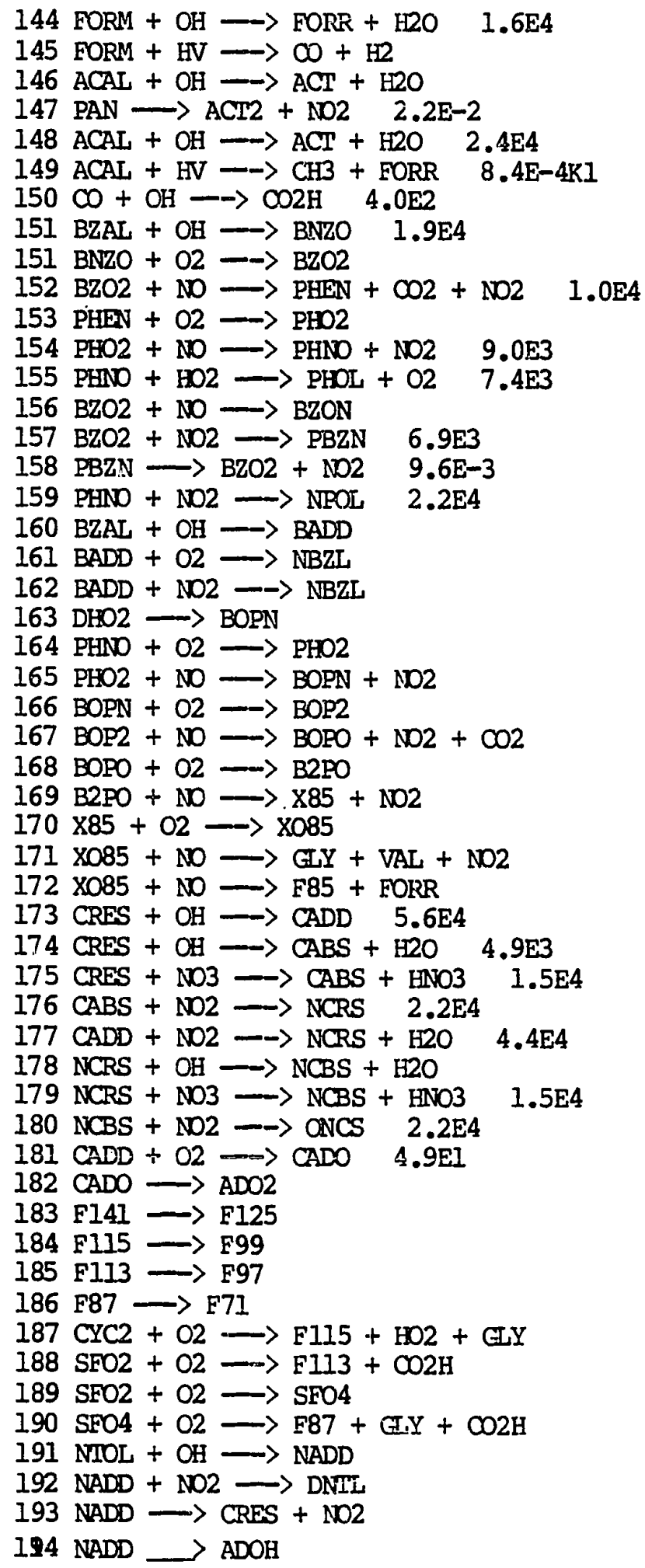


KEY TO POUE LETTER LCDE

\begin{tabular}{|c|c|}
\hline$\because O I \quad\langle\}^{-H_{3}}$ & $A_{6} \because 2 \quad C H_{3}-c-O_{2} \cdot$ \\
\hline BNZK (0) & $\mathrm{AL}=\mathrm{C} \quad \mathrm{CH}_{3}-\mathrm{C}-\mathrm{O}$. \\
\hline $\mathrm{BEZN}$ (0) $\mathrm{CH}_{2} \mathrm{NNO}_{2}$ & ALIN $\angle H_{3}-\ddot{\angle}-O N O_{2}$ \\
\hline BZAL (0) = & $\therefore \mathrm{HC} \mathrm{CH}_{3}$ \\
\hline ACCH & $\ldots: \mathrm{HN} \quad \mathrm{CH}_{3}$ \\
\hline$\therefore K E S$ of $_{O H}^{\mathrm{CH}}$ & FOFii: $\quad \dot{H}$ \\
\hline $\operatorname{Nim}$ OO & $I=C H-i_{H}-c_{A}-\dot{c}^{2}-H$ \\
\hline$A D C=\&$ & 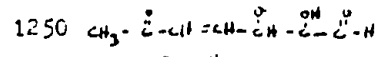 \\
\hline 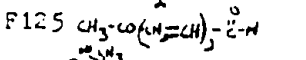 & CLLY H- \\
\hline$A\left[=0^{2}-2\right]$ & FANOO H- \\
\hline$A \subset 2 R$ & $\mathrm{CH}=\mathrm{CH}-\mathrm{CH}=\mathrm{COCH} 2$ \\
\hline FGy Y.onn-2pedenol & $\mathrm{R} 127 \mathrm{CH}_{3}-$ \\
\hline WLY J'yor & $490 \mathrm{CH}_{3}-$ \\
\hline F85 butemedial & $-\dot{C} H-\stackrel{C H}{C}=\ddot{C} \cdot H$ \\
\hline NCLY methyl glyoxal & $127 \mathrm{I} \mathrm{CH}_{3}-$ \\
\hline in & FCRA $H-C^{\circ i}$ \\
\hline F103 $\omega_{2}$. & $97 \mathrm{~A} \mathrm{CH} H_{3}-\stackrel{i}{C}-\mathrm{CH}=\mathrm{CH}-\dot{\mathrm{C} H}-\stackrel{\mathrm{OH}}{\mathrm{CH}} \mathrm{H}_{2}$ \\
\hline 12SF $\mathrm{sin}_{3}, \ddot{a}$ & EIHR $\cdot C H=C H_{2}$ \\
\hline$A_{2}=c-0$ & ETHO $\cdot 0-$ \\
\hline $125 \times-H_{3}$ & $9 S \mathrm{~A} \quad \mathrm{SH}_{3}-$ \\
\hline 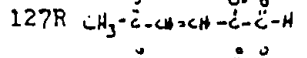 & $990 \mathrm{CH}_{2} \cdot \dot{i}-\dot{c}+\dot{c}_{H}^{*}-\ddot{c}_{H}$ \\
\hline 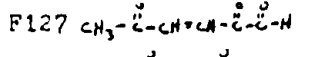 & $8502 H-\ddot{c} \cdot c t=c 4-\dot{c} \cdot 02$ \\
\hline $127 \times C H_{3}-i i c-i H-\ddot{c}-H$ & $85 R \quad I+-L-c$ \\
\hline 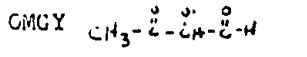 & $850 \mathrm{H}$ \\
\hline
\end{tabular}


KEY (con.)

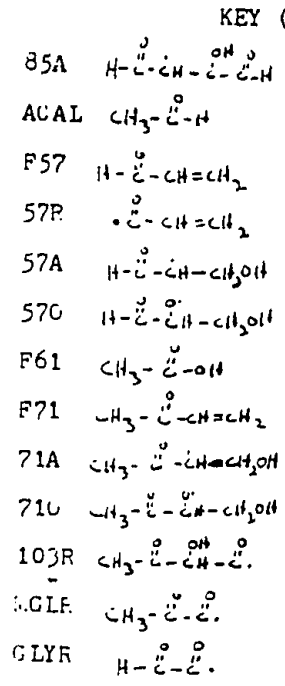

